Andrews University

Digital Commons @ Andrews University

1984

\title{
An Empirically Derived Base for the Validation of Standards for Industrial Arts Programs in Seventh-day Adventist Schools in the United States of America
}

P John Williams

Andrews University

Follow this and additional works at: https://digitalcommons.andrews.edu/dissertations

\section{Recommended Citation}

Williams, P John, "An Empirically Derived Base for the Validation of Standards for Industrial Arts Programs in Seventh-day Adventist Schools in the United States of America" (1984). Dissertations. 1551.

https://digitalcommons.andrews.edu/dissertations/1551

https://dx.doi.org/10.32597/dissertations/1551

This Dissertation is brought to you for free and open access by the Graduate Research at Digital Commons @ Andrews University. It has been accepted for inclusion in Dissertations by an authorized administrator of Digital Commons@ Andrews University. For more information, please contact repository@andrews.edu. 


\section{Andrews \$university}

Seek Knowledge. Affirm Faith. Change the World.

Thank you for your interest in the

\section{Andrews University Digital Library of Dissertations and Theses.}

Please honor the copyright of this document by not duplicating or distributing additional copies in any form without the author's express written permission. Thanks for your cooperation. 


\section{INFORMATION TO USERS}

While the most advanced technology has been used to photograph and reproduce this manuscript, the quality of the reproduction is heavily dependent upon the quality of the material submitted. For example:

- Manuscript pages may have indistinct print. In such cases, the best available copy has been filmed.

- Manuscripts may not always be complete. In such cases, a note will indicate that it is not possible to obtain missing pages.

- Copyrighted material may have been removed from the manuscript. In such cases, a note will indicate the deletion.

Oversize materials (e.g., maps, drawings, and charts) are photographed by sectioning the original, beginning at the upper left-hand corner and continuing from left to right in equal sections with small overlaps. Each oversize page is also filmed as one exposure and is available, for an additional charge, as a standard $35 \mathrm{~mm}$ slide or as a $17 " \mathrm{x} 23$ " black and white photographic print.

Most photographs reproduce acceptably on positive microfilm or microfiche but lack the clarity on xerographic copies made from the microfilm. For an additional charge, $35 \mathrm{~mm}$ slides of 6"x 9" black and white photographic prints are available for any photographs or illustrations that cannot be reproduced satisfactorily by xerography. 
Reproduced with permission of the copyright owner. Further reproduction prohibited without permission. 
Order Number 8725238

An empirically derived base for the validation of standards for industrial arts programs in Seventh-day Adventist schools in the United States of America

\author{
Williams, P. John, Ph.D.
}

Andrews University, 1987

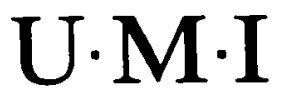

300 N. Zeeb Rd.

Ann Arbor, MI 48106

(

Reproduced with permission of the copyright owner. Further reproduction prohibited without permission. 


\section{PLEASE NOTE:}

In all cases this material has been filmed in the best possible way from the available copy.

Problems encountered with this document have been identified here with a check mark

1. Glossy photographs or pages

2. Colored illustrations, paper or print

3. Photographs with dark background

4. Illustrations are poor copy

5. Pages with black marks, not original copy

6. Print shows through as there is text on both sides of page

7. Indistinct, broken or small print on several pages

8. Print exceeds margin requirements

9. Tightly bound copy with print lost in spine

10. Computer printout pages with indistinct print

11. Page(s) lacking when material received, and not available from school or author.

12. Page(s) seem to be missing in numbering only as text follows.

13. Two pages numbered - Text follows.

14. Curling and wrinkled pages

15. Dissertation contains pages with print at a slant. filmed as received

16. Other

\section{University Microfilms International}




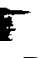

Reproduced with permission of the copyright owner. Further reproduction prohibited without permission. 


\title{
Andrews University \\ School of Education
}

\section{AN EMPIRICALLY DERIVED BASE FOR THE VALIDATION OF STANDARDS FOR INDUSTRIAL ARTS PROGRAMS \\ IN SEVENTH-DAY ADVENTIST SCHOOIS \\ IN THE UNITED STATES OF AMERICA}

\author{
A Dissertation \\ Presented in Partial Fulfillment \\ of the Requirements for the Degree \\ Doctor of Philosophy
}

by

P. John Williams

December 1984 


\section{AN EMPIRICAILY DERIVED DATA BASE FOR THE VALIDATION OF STANDARDS FOR INDUSTRIAL ARTS PROGRAMS IN SEVENTH-DAY ADVENTIST SCHOOLS IN THE UNITED STATES OF AMERICA}

\section{A dissertation}

presented in partial fulfiliment of the requirements for the degree Loctor of Philosophy

by

P. John Williams

SPPROVAL BY THE COMMITTEE:
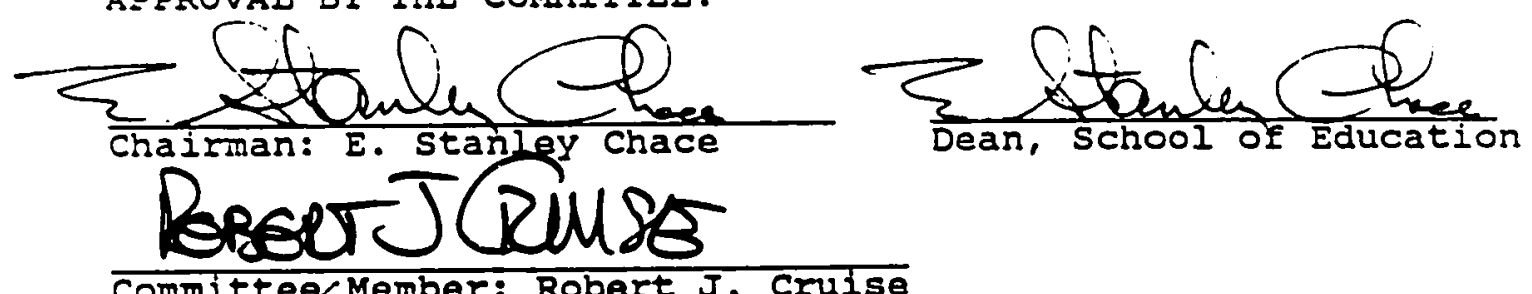

Committee Member: Robert J. Cruise
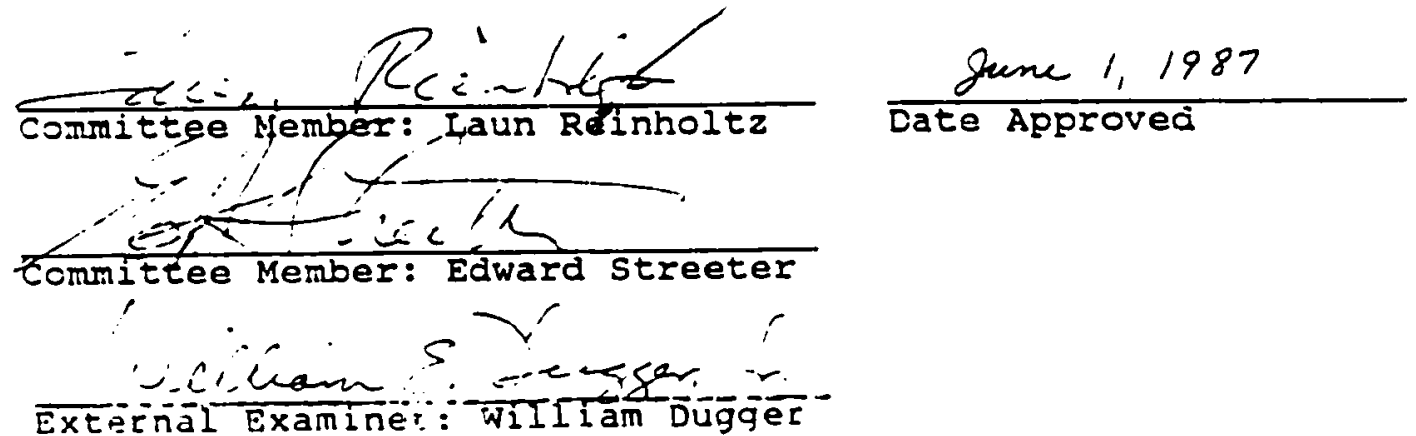


\begin{abstract}
AN EMPIRICALLY DERIVED DATA BASE FOR THE VALIDATION OF STANDARDS FOR INDUSTRIAI ARTS PROGRAMS

IN SEVENTK-DAY ADVENTIST SCHOOLS IN

THE UNITED STATES OF AMERICA
\end{abstract}

by

P. John Williams

Chairman: E. Stanley Chace 


\title{
ABSTRACT OF GRADUATE STUDENT RESEARCH \\ Dissertation
}

\author{
Ardrews University \\ School of Education
}

\begin{abstract}
Title: AN EMPIRICALIY DERIVED DATA BASE FOR THE VALIDATION OF STANDARDS FOR INDUSTRIAL ARTS PROGRAMS IN SDA SCHOOLS IN THE UNITED STATES OF AMERICA

Name of Researcher: P. John Williams

Name and degree of advisor: E. Stanley Chace, Ed.D.

Date Completed: December 1984
\end{abstract}

\section{Problem}

This study identified two problems. The first was that, at the time of writing, there existed no comprehensive data describing the number, nature, and status of SDA industrial arts programs. The second problem was the lack of comprehensive criteria for the evaluation and guidance of SDA industrial aris programs.

\section{Method}

Two sejarate methodologies were utilized to answer the 31 research questions. One related to the development, administration, and analysis of a survey, and 
the other to the development and validation of standards for industrial arts.

The responses from mailed surveys were computeranalyzed, and the resulting data formed the basis of the answers to the research questions.

standards fo:: industrial arts were compiled from computer searches and other sources before being pilot tested and then validated.

\section{Results}

1. Grade 9 is the focus of the industrial arts program as far as both numbers of students taking industrial arts and the numbers of courses offered is concerned.

2. Most principals perceive industrial arts as a general education course that has a role to play in the instructional program of college-bound students.

3. Both SDA and public-school industrial arts chairmen rate the academic ability of industrial arts students as below that of other students, and publicschool chairmen rate the academic ability of their industrial arts students as significantly lower than SDA chairmen rate their industrial arts students.

4. A significantly larger proportion of SDA schools have industrial arts programs than do public schools.

5. SDA industrial arts departments spend more per 
student on equipment and supplies than do public-school industrial arts departments.

\section{Conclusions}

From the data collected, the following conclusions were made:

1. SDA industrial arts programs are not following the latest curriculum davelopments in the area of industrial arts and technology education. The trend is toward consolidation while SDA industrial arts offerings are diversifying.

2. There are few significant differences between SDA and public-school industrial arts departments, apart from the most common course in the SDA system being auto mechanics, whlle that of the public schools is drawing.

3. There is a significant discrepancy between the current and ideal emphasis on the purposes of industrial arts as perceived by chairmen. 
TABLE OF CONTENTS

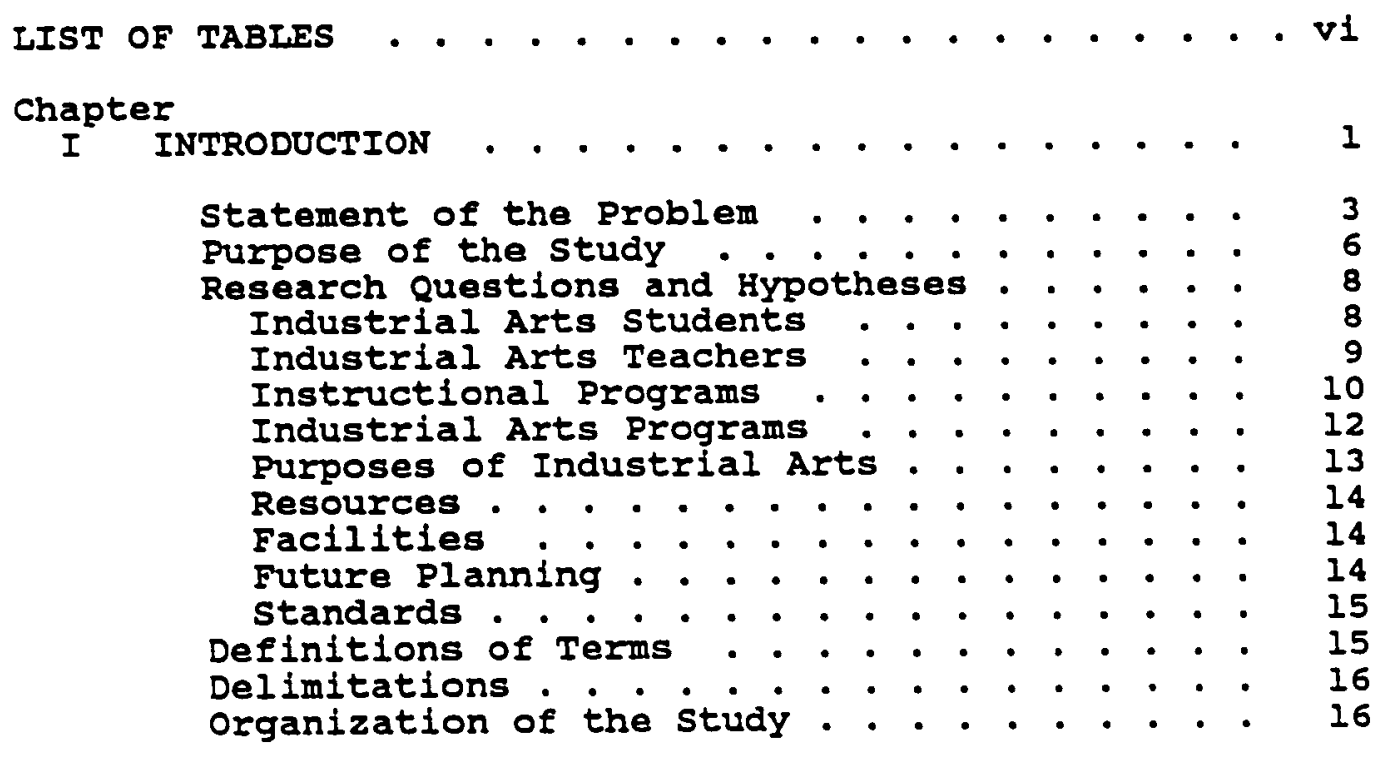

II REVIEW OF IITERATURE . . . . . . . . . . . . 18

Introduction . . . . . . . . . . . . 18

A Definition of Industrial Arts:....... 18

A History of Industrial Arts . . . . . . . . 24

Technological Changes Related to

Factors Influencing Industrial Arts . . . : 34

The Present State of Industrial Arts . . . 36

The Future of Industrial Arts......... . 43

Seventh-day Adventist Industrial Arts . . . 46

Industrial Arts surveys............ 50

Industrial Education Standards . . . . : . . 54

General Standards.............. 65

summary . . . . . . . . . . . . . 68

III METHODOLOGY . . . . . . . . . . . . . . 69

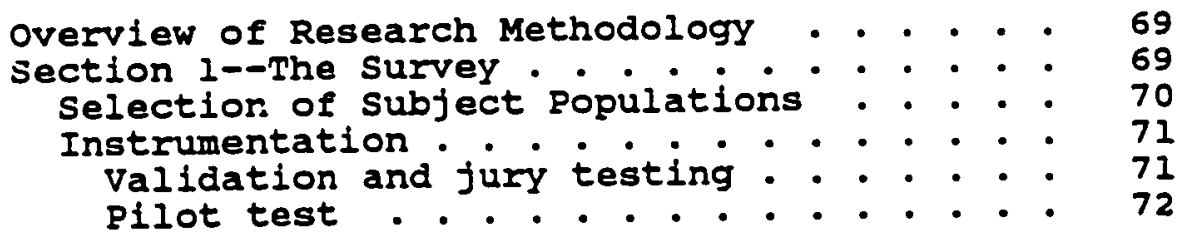

i11

Reproduced with permission of the copyright owner. Further reproduction prohibited without permission. 
Administration Procedures and Data Collection . . . . . . . . . . 72

Data processing and Analysis . . . . . . 76

Missing data . . . . . . . . . . 77

Data analysis......... . . . . 78

Statistical significance and

effect size............. . . 78

Section 2--The standards . . . . . . . . 79

Pllot study ............... . . 80

Field Validation Procedures . . . . . . 80

Statistical Validation Procedures. . . . 81

Research Questions and Methods . . . . . . 82

Industrial Arts students . . . . . . . 82

Industrial Arts Teachers . . . . . . . 84

Instructional programs . . . . . . . . . 85

Industrial Arts Programs ......... . 88

Purposes of Industrial Arts . . . . . . 89

Resources. . . . . . . . . . . . . 91

Facilities . . . . . . . . . . . . . 91

Future Planning . . . . . . . . . . . . . 92

Standards................... . 92

summary . . . . . . . . . . . . . 93

IV PRESENTATION AND ANALYSIS OF DATA • . • . . . . 94

Introduction . . . . . . . . . . . . . . . 94

Section 1--Analysis of Methodology . . . . 95

Response Rates .......... . . . . 95

Nonresponse Blas . . . . . . . . . . . . . 98

Section 2--The Survey . . . . . . . . . . 99

Industrial Arts students . . . . . . . 100

student enrollment . . . . . . . . . . 100

Programs of study... . . . . . . . 101

Industrial arts for students bound .... 102

for college : : : : : : : : : : : . : 102

Academic ability industriai arts : $\cdot$. : . 105

Industrial Arts Teachers . . . . . . . 105

Teacher contracts . . . . . . . . . 106

Supplemental pay . . . . . . . . . . 107

student-teacher ratio..... . . . . 108

Teacher certification... . . . . . . 108

Teacher experience . . . . . . . . . . 109

Teacher vacancies. . . . . . . . . . 109

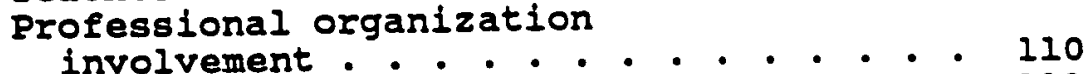

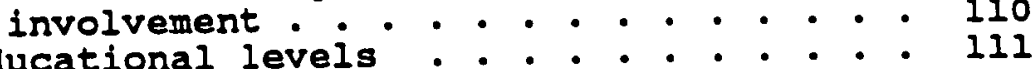

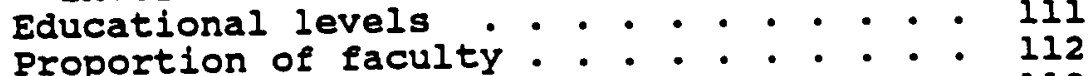

Instructional programs . . . . . . . . 113

Courses . . . . . . . . . . . . . 114

Laboratories . . . . . . . . . . . . 114

Course requirements . . . . . . . . . . 118

Classes... . . . . . . . . . . . 120

strengths and weaknesses . . . . . . . 120

iv 


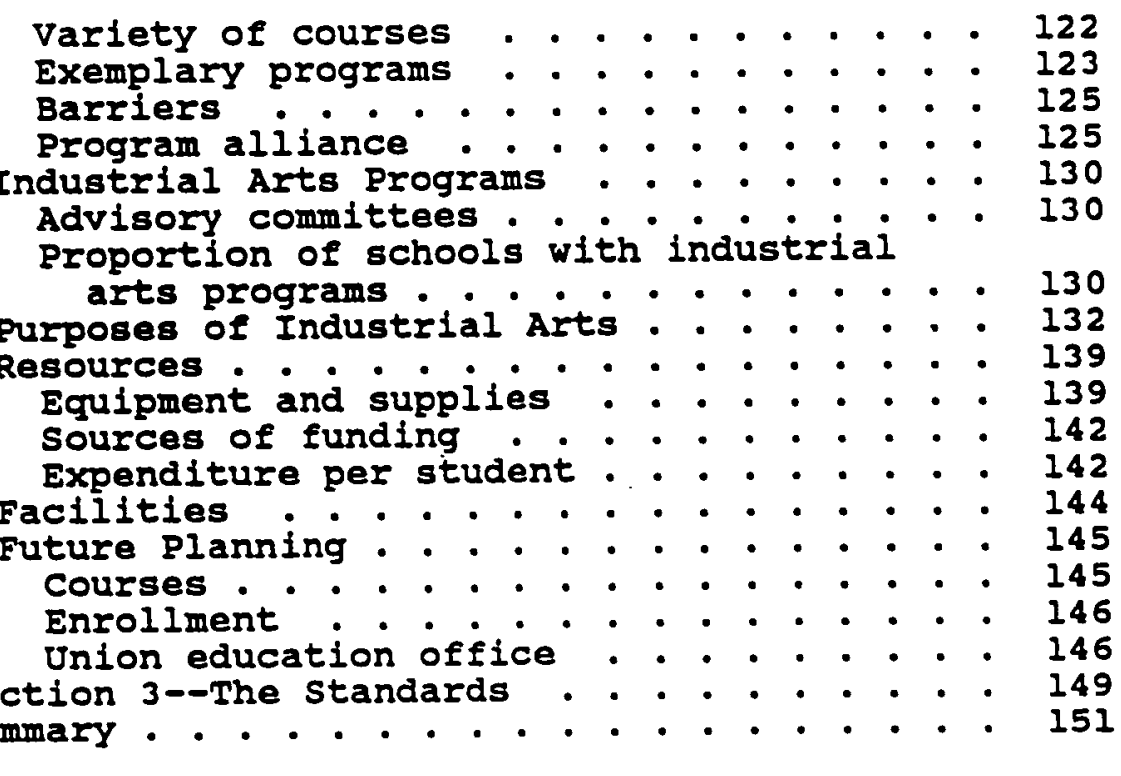

$\checkmark$ SUMMARY, CONCLUSIONS, AND RECOMMENDATIONS . • • 152

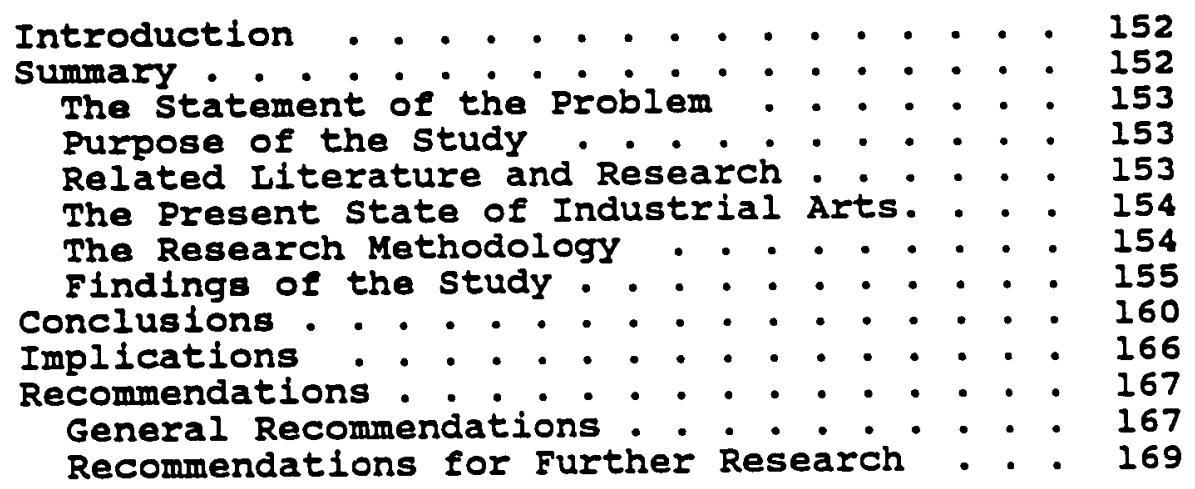

APPENDIX A. Survey Instruments . . . . . . . . . 170

APPENDIX B. Business Reply Mail Envelope . . . . . 183

APPENDIX C. Initial Mail-out Cover Letter . . . . 185

APPENDIX D. Post Card Reminder . . . . . . . . . 187

APPENDIX E. Second Cover Letter . . . . . . . . . 189

APPENDIX F. Third Cover Letter . . . . . . . . . 191

APPENDIX G. Fourth Cover Letters . . . . . . . . 193

APPENDIX H. Standards for Rating . . . . . . . . 196

$\mathbf{V}$ 
APPENDIX I. General Cover Letter for Standards . . . 229
APPENDIX J. Final Standards Document . . . . . . . . 231
APPENDIX K. Deleted Standards . . . . . . . . . . . 262
SELECTED BIBLIOGRAPHY . . . . . . . . . . . . . . . . 264
VITA . . . . . . . . . . . . . . . . . . . . . . . . 287

$\mathbf{v i}$

Reproduced with permission of the copyright owner. Further reproduction prohibited without permission. 


\section{LIST OF TABLES}

1. Mail Survey Follow-up Schedule . . . . . . . 73

2. Response Rates by Procedure and Population
in Absolute and Relative Frequencies . . . 95

3. Total and Industrial Arts Enrollments by Grade for SDA Schools... . . . . . . . 101

4. Programs of study Representative of Industrial Arts students . . . . . . . 101

5. SDA Principals' Views Regarding students Bound for College Taking Industrial Arts............ . . 102

6. Chairmen's Perceptions of the Academic Ability of Industrial Arts students as
Compared with General students . . . . . . 103

7. Length of SDA Industrial Arts Teachers' Contracts... . . . . . . . . . . . 106

8. Activities for Which SDA Industrial Arts Teachers Recelve Supplemental Pay . . . . . 107

9. Type of Certification Held by SDA Industrial Arts Teachers... . . . . . . . . . . 108

10. Relative Frequencies of Industrial Arts Teachers' Membership in Professional organizations . . . . . . . . . . . . 111 11. Educational Degrees Held by Industrial Arts
Teachers . . . . . . . . . . . . 112

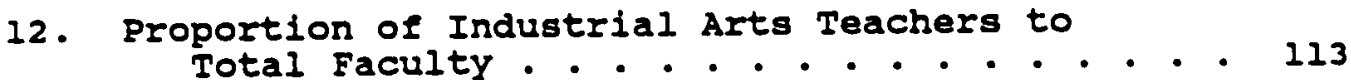

13. Data Related to Industrial Arts Courses
offered in SDA Schools . . . . . . . 115

14. Absolute and Relative Frequencies of Industrial Arts General Laboratories in SDA Schools .... . . . . . . . . . 116

vii 
15. Absolute and Relative Frequencies of Industrial Arts Unit Laboratories in SDA Schools... . . . . . . . . . . .

16. Absolute and Relative Frequencies of SDA Schools Requiring Industrial Arts Courses .... . . . . . . . . . . 118

17. Absolute and Relative Frequencies of SDA Schools Requiring Industrial Arts Courses in Specific Grades . . . . . . . . 119

18. Relative Frequencies of the Strengths and Weaknesses of Industrial Arts as Perceived by Chairmen . . . . . . . . . . 121

19. Relative Frequencies of Respondents Selecting Characteristics of Exemplary Industrial Arts Programs . . . . . 124

20. Absolute and Relative Frequencies of Chairmen's Perceptions on the Major Barriers to outstanding Industrial Arts Programs in SDA Schools ... . . . . . . 126

21. Relative Frequency of SDA Chairmen's and Principals' Perceptions of Programs with Which Industrial Arts Is Most Closely Allied

22. Relative Frequency of SDA and Public School Chairmen's Perceptions on Programs with Which Industrial Arts Is Most Closely Allied

23. Relative Fiequency of SDA and Public school Principals' Perceptions on Programs with Which Industrial Arts Is Most closely Allied

24. Proportion of SDA and Public Schools with Industrial Arts Programs . . . . . . . 132

25. Current and Ideal Emphasis on Purposes of Industrial Arts as perceived by SDA Chairmen

26. Current and Ideal Emphasis on Purposes of Industrial Arts as perceived by SDA principals . . . . . . . . . . . 135

27. Ideal Emphasis on Purposes of Industrial Arts as Percelved by SDA Chairmen and Principals 
28. Ideal Emphasis on Purposes of Industrial Arts as Perceived by SDA and Public school Industrial Arts Chairmen . . . . . . . . 140

29. SDA Industrial Arts Departments' Average Annual Expenditures on Equipment and supplies . . . . . . . . . . . . . .

30. Ideal and Actual Procedures Used for Providing Expendable Supplies by SDA Industrial Arts Departments . . . . . . . . 141

31. Sources of Funding for SDA Industrial Arts Courses .. . . . . . . . . . . . . . . 143

32. Industrial Arts Department Expenditures by school and by student on Equipment and supplies . . . . . . . . . . . . . . 144

33. Relative Frequencies of General Laboratory Facilities Available in SDA and Public Schools... . . . . . . . . . . . . 147

34. Absolute Frequency of SDA Schools Planning Additions and Deletions in Industrial Arts Courses .. . . . . . . . . . . . . 147

35. Union Education office Involvement in SDA Industrial Arts Programs . . . . . . . 148

36. Elements to Be Included in a statement of standards for Industrial Arts... . . . . 150 
CHAPTER I

\section{INTRODUCTION}

The rapid technological changes that have occurred in American society have resulted in confusion for the field of industrial arts--confusion as to the role of the school in the industrial and technological spheres of society. Should students leave high school with jobentry-level skills? If so, what skills? To what extent should all students be confronted with some aspect of industrial or technical education? If to some extent, then in what aspects? Should industrial and technical subjects be a part of the general or the elective curriculum? The changing nature of society has forced educators to contemplate such questions and new questions arise as rapidly as society changes.

Within the Seventh-day Adventist (SDA) educational system, role confusion has been compounded by a number of factors. First, the divergent constituencies that many schools serve have been a source of confusion. The needs of not only the local community but also more distant communities that may have different, if not conflicting, expectations of the school curriculum and resulting school product should be considered. 
second, many SDA educators feel that the school curriculum has been patterned upon the counsels of White which were given near the turn of the century. However, while general principals remain applicable, is it possible that not enough thought has been given to the fact that the educational context has changed enough since 1900 to render some of White's specific counsel inapplicable? An example is the issue of what role a school should play in the vocational preparation of its students. White's counsel $(1943$, p. 307 ; 1968, p. 168) would imply that each school be actively involved in vocational education. The implementation of such counsel, however, in the current system poses serious difficulty. For example, in what areas should a school establish vocational training curricula? Ana, in choosing only a few areas, is it fair that all students be forced to make a choice within the limited options that are available?

A partial solution for the public-school system has been the establishment of centrally located schools that deal exclusively with one vocational curriculum. To some extent, this public-school strategy has helped define the various areas of activity under industrial education. vocational-skill centers have been established in centralized locations to serve a number of high schools. There is then less confusion as to what individual schools teach. Such an option, however, is not as easily available to SDA schools. 
Third, the SDA school system in the united states of America (U.S.) has lacked a unified approach to the specific area of industrial arts, and no standard curriculum guides existed until the 1970s. This lack of uniformity and continuity has been reflected at the individual school level where the type of curricular offerings more often depended upon skill areas of the faculty than on an empirically derived and evaluated curriculum. Thus, with each change of faculty, facilities, equipment, and other teaching resources have been utilized inefficiently if at all.

\section{Statement of the Problem}

A difficulty for the area of industrial arts education throughout the U.S. Adventist system is the lack of uniformity. Uniformity does not imply that all schools should be teaching the same subjects; it does mean that the content of comparative levels of auto mechanics, for example, is basically the same no matter where it is taught. This type of uniformity provides the base for effective planning and evaluation on both the local and system-wide levels.

Two problems underlie this difficulty. First, there currently (1984) exists no comprehensive data describing the number, nature, and status of industrial arts programs in SDA high schools in the U.S.

Some people are familiar with one type of program in a particular geographical area, but no one appears to 
have a knowledge of the Adventist situation as a whole in the U.S.; hence, no basis is available to guide the continual growth and development of industrial arts education programs. Once the data exist, they could provide a quantitative and qualitative basis for the development of philosophies, program standards, programs, teacher training, and facilities.

The second problem within the Adventist system is the fact that there are no comprehensive criteria for the evaluation of industrial arts programs. A set of validated standards whereby teachers and administrators can evaluate an industrial arts program or design a new program have never been compiled. In fact, only relatively recently has any gulde been available that gives some unity to the various industrial arts programs offered in the SDA educational system throughout the U.S. During the 1960s, a number of Union conferences were active in developing curriculum guides for Practical Arts at the funior-high-school level. In 1978, the United States Division office of Education developed the framework which provided broad guidance for curricula development in a number of subject areas, including industrial arts. The Lake Union Conference, encompassing the states of Michigan, Wisconsin, Indiana, and Illinois, developed the framework for industrial arts into a detailed curriculum guide in 1982.

However, a thoroughly researched and valldated set 
5

of standards for industrial arts programs is still needed. Such standards, if accepted and utilized, would promote cohesiveness in industrial arts programs, accelerate further development of industrial arts, and give direction to resources to $\mathrm{fill}$ needs in all aspects of the program-philosophy, instruction, facilities, support systems, etc. These two problems have been addressed in the public sector of the industrial arts education system by a comprehensive description of the system and by the development and validation of standards (Dugger, 1980C, 1981), but this has not been done within the SDA system. within the context of this private system, these problems remain; they are uncharted areas. There are two sources for this assumption. one is the fact that the theory and philosophy of industrial arts within this SDA context is different from the corresponding philosophy related to the public-school system. The former philosophy approaches industrial arts from a more spiritual, moral, and character-development aspect; hence, data and standards that relate to this area of instruction are different. second, observation and experience within the two systems reveal some basic differences that would prevent the generalization of standards from one to the other-differences such as the average size of industrial arts departments, the number of faculty in industrial arts departments, the variety of course offerings, and the educational level of the teachers. Although standards 
have been developed and validated in the public sector, the invalidity of their generalizability to the SDA system renders this a continuing problem.

one problem that complicates any study of industrial arts is related to terminology. As Barlow (1967) pointed out, "One consistent trend from the beginning of the inaustrial arts movement has been its struggle with terms and concepts, causing confusion in oral and written communication" (p. 276). One of the causes of the confusion related to terminology is the pressures to which industrial arts has responded. Throughout the history of industrial arts in America there have been many factors shaping its nature, such as organized labor, technology, Federal Government, professional assoclations, teacher education, the Depression, and World Wars I and II. The history of the movement is a history of responses to pressures which have exerted influence in many, sometimes opposing, directions.

In summary, there are two problems. One is the lack of available information describing all aspects of the industrial arts programs in SDA secondary schools in the U.S. The second is the lack of valid standards available to these schools whereby existing programs can be evaluated or new programs be guided in development.

\section{Purpose of the study}

since the beginning of the SDA school system, industrial arts has played a role in helping many youth 
7

passing through the system to develop basic tool and design skills, to learn about industry and technology, and to define their educational and lifelong objectives (Babcock, 1980). Responding to diverse needs over space and time, industrial arts educators have developed a variety of programs and courses. Within this diversity, however, it is assumed that there exists a core of practices, goals, and standards which bind these educators and programs together. It is proposed and purposed that this dissertation describe, develop, and validate a common core of hitherto uncodified practices, goals, and standards for industrial arts education. Two areas of data developed here are:

1. Descriptive and comparative data of the industrial arts situation as it currently exists in SDA academies in the U.S.

2. Validated goals and standards that will facilitate the evaluation process and guide improvement of industrial arts programs in SDA academies in the U.S.

The descriptive data are based on the results of a comprehensive survey administered to SDA industrial arts and concerned personnel. Data relating to public-school industrial arts programs are from a national study conducted in 1980 (Dugger, 1980C). From this body of data and through selected validation procedures, an organized set of standards is produced in a format that allows for ease of industrial arts program assessment and guidance. 
Research Questions and Hypotheses

The study is organized around 31 specific research questions. Some of the questions have a related hypothesis, others are more descriptive. Related hypotheses are stated in null form following the appropriate research question.

\section{Industrial Arts students}

This section examines selected characteristics, perceived academic ability, and the proportion of students taking industrial arts.

1. What are some characteristics of industrial industrial arts students in the SDA high-school system?

The characteristics described to answer this question are related to the programs of study of industrial arts students, opinions as to whether collegebound students should take industrial arts, the number of students taking industrial arts, and the academic abilities of industrial arts students compared to other students.

2. Is there a significant difference between the ratings of SDA and public-school industrial arts chairmen concerning the academic ability of the SDA and publicschool industrial arts students, respectively?

Null hypothesis: There is no significant difference between the rating of SDA and public-school industrial arts chairmen concerning the academic ability 
of the SDA and public-school industrial arts students, respectively.

3. Is there a significant difference in the proportion of SDA and public-school students taking industrial arts?

Null hypothesis: There is no significant difference in the proportion of SDA and public-school students taking industrial arts.

Industrial Arts Teachers

Data examined that relate to industrial arts teachers include selected demographic characteristics, professional organization affiliations, educational levels, and the proportion of total faculty teaching industrial arts.

4. What are some characteristics of industrial arts teachers in the SDA school system?

The characteristics chosen to answer this question include the number of industrial arts teachers, teaching contracts, supplemental pay, student-teacher ratios, teacher certification, professional involvement, educational levels and experience, and the number of vacaut teaching positions.

5. Is a greater or lesser percentage of SDA industrial arts teachers involved in professional educational organizations than public-school industrial arts teachers?

6. Is there a significant difference between the 
educational levels of SDA and public-school industrial arts teachers?

Null hypothesis: There is no significant difference between the educational level of SDA industrial arts teachers and public-school industrial arts teachers. 7. Is there a significant difference in the proportion of total faculty involved in industrial arts between SDA and public schools?

Null hypothesis: There is no signiflcant difference in the proportion of total faculty involved in industrial arts between SDA and public schools.

\section{Instructional Programs}

Characteristics of instructional programs examined in this section include selected demographics, perceived strengths and weaknesses, the variety of course offerings, exemplary characteristics, major barriers to outstanding programs, and the programs with which industrial arts is most closely allied.

8. What are some characteristics of industrial arts inst:ructional programs in SDA secondary schools?

The characteristics described relate to industrial arts facilities, courses, classes, and requirements.

9. What are the perceived strengths and weaknesses of current industrial arts programs in SDA secondary schools?

10. Are the perceived strengths and weaknesses of industrial arts programs in SDA secondary schools 
significantly different from the perceived strengths and weaknesses of industrial arts programs in public schools?

Null Hypothesis: The perceived strengths and weaknesses of industrial arts programs in SDA secondary schools are not significantly different from the perceived strengths and weaknesses of industrial arts programs in public schools.

11. Is there a difference in the variety of course offerings between SDA and public-school industrial arts programs?

12. What are considered the characteristics of an exemplary industrial arts program?

13. Are there significant differences among the characteristics of an exemplary industrial arts program as suggested by SDA chairmen, principals and Union educatior: directors?

Null hypothesis: There are no significant differences among the characteristics of exemplary industrial arts programs as suggested by SDA chairmen, principals and Union education directors.

14. What are considered the major barriers to having an outstanding industrial arts program?

15. Is there a significant difference between SDA industrial arts chairmen and principals in their perceptions of the programs with which industrial arts is most closely allied?

Null hypothesis: There is no significant 
difference between SDA industrial arts chairmen and principals in their perceptions of the programs with which industrial arts is most closely allied.

16. Is there a significant difference between SDA and public-school chairmen in their perceptions of the programs with which industrial arts is most closely allied?

Null hypothesis: There is no significant difference between SDA and public-school chairmen in their perceptions of the programs with which industrial arts is most closely allied.

17. Is there a significant difference between SDA and public-school principals in their perceptions of the programs with which industrial arts is most closely allied?

Null hypothesis: There is no significant difference between SDA and public-school principals in their perceptions of the programs with which industrial arts is most closely allied.

\section{Industrial Arts Programs}

18. How many SDA schools have advisory committees associated with their industrial arts departments?

19. What proportion of SDA schools have industrial arts programs?

20. Is there a significant difference between the proportion of SDA and public secondary schools with industrial arts programs? 
Null Hypothesis: There is no significant difference between the proportion of SDA and public secondary schools with industrial arts programs.

Purposes of Industrial Arts

21. Is there a significant difference between the current and ideal emphasis on the purposes of industrial arts as perceived by SDA industrial arts department chairmen?

Null hypothesis: There is no significant difference between the current and ideal emphasis on the purposes of industrial arts as perceived by SDA industrial arts department chairmen.

22. Is there a significant difference between the current and ideal emphasis on the purposes of industrial arts as perceived by SDA principals?

Null hypothesis: There is no significant difference between the current and Ideal emphasis on the purposes of industrial arts as perceived by SDA principals.

23. Is there a significant difference between the perceptions of SDA chairmen and principals of the ideal emphasis on the purposes of industrial arts?

wull hypothesis: There is no eirnificant difference between the perceptions of SDA chairmen and principals on the ideal emphasis on the purposes of industrial arts.

24. Is there a significant difference between the 
perceptions of SDA and public-school industrial arts chairmen on the ideal emphasis on the purposes of industrial arts?

Null hypothesis: There is no significant difference between the perceptions of SDA and publicschool industrial arts chairmen on the ideal emphasis on the purposes of industrial arts.

\section{Resources}

Financial characteristics described relate to equipment and supplies, methods of charging students, and sources of funding.

25. What are the general characteristics related to resources in SDA industrial arts?

26. Do SDA industrial arts departments spend more or less per student on equipment and supplies than publicschool industrial arts departments?

\section{Facilities}

27. Is there a difference between the number and varlety of industrial arts general laboratory facilities avallable in SDA and public schools?

\section{Future planning}

28. What are the projections for enroliment and course offerings in industrial arts in SDA schools?

29. What guidance is given to SDA industrial arts programs by the Union education offices? The types of 
15

guidance considered relate to certification requirements and curriculum development.

Standards
30. What areas of industrial arts should a set of standards cover?

31. What are the standards whereby industrial arts programs can be evaluated and guided in their development?

\section{Definitions of Terms}

The terms used in this study are defined as follows:

Industrial Education--a generic term applying to all types of education related to industry including industrial arts education, vocational industrial education, and much technical education (Strong \& Schaefer, 1975).

Industrial Arts--those phases of general education which deal with technology: its evolution, utilization, and significance; with industry: its organization, materials, occupations, processes, and products; and, with the problems and benefits resulting from the technological and industrial nature of society (Maley, 1973).

Vocational Education--a generic term encompassing vocational or technical training or retraining designed to prepare individuals for gainful employment as semiskilled or skilled workers or technicians, or to prepare 
individuals for enrollment in advanced technical education programs (strong schaefer, 1975).

Data base--descriptive data gathered by surveys from those involved in industrial arts and related to industrial arts offerings in SDA secondary schools.

standards--a set of validated statements representing the essential basic elements of industrial arts programs, designed for use as measures of quality against which existing industrial arts programs and activities can be evaluated and as guides for new and expanding programs (Dugger, 1980a).

\section{Delimitations}

1. The emphasis of the data analysis procedures are descriptive and comparative.

2. The descriptive data base and standards are to be generalizable only to industrial arts programs in SDA high schools in the United states of America.

\section{organization of the study}

The dissertation is organized in the following format:

Chapter 1 covers the background of the study, the statement of the problem, the purpose of the study, research questions and related hypotheses, delimitations, definitions of terms, and the organization of the dissertation.

chapter 2 reviews related literature and covers 
the history, philosophy, and nature of industrial arts; industrial arts surveys; and educational standards. Chapter 3 states the research questions, describes the methods and procedures utilized in the collection and treatment of data, and the instrument and standards designed.

Chapter 4 presents an analysis of the data, including the findings, interpretations of the results, the tests of the hypotheses, and answers to the research questions.

Chapter 5 presents a summary of the study with conclusions, implications, general recommendations, and recommendations for further research. 
CHAPTER II

REVIEW OF IITERATURE

\section{Introduction}

The review of literature is divided into three areas: (1) a historlcal review including the beginning of industrial arts in this country, as well as the present status of industrial arts; (2) an investigative review to seek out definitions and philosophies of industrial arts programs in public schools as compared with christian schools (in particular the seventh-day Adventist schools); and (3) a review of surveys of industrial education programs, and the development of general and industrial arts standards.

In addition to manual searches to discover literature for this review, the Educational Resources in Education (ERIC), Dissertation Abstracts International (DAI), National Technical Information Service (NTIS), and Abstracts of Instructional and Research Materials in Vocational and Technical Education (AIM/ARM) were computer-searched for relevant literature.

\section{A Definition of Industrial Arts}

It is meaningless to discuss definitions of industrial arts in the absence of any time framework. It 18 
is obvious from the brief review of the beginnings of industrial arts in this study that the term implied different activities to different people at different times. A review of recent literature, however, seems to indicate a consensus of opinion as to the definition of industrial arts. Bonser and Mossman (1938), Hales and snyder (1982a), The Illinois Plan for Industrial Education (1983), Maley (1973), olson (1974), the Technical Foundation of America (n.d.), and wilber (1948) all basically define industrial arts as those phases of general education which deal with technology: its evolution, utilization, and significance; with industry: its organization, materials, occupations, processes, and products; and with the impact (problems and benefits) resulting from the technological and industrial nature of society.

Although the basic definition has remained the same over a period of time, Worthington (1982) pointed out that key words in this definition have changed. Wilber's (1948) definition excluded the term technology, Maley (1973) popularized that term along with industry, and Hales and snyder (1982a) included "comprehensive" to describe the industrial arts program.

A number of authors have expressed concern that the last phrase in the definition, "the impact of technology and industry," be given equal emphasis with the remainder of the definition. Peter and peter (1978) 
adequately express the concern of Maley (cited in "An Interview with Three Curriculum Experts," Man/Society/ Technology, 1980), Ritz (1981), and Yarbrough (1977) by stating that

students must learn that technological advancement has both positive and negative consequences. students need to gain experience in making value judgments about what they are doing in industrial arts. Value judgments control the production of industry and also the utilization of technological discoveries. (Peter \& Peter, 1978, p. 29)

This statement implies an understanding of the terms industry and technology. The Technical Foundation of America in a paper titled Industry and Technology Education (n.d.) defines industry as part of the societal economic institution that uses resources to produce goods and services, and information to meet the needs and wants of individuals and society; and technology as the creation and use of tools, resources, and systems to manage manmade and natural environments to extend human potential and the relationship of these to individuals, society, and the civilization process (p. 5).

Although speciflc definitions vary, the following universal themes have been 1solated by Israel (1981a) and are vital to an understanding of contemporary industrial arts :

1. Industrial arts deals with the overall study of industry/technology compared with a concentration on a specific area or a specific technology.

2. Industrial arts is a study of the broad 
21

concepts of industry and technology, not the study of all the different types of industries or technologies.

3. Industry/technology must be studied in the social/cultural context.

4. Industrial arts includes problems resulting from or relating to the industrial-technological setting.

5. Certain aspects of technology (origin, development) and industry (organization, materials, occupations: should be studied (p. 3,4$)$.

Each component of the school curriculum must be unique in some respect to Justify its inclusion. Maley (1973) identified the following characteristics of industrial arts:

1. Its content centers around industry and technology--an imperative given the context of contemporary existence.

2. It correlates with most other secondary-school subjects.

3. Its broad potential provides for varied opportunities and educational experiences to cope with individual differences.

4. Its more complete approach to development is valuable because of integrally interwoven physical and mental processes.

5. Its varied methodology reaches a varied clientele.

6. Its dynamic content must adjust with the 
changes in industry and technology.

When viewed in terms of the functions of the school in society, these identified characteristics of the subject of industrial arts have the potential to contribute to these functions. Olson (1974) Identifled one of the primary functions as acquainting youth with the nature of their culture. Given that the American culture is characteristically and intensely technological, he concluded that the primary function of the school, then, is to acquaint the young with the nature of the technological culture and the technology itself; thus industrial arts becomes the "interpreter of technology for the American schools" (Olson, p. 36).

Another school function, according to Hornbake $(1980)$, is related to the fact that "the continued vitality of a civilization lies in its ability to identify the basic problems of the society and then work out satisfactory solutions" (p. 27). Martin (1983) identified one of thase basic problems as technical literacy (p. 6 ). with technical literacy being one of its objectives, industrial arts has the potential to play a role in the solution of this problem.

The areas of content for Industrial arts programs are generally accepted to be communication, construction, transportation, and manufacturing (Fuglsby, 1978 ; Illinois Plan for Industrial Education, 1983; Lauda, 1982 ; Maley, 1973; NADOE, Framework for Applied Arts K-12, 1979 ; 
Ray, 1980; Ritz, 1981). These areas have been justified by Barrier (1983) on the basis of their universalism. Barrier has analyzed the historical and social aspects of human endeavors in various cultures and has isolated three universal technological endeavors which have developed and progressed into established bodies of knowledge: communication, production, and transportation. These elements are found in all cultures regardless of their stage of development. To these three was added manufacturing to comprise "the four major human productive activities" (Technical Foundation of America, n.d., p. 3). viewed in terms of traditional industrial arts, this definition implies a movement from the narrow to the broad; for example, toward communication concepts from the more narrow areas of printing and drafting, and toward transportation rather than automotives or electronics. concepts should be considered broadly because rarely are they isolated as purely as they are encountered in unit shops or laboratories.

This review of literature reveals the concept of industrlal arts to be a broad-based part of general education; it is applicable to all students and its rationale is derived from the nature of the current technological society and the belief that students need to be technically literate in order to function optimally, regardless of the role they play in society.

The context of the original inception of 
industrial arts in U.S. education, and its history, attests to the fact that these foregoing concepts are long-standing and basic elements of industrial arts.

\section{A History of Industrial Arts}

Industrial arts did not begin contemporaneously with general education in the United states. American educational consciousness in the general population was aroused abcut 1820. General enthusiasm for public schools was slow to develop, but within 50 years common public free education was an integral part of American society. Beginning with Massachusetts in 1851, the United States began requiring its residents to attend school at least to grade 8 . Then followed the public provision for education beyond the elementary level, and with the high school came a vastiy expanded curriculum, one more practical when compared to the original classical curriculum. It was in this environment that industrial arts found its beginnings.

Industrial arts historians agree that a sense of the need for industrial arts education in schools developed toward the end of the nineteenth century out of the social/industrial milieu of the times. Despite the terminological confusion in evidence in retrospect, similar types of courses were included in the educational curricula of the schools before this time. This is illustrated by the Morrill Act of 1862 whlch provided for the establishment of agricultural and mechanical colleges 
resulting in such courses; and the st. Louis Manual Training School established in 1880 by the Manual Training Movement which reflected the concern for manual and industrial training and education.

Historians do not agree, however, on the specific roots of the industrial arts movement. some, with a desire to clarify the confusion that has historically and currently enveloped the role of industrial arts compared with other types of industrial education, view the development of industrial arts as separate from the manual training/vocational education movement. Others see it as a direct outgrowth of the manual training movement. "The actual evolution from manual training to industrial arts has been a long slow process," stated Barlow (1967, p. 240), a proponent of the latter view. While recognizing the confusion of terminology at the time, Barlow nevertheless saw a progression from manual training--about 1876-- to manual arts--about 1894 --and then industrial arts--about 1910 .

Each term was supposed to have a meaning all of its own. . . manual arts gave an improved design concept to manual training, and industrial arts represented a further refinement of purpose and direction. (Barlow, 1967, p. 240)

Barlow was not alone in this perception of history; he echoed Bennett (1937), Feirer and Iindbeck (1964), and stombaugh (1936). It is true that many educators in the early 1900 s viewed industrial arts similarly, that is, as a development out of the manual 
arts movement. Richards (1904), director of the manual training department of Columbia University, suggested, in a Manual Training Magazine editorial, that the term industrial arts be substituted for manual training. He contended that

we are rapidly leaving behind the purely disciplinary thought of manual training. . . Now we are beginning to see that the scope of this work is nothing short of the elements of the industries fundamental to modern civilization. (pp. 32,33 )

A statement by the U.S. Department of Interior's Bureau of Education in 1918 indicated the relationship of industrial arts with training concepts.

The demand for large numbers of young people having some practical mechanical ability is so great that no school should hesitate to do what it can in any line of technical and mechanical instruction for ihich it has, or can secure, the necessary equipment and teachers. (p. 3)

In 1917, Jensen advocated industrializing manual arts. Dean (1918) used the terms manual arts and industrial arts synonymously with manual training. In a presentation to the National Education Association, Jensen proposed that "a newer conception must utilize the work and give the boys along with their manual arts the elements of practical training for industrial pursuits" (p. 454) .

Even as late as 1925, industrial arts was seen to have strong vocational goals. "The aim of the industrial arts then, in the senior high school should be, first, vocational, either immediately or remotely" (Bennett, 1925, p. 226). 
Conirasted with this view of industrial arts as a stage in the continuum of development from manual training and arts is the view that the antecedents of industrial arts are found in the social reform movements of the late nineteenth century. At that time fundamental changes were occurring in American society--industrial/urban expansion, manufacturing, and transportation development. The basic shift from an agrarian to an industrial and urban society was causing much social dislocation. As a response to the social problems, reformers focused on education as a means of directly influencing ghetto living. In this context, there developed a demand for education suited to the working classes (Herschbach, 1979).

By the late nineteenth century, traditional educational practices were entrenched in the public-school system, but private groups experimented freely. It was considered by these reformers that through the schools, the necessary general work skills could be provided. "Youths cannot be good citizens unless they are useful citizens and they cannot be useful citizens unless they have learned to work" (Newell, 1877, p. 13). The success and popularity of this approach within private institutions and groups eventually led to a demand for publicly supported programs.

Herschbach (1979) described this approach as basically Froebelian. Froebel designed an approach to education that was used in the kindergarten, a system of 
play activities intended to provide skill development, "the best preparation for the arts and trades. The senses were sharpened, the hands trained and the body was made lithe and active" (Cooper, 1886, p. 53-58). Meleney (1886) considered the activities appropriate to enhance the development of general underlying physical and mental abilities basic for the subsequent development of more technical skills, rather than providing specific skill training. This approach to education contrasted boldly with traditional educational thought at the time.

The proponents of this new approach to education were quite adamant about both the sources and the goals of their ideals. McPherson (1976) stated that

Russell, Bonser, Mossman, Dewey, Kilpatrick and others in the Progressive Education Movement denounced manual training and clearly distinguished between vocational and industrial arts education. Their philosophy was child-centered, activity-oriented and humanistic; they viewed industrial arts as an integral part of general education. (p. 140)

Bonser and Russell (1914) perceived industrial arts to be the result of the "progressively broadening tendency to bring the work of the school into a more vital relationship with the immediate world of activities and interests in which the child lives" (p. 24).

The Industrial Education Association, incorpcrated in 1884, formulated ten Articles of Faith, "stating the assoclation's principles to guard against 1ts work degenerating into a manual training school." One of the aims "stressed the importance of industrial training 
combined with general education" (Cremin, Shannon \& Townsend, 1954, p. 17).

Dewey successfully combined the ideas of these early industrial arts advocates into a coherent philosophy. He believed children have a natural impulse to communicate, construct, investigate, and experiment, and that industrial activities are the best means to bring these impulses into correlation with a broad range of ideas, knowledge, and facts (Dewey, 1915).

Industrial arts thus provided a way for the reformers to blend concern for individual growth and development and social goals (Herschbach, 1979, p. 12). Although resisted at first by traditional educators, industrial arts eventually became an accepted segment of the high-school curriculum, influenced heavily by the sloyd system (a variety of tools and materials utilized in the construction of useful products by individual students) rather than by more vocationally oriented schemes.

After the turn of the century, with strong public demand for vocational education, the role of industrial arts was further clarifled, and "by 1930, its place in the general school program was generally accepted" (Barlow, 1967, p. 254) by all groups, regardless of whether they saw the source of industrial arts in the manual training movement or in the desire for social reformation.

From the very inception of industrial arts, the 
practice has responded to pressures and changes in the societal context in which it existed. At the time of this study (1984), the movement continues to react to contextual pressures, specifically, to burgeoning technology.

\section{Technological Changes Related to Industrial Arts}

In reviewing the literature relating to industrial arts, one of the few issues on which there appears general agreement relates to societal changes.

Authors perceived the changes in different ways. McHale (1969) viewed the situation as follows:

ours is possibly one of the most critical periods in human experience. Poised in the transition between one kind of world and another, we are literally on the hinge of a great transformation in the whole human condition. The next 50 years may be the most crucial in all of man's history. All of our previously local actions have now been magnified to planetary scale. The knowledge with which we might make the correct decision is barely adequate -- yet our gross errors may be perpetuated for many generations. (p. 15)

Richardson related to the changes more poetically

but no less significantly:

There was a time when the seas seemed endless and the skies vast enough to swallow any of the mistakes and errors of man. The world used to be big and men could afford to be small. Now the world is small and men must be big. (Richardson, 1976, quoted in "The society of the Future: Implications for Learning Through Industrial Arts", Journal of Epsilon Pi Tau, 1978)

starkweather (1976b) made the statement that "few informed persons now doubt that technically advanced societies like the United states are undergoing major transformations to some sort of 'post industrial' age" 
(p. 64); and Duvall (1980), in discussing society and technology, stated unequivocally that "without question we are now standing at the crossroads" (p. 19).

Bell (1973) and Toffler (1975) saw the history of society in stages, the present being the verge of a new post-industrial stage. Mangano (1976) saw the changes as the death of "hard technology" and a future of non-violent and environmentally gentle "soft technology". Maley (1980) noted that the new soclety faces problems and uncertainties quite different from previous generations living in more stable times (p. 11). Israel (1981b) estimated that the average rate of change in technology has decreased from 8 to 15 years to 1 to 5 years (p. 9). The Technology Foundation of America saw the differences between the past and present in the rate of change and the visibility of change. Change now occurs much more rapidly than it did in the past. It is more difficult for people to understand these changes because technology is not as observable as it used to be (Technology Foundation of America, n.d.).

There is a general feeling in the literature of industrial arts educators that industrial arts is ideally suited to assist in the education of society for the technological knowledge that is needed by that society (Maley, 1980; Mangano, 1976; Olson, 1974; Starkweather, 1976b; Walters, 1977). Martin (1983) identified technological literacy as one of the basic problems in society, 
a problem that should be addressed by industrial arts because technological literacy is one of the goals of industrial arts (p. 6). A function of the school is to acquaint the young with the nature of their technological culture (Olson, 1974, p. 36).

If there is a basic relationship between industrial arts and technology, and "technology is at the threshold of a new era" (Maley, 1980, p. 12), then industrial arts is also necessarily on the threshold of something new (p. 12). The current literature in industrial arts reflects this feeling, emphasizing that industrial arts must change in order to meet the current needs of society and to maintain relevancy in the curriculum. Concomitant with this notion, vickery (n.d.) called for a change in course content from the traditional woods, metals, and drafting to courses such as manufacturing, construction, transportation, and communication. "Although manipulative activities will continue to be an important part of industrial arts, they will be designed for learning about [these] broader conceptual areas of industry and technology" (Starkweather, $1976 \mathrm{C}$, p. 82).

Bensen (1979) and walters (1977) stated the case most forcefully:

It is apparent that most industrial arts programs reflect a technology of a pre-industrial culture. Industrial arts, as most perceive it, is an anachronism in modern society. Industrial arts educators are teaching skilis that the majority of 
students will never use because they will never need to use them. (Walters, 1977, p. 234)

Industrial arts as we know it is in serious trouble if we do not as a profession bring our programs into focus with the current state of the art of technology. We can no longer cling to a few selected activities which were based on a technology of half a century ago and pawn tt off as relevant. (Bensen, 1979, p. 335)

Lange and Hayes (1981) indicated the logic of change in industrial arts from industry to technology because industry is no longer the basis of the economy.

Hacker and Barden (1983) saw

a movement toward technology-based curriculum content as a logical step in the evolution of industrial arts. The shift toward technology education is in harmony with the transcendent change occuring in advanced post-industrial soclety, and must proceed as rapidly. (p. 10)

In supporting the call for change in industrial arts, Israel (1981b) examined the rate of change of technology and education. He stated that the average rate of change in industry or technology was 1 to 5 years, while the rate of change in education was 10 to 20 years. Because new technology is developing at a faster rate than education is updated, major changes in industry/ technology are not studied in industrial arts courses until 16 to 30 years later. For example, it took 30 years before mass-and-line-production activities were incorporated into industrial arts programs (p. 9).

In looking at and comparing the technological real world and industrial arts programs, some authors have developed a "gap" concept. Tyler and Miller (1966, p. 221) saw the gap as having developed between the 
cleverness of man's inventions and his ability to make wise social decisions about them. Iuftig (1977, p. 142) saw the gap existing in the amount of knowledge separating the technologist from the majority of the populace. starkweather (1978, p. 12) perceived the gap as being between the typical industrial arts program, emphasizing the construction of the project and current or future industry and technology. A redesigned industrial arts curriculum that reflects current and future technology is seen as the solution to closing the gap.

\section{Factors Influencing Industrial Arts}

Apart from the widespread impact of technological changes, there are other forces that continue to influence the nature of industrial arts. Any school program is susceptible to demographic changes. Starkweather (1976a) noted that while on a national level the decreasing birthrate eventually leads to school and program closings, in the ghetto areas the birthrate does not follow the national declining trends. The United States Bureau of the Census in 1977 predicted that after the decline in the number of school-age children, the numbers would begin to rise again.

A 1977 Harris Poll found several changes in American attitudes, specifically that Americans

1. prefer to cooperate rather than to compete

2. think modern technology has caused as many problems as benefits to people 
3. would prefer a clean environment to one which provides jobs

4. believe education should be more studentoriented than success-oriented

5. prefer to spend more time getting to know each other than speeding up the ability to communicate through technology

6. believe that it is more important to appreclate human values--as opposed to material values--than to find ways to create more jobs for producing more grods (Starkweather, 1978, p. 10-11).

Such attitudes and forces are bound to change the educational system and the related nature of technology. In deriving implications for education from the 1980 census, Long (1981) noted that the strong interstate migration patterns create changing demands for education, and that by 1990 most workers will be in mid-career and highly educated. Retraining and continuing education in the face of strong competition for jobs influences patterns of technology education.

To this point, this chapter has examined literature related to a definition and history of industrial arts and to those technological and other forces that impact upon the nature of industrial arts. The literature examined next relates to the present state and future projections of the nature of industrial arts. 


\section{The Present state of Industrial Arts}

The call for change in industrial arts to keep pace with its subject matter implies that change and revision have not been ongoing within the profession. Copeland (1982) stated that change has been occurring much too slowly and has not kept pace with the knowledge base. "Many industrial arts programs are no different in terms of content and practice than they were in the fifties and sixties" (p. 12).

The controversy of the 1980 s surrounding the need for change has often focused on the profect as a symbolic rallying point. The construction of individual projects by students had become one of the readily ldentiflable characteristics of industrial arts (Barlow, 1967, p. 257). Project methodology partly grew out of the experimental work of John Dewey around the turn of the century. starkweather (1976a) used the continued practice of producing projects as evidence that

industrial arts educators are doing very little thinking about the years ahead or they would not be producing projects such as the proverbial lamp or birdhouse, which are supposedly interpreting industry and technology. (p. 199)

Copeland (1982) characterized the project approach as "very limited because students are not provided with broad experiences that will assist them in living in a highly technical society" (p. 11).

The project, however, has not been without its advocates. In an article titled, "The project Is Alive 
and Doing Well", Miller (1974) stated that it was doing so well that most teachers enjoyed teaching with this method. The advantages of the project included student and teacher motivation, a homeward-bound symbol of development, and a source of enjoyment for the students. Ressler (1977) decried the movement away from the project "to a more theoretical technology-related curriculum" (p. 250) and stated that the project method provided students with survival skills which were of tremendous importance. Barich (1977) advocated a return to the traditional role of promoting excellence and fine craftsmanship. Feirer (1979) supported the profect approach as an element of his call to return to the basics.

This project-versus-technology conflict is symptomatic of general confusion and fragmentation in the ranks of industrial arts educators. Much of the literature views the basic cause of this confusion as a lack of consensus regarding the relative importance of the functions of industrial arts (Barich, 1977; Bensen, 1979; Dugger, 1980c: Lauda, 1980; Leutkemeyer, 1983; Starkweather, 1976a). Liange and Hayes (1981) Identified the major controversy between the extent to which industrial arts should teach modern technology and the extent to which it should emphasize the development of psychomotor skills through the use of tools (p. 8).

Prakken (1977) sounded one of the few optimistic notes to be heard among industrial arts educators 
regarding current industrial arts programs. In an article titled, "Whither Are We Going?," his answer was, "Up." His cause for optimism included the unprecedented progress of industrial arts in the preceding 15 to 20 years, the high caliber of teachers and standards of teacher-training institutions, and the increased knowledge and application of suitable methodology (p. 7 ).

Israel (1981a, 1981b) took a historical approach to the confusion and traced the gradual development of the profession in two different directions: some had become more liberated in their thinking by keeping pace with technology, while project teachers, in the other direction, had updated their rationaie based on the return to basics.

The diversity that presently exists in industrial arts can be plotted on a continuum: at one end is the emphasis of industrial arts on the use of take-home projects for the purpose of students learning skills and processes; at the other end is the recommendation that industrial arts be renamed as technology education. (Israel, 1981a, p. 5)

Content for the subject matter of industrial arts is derived from three sources: the mechanical trades, industry, and technology. Confusion, claimed Brown (1977), is a result of the fact that these three sources are not complementary but independent, and this produces philosophical divisions. It is not difficult to find literature that advocates each of these sources. For example, wright (1982) related to industry, Ritz (1981) 
championed technology, and Feirer (1979) proposed a return to "technical emphasis."

Evans (1982) reinforced Brown's (1977) observations with his statement that "Industrial arts is unbelievably fragmented, with tive types of courses": (1) cottage arts and crafts; (2) vocational education for predropouts; (3) exploration of the world of work; (4) exploration of technology; and (5) practical arts (Evans, 1982, p. 14).

Martin (1983) took a more fundamental approach than the above:

some would contend that the root of our problem resides in the division in our profession--the traditionalists, the technology educationists and the industry based educationists . . . dividing and preventing the profession from reaching any kind of consensus on any matter, however large or small. I would contend that the problem is much more fundamental than that. I believe that it is simply one of change. (p. 4)

Martin believed that the profession must first address questions related to purpose prior to determining direction.

A 1961 dissertation (Miller) argued that Industrial arts had no clear set of unique objectives; on the national level it accepted those published by the American Vocational Association. Miller examined these adopted objectives to determine if they were consistant with the characteristics and definitions of industrial arts and concluded that they were not. This, he stated, added to the confusion in the fleld (p. 1922,1923). 
Much of the historical literature in industrial arts utilizes the philosophy of Deway as the basis for industrlal arts (Bennett, 1937; Brown, 1977; Svendsen, 1963). One unique characteristic of Dewey's philosophy was his criticism of traditional dualisms such as mindbody, theory-practice, and lelsure-work. "Dewey's philosophy combined knowing and doing. It was an attempt to bridge the gap between humanism and science/technology" (Leutkemeyer, 1983, p. 3), rejecting any one source as being the most important. Leutkemeyer pointed out the anomaly of the current confusion in which the broad philosophy of Dewey that many agree was one of the bases for industrial arts seems to be rejected by its theorists who advocate such dualisms (p. 3).

Accompanying the term confusion is the term stagnation as applied to industrial arts in describing the practicing profession (Worthington, 1982). According to Maley (1980), stagnation is the result of "confusion of purposes, programs, allegiances, emphasis and direction" (p. 10). According to Israel (1981b), stagnation is a result of diversification and resultant loss of sense of mission. Whatever the specific cause, there is general agreement that the practicing industrial arts profession has undergone very little change in the last 15 to 20 years (Dugger, 1980b; Hacker \& Barden, 1983: Israel, 1981b).

This stagnation occurs in spite of the fact that 
41

forward-looking educators have been proposing change for more than four decades (Copeland, 1982). Examples of some of the results of these proposals for change include:

Illinois Plan for Industrial Education (1982)

The Jackson's Mill Curriculum Project (1982)

Miami state Plan (1981)

The Plan for Futuring of Occupational and Practical Arts Education (1981)

The Maryland Plan (1973)

The General Industry Program (1972)

The syossett Plan (1969)

Industrial Arts Curriculum Project (1969)

The American Industry Project (1962)

Recommendations from these plans represent a broad-based approach to technology education which has had an impact on the literature, but has "yet to influence the majority of practicing teachers" (Starkweather, 1976a, p. 199). Devore (cited in "An Interview with Three Curriculum Experts", Man/Society/Technology, 1980) saw this "difference between what the field has professed to be and the behavior of the practitioners in the field" (p. 1I) as the cause of the confusion among industrial arts educators.

In corroboration of this dichotomy, Lange and Hayes (1981) saw little evidence to suggest that all this activity in industrial arts has resulted in any change in the schools. "Many of the new programs are well known, 
but not implemented broadly. In most schools the curriculum is the same as it was twenty years ago" (p. 8), highly project-oriented with the psychomotor activity of the project as the basis for student motivation.

In spite of this,

the profession also has the tools, the imagination and the capability for building and/or inventing the $\mathrm{kind} / \mathrm{s}$ of industrial arts that will make a major contribution in a society dependent upon an increasing knowledge of as well as the judicious use of technology and the fruits thereof. (Maley, 1980, p. 15)

One of the reasons for the current disenchantment with traditional industrial arts programs is that the narrow disciplines of study are not reflective of the real world. The breakdown of these horizontal hierachies that have divided human knowledge are the result of the combined impact of new technology, new knowledge, and social change (Toffler, 1971). This problem is being addressed theoretically by utilizing systems analyses and practically with an emphasis on interdisciplinary education. Probably the best known systems approach was developed by the Jackson's Mill Project (Hales \& snyder, $1982 \mathrm{a}, 1982 \mathrm{~b})$ in which the four elements of industrial arts--communication, construction, manufacturing and transportation--were interrelated as four subsystems which must be viewed through their interrelationships, inputs, processes, and outputs. The thinking of Hacker and Barden (1983) and Weatherspoon (1976) reflected a similar approach. 
Practically, the problem is approached by a call for interdisciplinary education. Alexander (1973), in an article titled "Putting It All Together", saw the problem as the subjects becoming more and more specialized and the students becoming less and less able to tie the concepts and skills together into a meaningful, relevant experience (p. 43). Educators (Alexander, 1973; Maley, 1984; Starkweather, 1976a; Vescerra \& DiMeo, 1982) have contended that industrial arts cannot be taught within a single discipline if education is to be directed toward the whole child as a functioning individual within a technological society. Evans (1982, p. 14) went so far as to suggest that if industrial arts were taught as it should be--integrated with other subjects and reflective of society--it would disappear as a separate subject in the elementary and juntor high school.

\section{The Future of Industrial Arts}

Much of the Industrial arts literature calls for changes in industrial arts, not just to update it to what is happening in society, but to orient it toward the future. A study by starkweather (1976b), which utilized the delphi technique, suggested that "members of the profession do more planning ahead. Too much education in the past has been after the fact" (p. 64). There should be a conscious effort to "search for our objectives and methods in the future rather than the past" (Toffler, 1971, p. 339). 
Too often we look at the future as being a series of events, opportunities, and disasters that overtake and engulf us from "out-there"; but we should think of the future as being ours to create, ours to fashion, and ours to dream. Our futures will come out of the best that our logic and our rationality can create. But even more importantly, they will also come from the best that we can dream. (Pascerella, 1979, p. 60)

Maley (cited in "An Interview with Three Curriculum Experts", Man/Society/Technology, 1980, p.10) and Richardson (1976, quoted in "The society of the Future: Implication for Learning Through Industrial Arts", Journal of Epsilon Pi Tau, 1978) visualized a future-oriented industrial arts as being much more directed toward the human qualities considered of prime importance, such as the abllity to cope with new and different situations, to anticipate and cope with change, to think critically, to solve problems, to effectively analyze information, to communicate, and to learn how to learn.

As a result of starkweather's (1976b) delphi study of the future of industrial arts, he predicted a number of changes:

1. The name of industrial arts would be dropped for some more relevant title for an era dominated by technology (p. 67).

2. The program would move in the direction of the application of technology in the solution of major problems facing mankind (p. 67).

3. The content of industrial arts would stress 
the impact of technology, both positive and negative, on society (p. 67).

4. The program would include a stronger bent toward man's social-technological problems (p. 67).

5. There would be a continuing trend for content to be organized around issues and problems associated with technology and society rather than jobs, skills, careers, and occupations (p. 68).

6. New programs of study would become more interdisciplinary and systems-oriented (p. 68).

7. An even broader range of experiences would substitute for organized school classes, credit, and experiences (p. 69).

8. There would be a development of a general industries laboratory away from unit or specific laboratories (p. 70).

9. The physical plant would become more open and flexible with little or no fixed or large equipment (p. 70).

10. The affective domain and values and value systems would become more important (p. 70$)$. In summary, the literature reflects the position that changes in society have created a unique need that the schools must 11l, and that is a need for technology education. Philosophically, industrial arts is ideally suited to fill that need. The cause for an optimistic outlook regarding the future role of industrial arts is 
contingent upon the imperative that practitioners reorient their programs more to the needs of students in the context of a technological society rather than the traditional retrospective approach that industrial arts practitioners have maintained.

\section{Seventh-day Adventist Industrial Arts}

In the search related to this study, no literature that made a comparison between industrial arts in seventhday Adventist (SDA) schools with that in public schools could be found. From a study of various curriculum guides, it seems that the titles of the subjects taught are generally similar: crafts, drafting, graphic arts, woodwork, metalwork, and auto-mechanics. There seem to be two tendencies toward uniqueness--the inclusion of electronics by public schools, and of gariening by SDA schools (Corpus Christi Public schools, Industrial Arts Teaching Guide, Introduction to General Shop, 1973; Lake union Conference, curriculum Guide/ course outline for Practical and Industrial Arts K-12, 1982; NADOE, Framework for Applied Arts R-12, 1979; Oregon State Department of Education, Industrial Arts in oregon Schools, 1967; Peoria Public Schools, Secondary School Curriculum Guide for Industrial Arts, 1977).

Most of the goals and objectives stated in publicschool industrial arts curricula are reiterated in the curricula of SDA schools. Examples are goals related to 
47

critical thinking, basic skills, use of leisure time, aesthetic values, intellectual curiosity, and value and dignity of labor (Lake Unton Conference, Evaluative Criteria for Seventh-day Adventist Schools K-10, 1982, p. 11). There are differences, however, in the philosophies, goals, and objectives of SDA industrial arts program compared with public-school industrial arts, differences centering around the Christian approach to the subject by the former.

The differences in the SDA approach to industrial arts compared with the public-school approach center around Christian idealism. For example, while publicschool educators are cognizant of the fact that industrial arts has the potential to contribute to a number of the different areas of human development of students--social, physical, and mental (Olson, 1974), SDA educators would add the spiritual domain to these three (NADOE, Implementation of the Seventh-day Adventist curriculum K12, 1981).

Many of the specific and unique goals of SDA industrial arts emanate from the philosophy that each person is created in the image of God, and the role of education is to restore students to that image (NADOE, Framework for Applied Arts K-12, 1979, p. 1i1.). The implications of this philosophy relate to the goals of individuality: eree, creative, responsible thought and action; individual respect; positive self-image and 
concept; and creativity (Lake union Conference, Evaluative Criteria for Seventh-day Adventist Schools K10, 1982, p. 12; Laverman, 1970). Even though some of these goals are accepted by both types of industrial arts educators, the philosophical rationale underlying the goals is different.

other unique goals of SDA industrial arts relate to the evangelical role of the church and the preparation of students to act in that role, though in its translation into specific objectives, this goal usually loses its uniqueness. An example would be found in goals such as the provision of opportunity for student acquisition of "concepts, skills and values needed in order to practice SDA principles" and "through which he may glorify God and promote and enhance the mission of the church" (Rationale for the Teaching of Practical Arts, n.d.).

The National Union of Christian Schools published a curriculum resource paper in 1970 in which Gerald Laverman developed a philosophy of industrial arts that related to technology. When compared with the pretechnology age, this phllosophy is more relevant in the light of the tendency to relate industrial arts to technology as a source of subject matter: whereas, in the past, the philosophical implications have been directed more toward laboratory methodology and the studies of independent subjects.

Laverman developed three concepts related to 
technology. The first is that education which relates to technology empowers man with the knowledge necessary to control the environment to meet human needs. This becomes a liberation process enabling man to seek a fuller realization and utilization of his God-given abilities (p. 21).

second, the understanding and study of technology can be constructively viewed by man as a potential means of human expression and concern for his fellow-man. This utilization of technology erees man for higher living and permits the development of unknown, unused talents ( $P$. 17).

Third, Laverman viewed technology not only as a revolution but also as a revelation by which man can more completely fulfill God's directives. God's first command to man was to subdue the earth and have dominion over it, and technological knowledge is the tool by which man can fulfill this directive (pp. 20,21).

These concepts are not present in public-school industrial arts philosophies, and therein lies a significant difference between public school and christian school industrial arts philosophies. It is one of the purposes of this study to determine if selected elements of the industrial arts programs are different in response to these differing philosophical approaches.

Thus far, this chapter has summarized the itterature directly related to industrial arts. The 
remainder of the chapter deals with standards and surveys that have been developed.

\section{Industrial Arts surveys}

The literature search conducted for this review revealed a number of surveys that were delimited to certain aspects of industrial arts, certain populations or geographical areas. For example, Osterndorf's (1973) summary for the U.S. Office of Education covered only course offerings and enrollments in each course area.

only two comprehensive national surveys of industrial arts programs in the United states were discovered. The first, printed in 1966, was based on data collected in the $1962-1963$ school year. The survey, Industrial Arts Education, was conducted by schmitt and Pelley of the United states Department of Health, Education, and Welfare. The purpose of the study was to collect data which could provide information on the following basic questions:

1. What is the Instructional program in industrial arts?

2. To what extent do schools offer industrial arts education?

3. What objectives are emphasized?

4. Does the size of a school affect industrial arts course offerings?

5. To what extent is industrial arts required of all students? 
51

6. What are the major problems confronting industrial arts teachers?

7. What is the educational background of the industrial arts teacher?

8. How many industrial arts teachers are there in the United States?

Two survey instruments used to obtain data for the study were administered to 2,259 principals and 3,040 industrial arts teachers.

The study examined such factors as the teachers' backgrounds, ability of students, teaching problems, methods of teaching, course offerings, and instructional content. The data were reported in relation to the enrollment size and type of school. Some of the findings were:

1. Three-fourths of the American public secondary schools had industrial arts programs. A definite relationship existed between the size of the school and the frequency of Industrial arts programs: more of the larger schools had industrial arts programs than did the smaller schools (p. 28).

2. Of the ten purposes of industrial artss identified on the survey forms, four ranked highe:t in the degree of emphasis placed on them by both industrial arts teachers and principals:

a. To develop in each student a measure of skill in the use of common tools and machines 
b. To discover and to develop creative technical talents in students

c. To provide general all-around technical knowledge and skills

d. To develop problem-solvirig skills relating to materials and processes (p. 28).

3. Of over 40,000 industrial arts teachers in public secondary schools, 94.4 percent held a regular or standard teaching certificate (p. 28).

4. To determine instructional content most teachers used curriculum guides which they themselves prepared (p. 29).

5. The seven teaching problems that caused industrial arts teachers the greatest degree of difficulty were:

a. Keeping up with advances in technology

b. Arranging and conducting field trips

c. Finding adequate preparation time for experiments and demonstrations

d. Finding time to help individual students

e. Providing for the slow learner

f. Providing career guidance materials in industry

g. Acquiring and teaching modern concepts of industry (p. 29).

6. From 25 to 30 percent of the instructional time in industrial arts classes was devoted to theoretical 
or related instruction; conversely, 70 to 75 percent was devoted to laboratory activities. Industrial arts courses met generally for a full school year, 5 days a week, for 1 period a day (p. 29).

The second and more recent survey of industrial arts programs was completed in 1980 (Dugger, b). The project was directed by Dr. W. Dugger of the Virginia Polytechnic Institute and state university and funded by the United States office of Education. The data collected included national demographic information on secondary school industrial arts teachers and students, and data about elements of industrial arts programs such as facilities, content, instructional programs, philosophical views, and students. State and territorial industrial arts supervisors, secondary-school principals, guidance coordinators, and industrial arts chairpersons were surveyed.

The data collected were grouped into eight sections for presentation: philosophical views, instructional program, students, student organizations, teachers, facilities, Inance, and evaluation.

some of the findings (Dugger, 1980c) were as follows :

1. Developing in students a "measure of the skill use of common tools and machines" was rated as the number one goal by a majority of respondents (p. 10).

2. One hundred percent of the guidance 
coordinators reporting said they believed college-bound students should take industrial arts courses (p. 11).

3. The enrollment of females in industrial arts was well below that of males, but some efforts were being made to increase those enrollments (p. 13).

4. In 1978-79 there were 1,077 unfilled industrial arts teaching positions (p. 15).

5. Of the 55,953 industrial arts teachers employed one percent was female (p. 15).

6. Twenty-eight states and territories reported receiving federal funds for industrial arts programs ( $p$. 16).

7. Regarding existing industrial arts programs, at least 45 percent of the chairpersons perceived course content to be the greatest strength of the programs, while 41 percent regarded funding as such (p. 17).

There does not currently exist any comparable or comprehensive survey of industrial arts programs within the SDA educational system.

\section{Industrial Education Standards}

As defined in chapter 1 of this study, a standard is a statement that is representative of the basic elements of the program for which it was designed and has two functions: evaluation and guidance. The virginia state Department of Education in the introduction to standards of Excellence for Reading Programs in Virginia 
(1976) expanded on these purposes to include:

1. The suggestion of components which can strengthen programs

2. The communication of information about programs to the profession and the public

3. Guidance in identifying exemplary programs (p. iv).

The Standards for Evaluation of Educational Programs, Projects, and Materials (American Psychological Association, 1981) inextricably relates standards to evaluation and proposes the following benefits of sound industrial arts standards:

1. A common language to facilitate communication and collaboration in industrial arts

2. A conceptual framework by which to study the often confusing world of industrial arts

3. A public statement of the state of the art in industrial arts

4. A basis for self-regulation and accountability by professionals in industrial arts

5. An aid to developing public credibility for industrial arts (p. 7).

It was also pointed out, however, that there can be risks in developing and using standards:

1. Promoting a field that possibly is not needed 2. Legitimizing practices within the field that may be invalid or harmful 
3. Concentrating attention on matters that are of relatively little importance while diverting attention from major issues

4. Encouraging bad practices because they are not explicitly prohibited in the standards

5. Impeding innovation.

At the American Vocational Association convention in Los Angeles in 1927, the industrial arts educators requested that the Executive Committee appoint a committee to study the problems of industrial arts. In 1928 a committee was appointed--the committee on standards of Attalnment in Industrial Arts Teaching (Barlow, 1967). The committee limited their work to a study of things which pupils should know and be able to do in industrial arts by the close of the junior high period. The committee existed for 18 years during which they made six reports.

The first report was made in 1929. The first edition of 1000 lasted less than 1 month. Great claims were made about this series of reports.

It is probable that no other publication in the area of industrial arts has been used by so many teachers and administrators. Certainly, none has exerted an equally significant influence upon the progress of industrial arts in public education in this country. (Smith, 1948, p. 7)

In 1946, the standards were revised for use by the teacher in evaluating and strengthening courses and generally improving instruction. Instruction was divided into three phases: doing (skills), knowing (information), 
and being (attitudes and habits). Industrial arts was seen to be a part of general education--instruction aimed at broad, unspecialized, and remote values. The goals were to sample and explain the mechanical world, to develop industrial and social intelligence rather than technical efficiency, and to provide pupils with experience, knowledge, and insight to help meet the demands of any calling (p. 7). The standards listed 18 subject areas with long lists of skill and information standards related to each area.

Educators of the time were eager to receive the standards. They were seen as something tangible, a foundation for the future development of Industrial arts, and a basis for extensive evaluation (Barlow, 1967, p. 183). These were, possibly, the first widely accepted standards related to the fleld of industrial arts. At the time of this review, there are three areas related to industrial education which now have nationally developed and validated standards: agriculture, home economics, and Industrial arts. Each has been sponsored by the United states office of Education and covers a broad range of subjects within a specific curricular area. The first of these three, The standards for Quality Vocational Programs in Agriculture/Agribusiness Education (Crawford \& Carter, 1977), has been developed by the profession to serve as a model against which all the existing programs can be evaluated. The process was 
initiated in 1968 when professional conferences, committees, and projects began developing standards for the field, although the formal process did not commence until 1976 with a seminar in Ransas City, Missouri, and a Urited states office of Education contract award to Iowa state University.

The standards were developed for all taxonomies within the agricultural education profession, as well as for adult education, teacher education, and state supervision in agriculture. There was also a section of standards common to all programs. The stated primary purpose of the standards was to assist the agriculture instructor in the evaluation and upgrading of the local program. An accompanying handbook was developed to guide in preparing and conducting the evaluation procedure and also to assist in developing a plan for upgrading the program.

In 1978, in response to recommendations from the American Industrial Arts Association and the American Vocational Association, the United States office of Education funded the standards for Industrial Arts Programs Project at virginia Polytechnic Institute and state University to develop standards for industrial arts. The objectives of this project were:

1. To develop a data base on industrial arts programs

2. To develop a set of standards and related 
handbooks for ensuring quality industrial arts programs

3. To familiarize, publicize, and demonstrate the standards developed for industrial arts programs.

In developing the data base, four different surveys were distributed to 54 state and territorial supervisors and to a sample of 2,235 public-school principals, guidance personnel, and industrial arts chairpersons in the United States.

The standards were developed and validated during a series of regional workshops attended by over 400 industrial arts supervisors, teacher educators, and consultants. Prior to the validation workshops, the workshop participants were sent a copy of the standards which had been developed and edited through the eight previous workshops. Each participant was asked to fieldtest the standards in the school system or university he/she represented. In the validation materials, it was requested that the participants, after field-testing the standards, indicate the degree of acceptability of a given standard. If they felt that a standard was not acceptable, space was provided on the document for suggestions to improve that standard to make it acceptable. From the participants at the three validation workshops, 70 percent acceptance was sought on each of the individual items in the standards. Further, the comments on how unacceptable standards could be improved were considered. From the input in these three validation 
60

workshops, the final standards document was produced. It contains 235 individual statements which can be used to assess the quality of an industrial arts program. The statements are divided into ten major topics: philosophy, instructional program, student populations, instructional stafe, administration and supervision, support systems, instructional strategies, public relations, safety and health, and evaluation. These topics had been formulated through a literature review and input from the project staff and advisory committees.

upon completion of the nationally developed standards, each state was encouraged to either adopt or adapt the standards for its own use. Michigan acted on this recommendation; the Michigan Industrial Education society appointed a committee of industrial arts teachers to review the national standards and comment on their appropriateness for Michigan. The department heads of all teacher education institutions were also contacted and asked to review the standards with their staff and submit recommendations. The committee then reviewed the comments and recommendations and finalized the content of the Michigan Industrial Arts standards (1982). Very little difference between the national standards and the Michigan standards can be noted.

In 1979, the University of Texas Division of Home Economics at Austin was awarded a contract by the united states Department of Education to identify existing 
61

standards and to develop new standards and an accompanying handbook for vocational home economics education (Griffin, 1981).

The project began with a search of literature and a request of appropriate materials from all the states and territories. A preliminary set of standards and handbook were presented in early 1980 to workshops at which a total of 472 persons reviewed and critiqued the materials. Reaction to the revisions was allowed at the 1980 American Vocational Association meeting. The final draft was reviewed by the advisory committee, the United states Department of Education project officer, and Vocational Home Economics program specialist.

The final product, Vocational Home Economics Education standards, was composed of nine volumes, each containing a handbook and a complete set of standards for a specific educational level and type of instructional program.

Another project involving the development of national standards in the area of Home Economics education was undertaken in 1979 by Iowa state University. Returns from 117 questionnaires in 50 states were used to develop standard statements. Respondents rated standards on an 11-point scale to indicate the degree of importance of general program standards.

Five steps were involved in the development of standards for vocational education in correctional 
institutions (Schroeder, 1977). First, a search of the literature was conducted to locate existing standards. second, 32 standards in five broad areas--curriculum and instruction, students, staff organization and administration, physical plant, equipment and supplies-were synthesized. Third, a panel of 11 experts reviewed the standards four separate times. The fourth step involved field validation of the developed standards by 185 administrators and teachers. The final 34 standards were reviewed by an 11-member advisory committee.

Another project that developed standards on a national level related to distributive education programs (Iucas Miles, 1978). It was sponsored by the American Vocational Association and involved a variation of the delpht technique which required respondents to make judgments about the approprlateness of standards in reflecting philosophical statements. Materials were distributed to a panel of experts on three separate occasions. In the final round all the standards were accepted by at least 75 percent of the respondents.

A number of studies have been done to validate national standards on smaller or different populations. walker and Hemp (1978) validated the national agriculture standards on agricultural occupations programs in Illinois community colleges. One hundred seventeen teachers in Illinois rated the national standards as essential, important, nice to have, and not needed. Absolute, 
relative, adjusted, and cumulative percentages on each item were computed to determine the relevant standards. stitt (1978, 1979) also utilized national standards to develop standards for secondary schools and vocational centers of Illinois. The standards were first pretested by five district directors, then rated by 413 agricultural occupations instructors in Illinois. of the 195 standards, 27 were below the 65 percent acceptance level. Of these 27,15 were eliminated, two accepted, and ten modified.

Hemp (1979) utilized the national standards in agriculture to develop standards in teacher education in agriculture for Illinois. University teachers in Illinois rated each of the national standards to retain, revise, or discard. An 83 percent response rate was achleved. A chl-square was computed on the two groups of respondents, and if a significant difference was found, then further consideration was given to the standard.

Two dissertations have been written involving standards for industrial arts. Bateson (1952) determined standards for industrial arts laboratories, and Hildreth (1976) for safety and health in industrial arts operations. Bateson began by gleaning standards from a literature review and then submitting them to a jury of seven industrial arts specialists for determining the optimum standard for each facility. Another jury of five specialists in industrial arts determined the relative 
contribution to a functional laboratory of each facility with its optimal standard. Hildreth used the jury technique (three groups of ten jurors each) to determine which of the standards developed in the Occupational Safety and Health Act were most benificial to school personnel.

In 1971; the American Vocational Association published a pilot test edition of Instruments and Procedures for the Evaluation of Vocational/Technical Education. The project was funded by the United States office of Education and examined over 500 pieces of ilterature on evaluation, utilizing special consultants, meetings, and interviews to develop the institutional and program-evaluation forms. The forms were designed for a three-phase evaluation: self-evaluation, on-site evaluation by experts, and review by an independent third group. The statements in the program forms are in effect program standards, couched in evaluative terminology. They cover the philosophy and objectives, needs, indicators of success, organization and management, advisory committee:s, research and evaluations, the teaching-learning process, curriculum, learning resources, supplies and equipment, and instructional space and facilities.

The state of California has developed program standards for industrial arts education (Los Angeles county superintendent of schools, 1975). The standards 
65

were developed with the cooperation of over 900 industrial educators in california. The 24 standards broadly cover legal program requirements, professional staff qualifications, course objectives, equipment facilities, materials and services, and occupational and vocational education orientations.

A project funded by the Kansas state Department of Vocational Education in cooperation with Kansas state University (1978) validated and/or modified a set of standards for quality vocational education programs. A literature review was conducted to provide information to a jury of representative experts. The standards were clustered into four areas: program planning (philosophy, objectives, future needs), program execution (curriculum, teaching-learning process, instruction, staff management): program support (personnel, student recruitment and admission, personnel services, student organization, records, instructional space and facilities, learning resources, advisory committee); and program results (student skill and proficiency, follow-up of placement, and satisfaction).

\section{General standards}

The remainder of this chapter reviews a number of studies conducted to formulate standards in areas other than industrial education. The methodology rather than 
the content of the standards is the main focus of these reviews.

Three dissertations dealing with the development of standards or evaluative criterla (DeTombe, 1974; Sheets, 1958; Wiseman, 1972) ut1lized the jury technique and a rating scale of four or five points from high (or essential) to low (or undesirable) to determine acceptable standards.

In validating competencies for vocational education teachers, administrators, and managers, Resnick (1977) utilized a consensus model variation of the delphi technique on three groups of participants: 55 teachers, 21 administrators, and 22 managers. The Maryland state Department of Education (1978) developed 21 standards as a guide to the evaluation of school mathematics programs. A committee of 15 representatives developed a working copy which was distributed to 500 local education agencies and institutions of higher education. Reactions and comments from the 240 returns were considered by the committee in the final document.

In developing a methodology to establish standards for occupational therapists, Madeline Gray (1976) outlined a procedure beginning with the selection of a task force according to the following criteria:

1. Expert knowledge and skill in the area

2. Experience in the development of standards

3. Representation of a particular type of work 
setting and experience

4. Ability to work in groups

5. Interest and avallability.

standards were formulated from the response to a questionnaire and a literature review and were evaluated and critiqued by over 200 practitioners. The desired characteristics of the standards were that they be relevant, understandable, measurable, behaviorable, and achievable.

other procedures utilized in the development of standards was a needs assessment and critical review by experts (Healey, 1974), conferences and group discussions (Council for Exceptional Children, 1966), and advisory panel and task force consultation (New York City Human Resources Administration, 1979).

It seems from this review that there are no generally utilized procedures to follow in developing standards; the procedures depend upon the resources avallable, the nature and scope of the standards, and the environment in which the standards are to be used. If there is one commonality among the varying procedures, it is that at some stage of the development the proposed standards must be exposed to a group of experts in the field and/or closely related fields for some form of evaluation or rating for the purposes of validation. 
Summary

This chapter began by reviewing the literature relating to definitions of industrial arts. It then examined the origins and history of industrial arts in the U.S., the factors that have influenced industrial arts up to the present, and the projections for the future. The philosophy of industrial arts as it relates to SDA schools was reviewed; and finally, the development of general and industrial arts surveys and standards was reviewed. 
CHAPTER III

\section{METHODOLOGY}

\section{Overview of Research Methodology}

This chapter outlines the methodologies utilized in this dissertation. There are two major tasks to be accomplished in order to answer the research questions of this study. one relates to the development, administration, and analysis of the survey; and the other to the development and validation of standards for industrial arts. The different methodologies for each are dealt with in sections $I$ and 2 respectively of this chapter. Prior to the summary at the end of the chapter, the research questions are stated, together with the source of the data used to answer each question, and the appropriate statistical methodology to test the hypothesis, if applicable.

\section{Section 1--The survey}

Three different survey instruments were developed to gather data from three different SDA populations in order to answer the research questions. One population consisted of chairmen of industrial arts departments in SDA high schools in the United states, the second population was the principals of those same schools, and 
the third population was the directors of the SDA Union education offices. The instruments are hereafter respectively referred to as the chairmen's survey, the principals' survey, and the Union survey.

The data related to the public-school system were gathered from a 1981 national survey of public schools in the U.S. (Dugger, 1981a).

\section{Selection of Subject Populations}

The proposed populations consisted of 86 chairmen, 86 principals, and eight Union directors. The size of the three populations was considered sufficiently small to be accommodated by the financial and time limitations of the researcher; as a result, no sampling procedures were utilized. It was subsequently discovered that four of the schools did not conduct industrial arts programs, effectively reducing the chairmen's proposed population to 82 .

The source of the initial population data was the Seventh-day Adventist Yearbook (Review and Herald Publishing Association, 1983). Because this was published prior to the beginning of the school year, it was outdated by the time school began, and the information taken from it had to be updated with current information from union Education Directories.

The population information from these sources consisted of names, titles if any, addresses, and telephone numbers. In situations in which there was more 
71

than one industrial arts teacher per school, the title of chairman was substituted for the name in the correspondence.

\section{Instrumentation}

The research instruments were modified from instruments utilized in a national study of industrial arts by Dr. W. Dugger (1981), of the Virginia Polytechnic Institute and state University, from whom permission was granted to modify the instruments. The national study, as a result of a united states office of Education suggestion, was particularly oriented to sex equity, student industrial arts organizations, and students with special needs. Some instrument items relating to these specialized areas were deleted while others related to peculiar aspects of the SDA educational system were added. To permit valid comparisons at the data analysis stage between the results of the national study and the results of this study, many of the items from the national study instruments were repeated on the survey instruments for this study.

\section{Validation and jury testing}

Afcer the initial selection, the items were structured in a logical sequence approximating the design of the final instrument. copies were distributed to a jury of nine experts representing the areas of research design, instrument design, Industrial arts, and computer 
analysis for the purposes of determining content and face validity. Copies of the 31 research questions that were to be answered by data from the instruments were also distributed to the fury. Most of their suggestions were incorporated into the final instrument.

\section{Pilot test}

The instruments were pilot-tested on a group of 11 administrators and industrial arts teachers for further refinement. Upon completion of the pilot test and consideration of the problems and suggestions, the instrument was finalized.

After the questions were entered into a computer, the printout was reduced 74 percent and each item was formatted into the final layout of the instrument. copies of the survey form were printed black on grey (see appendix A).

Administration Procedures and Data Collection

The procedures followed in this study were the result of an extensive review of the literature related to survey methodology. At the conclusion of this review, the method chosen was a variation of Dillman's (1978) Total Design Method (TDM). Dillman's method consisted of a postcard reminder after 1 week, a replacement package after 3 weeks, and a certified reminder after 7 weeks. A number of researchers have utilized variations of this procedure with success (Pride, 1979). 
The dates on which the follow-up procedures were initiated in this study are itemized in table 1 . The initial mail-out was sent on April 2, 1984. The package included a survey form, a business reply mail envelope (see appendix B), and a cover letter (see appendix C) .

TABLE 1

MAIL SURVEY FOLLOW-UP SCHEDULE

\begin{tabular}{|c|c|c|}
\hline Procedure & Date & $\begin{array}{c}\text { Days After } \\
\text { Initial Mailout }\end{array}$ \\
\hline $\begin{array}{l}\text { Initial mallout } \\
\text { Postcard reminder } \\
\text { Second reminder } \\
\text { Third reminder } \\
\text { Fourth reminder } \\
\text { Telephone reminder } \\
\text { Closure }\end{array}$ & $\begin{array}{l}\text { April } 2,1984 \\
\text { April } 12 \\
\text { April } 27 \\
\text { May } 15 \\
\text { May } 21 \\
\text { May 29-30 } \\
\text { June } 6,1984\end{array}$ & $\begin{array}{l}10 \\
25 \\
43 \\
49 \\
57 \\
65\end{array}$ \\
\hline
\end{tabular}

Research indicates that the inclusion of a postage-paid reply envelope significantly increases the response rate (Pride, 1979; Peterson, 1975; Babbie, 1973; Ferris, 1951). The type of postage was business reply, permitting billing for only those envelopes utilized in returning survey forms. The cover letter was computergenerated using a program that individualized each letter by printing the appropriate title, name, address, and institution wherever required throughout the letter, thus enabling each respondent to be addressed personally. The stationary was imprinted with an SDA Industrial Arts project logo. This logo was designed for 
use on the project stationery in an attempt to stimulate interest and to set the survey apart from other surveys. The cover letter was completed by individually signing each letter with the "pressed blue ball point pen" method (Dillman, 1978, p.173). The package was assembled and folded according to the TDM (Dillman, 1978, p.181). The outer envelope was addressed with a computer-generated label and malled at bulk rate. The bulk-rate mailing resulted in a saving of over $\$ 50.00$ when compared with first-class rates.

Six separate solicitations for cooperation were made. The first follow-up reminder consisted of a postcard (see appendix D) sent to each subject 10 days after the original mailing. The card thanked the early respondents, emphasized the importance of the study and the significance of each respondent, and invited the recipient to call collect if a replacement questionnaire was required. The logo was printed in black on the front of the buff-colored card. Each card was individually signed and addressed with a computer label.

As a result of the invitation to request a replacement questioniaire, 12 calls were received and the appropriate instruments were forwarded between April 17 and 19. It was then realized that due to the delays in the bulk-mail procedure, some in the population had not yet received the initial package.

The second follow-up reminder was sent to all 
those who had not responded by April 27. The package was the same as the initial mail-out, but with a different cover letter (see appendix E). The letter was computergenerated and personalized as was the initial cover letter. It reaffirmed the significance of the study and of each individual response.

The next follow-up was sent to all those who had not responded by May 15. The package again contained a postage-paid reply envelope and a survey form. The cover letter (see appendix F) was no more strongly worded than previous reminders, but it again emphasized the contribution of each respondent to the project.

The fourth follow-up (see appendix G) was not a part of the TDM design, but seemed particularly appropriate for these populations. BY MaY 21, it was realized that there was a higher percentage rate of returns from the principal population than from the chairman population. Letters were then sent to the 21 principals who had responded, but whose industrial arts chairmen had not. The letter thanked the principals for their time and effort and requested them to personally remind the industrial arts chairmen to respond, noting that because of principal-chairman comparisons to be made, the principals' responses would be useless if there were no data with which to compare. A similar procedure was followed for the four chairmen who had responded, but whose principals had not. These letters were more 
individualized than previous letters by naming the appropriate academy in the text of the letter.

The final effort to enhance responses was made on May 29 and 30 by attempting to make a telephone call to nonrespondents. Emphasis was placed on the industrial arts chairmen, because the response rate of the principals (90 percent) and Unions (100 percent) was considered acceptable. For those chairmen who could not be contacted personally, messages were left with secretaries to "give them a push." A total of 28 schools were called.

some of the the techniques utilized in the administration procedures of this study were supported by research as contributing significantly to a higher response rate. For example, some of the key techniques included personalization (Carpenter, 1974; Cox, 1974; Dillman \& Frey, 1974; Matteson, 1974), printed letter head and instruments (Ford, 1968; Moss, 1981), the inclusion of a replacement questionnaire (Dillman, 1972; Futrell, 1981; orr, 1965), follow-up phone calls (Leslie, 1970: Longworth, 1953), the promise of feedback (Powers, 1982), postcard and letter follow-ups (Blumberg, 1974; Moss, 1981; Pride, 1979), the title of the signatory (Rocher, 1963), and the inclusion of a postage-paid reply envelope (Blumberg, 1974).

Data Processing and Analysis

The raw data contained in the survey responses were coded for analysis. Two questions on the principals' 
77

survey form (12 and 16) and three questions on the chairmen's survey form $(12,13$, and 14) were analyzed by hand. This was considered the most efficient procedure for these questions. Because of the small number in the Union population $(N=8)$, all questions on the Union survey were analyzed by hand. The remaining data were entered into a computer, resulting in two files: one of 76 variables by 68 cases, and the other of 69 variables by 78 cases. These represented chairmen and principals, respectively.

\section{Missing data}

An analysis of the Union surveys revealed that there were no missing data for any of the cases. In the chairmen's data there were 33 complete cases of 82 total cases, and in the principals' 43 out of 86 cases. It was subjectively decided that three was the maximum number of missing variables permissible per case. This resulted in the deletion of one case. Missing variables were estimated for the other cases. The magnitude of the correlations and the pattern and total number of missing values (Dixon \& Brown, 1979) were analyzed. As a result of this analysis, the missing values were estimated and replaced using means or medians, depending on the normality of the variable distribution. Means and medians were computed on each variable for all complete cases, and then used to replace the missing values. 
Data analysis

The BMDP2D (Dixon \& Brown, 1979) computer program was used to describe the distribution of the data and to compute means, medians, and absolute and relative frequencies for each variable. The other statistics required were completed on the computer where programs were readily available, or by hand in the absence of programs.

Statistical significance and effect size

For all signiflcance testing, alpha was set at the .05 level of confidence, unless otherwise noted. This means that the probability has been accepted that the differences between groups are due to chance 5 percent of the time.

The accepted significance level indicates only the probability that the results are really significant; it is the effect size that relates to the worth or value of those results by postulating the minimum detectable difference that needs to be found in order for the results to be meaningful. The effect size was calculated using the following generic formula:

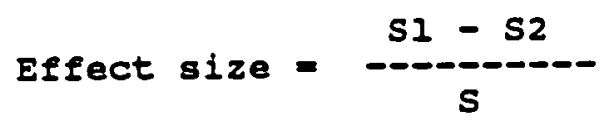

where $S 1=$ the statistic for the first population
$S 2=$ the statistic for the second population
$S=$ a standard error measurement. 
If the difference is found to be significant, and the effect size is computed to be greater than that calculated, then power is computed utilizing alpha and $N$ (sample size) in the formula where delta is equal to the effect size times the square root of $N$. Power indicates the probability of getting a significant result or of actually rejecting a false null hypothesis.

\section{Section 2--The standards}

Two relevant research questions to be considered under this section are:

1. What areas of industrial arts should a set of standards cover? Relative frequencies are computed from the responses to item 4 on the chairmen's survey, item 20 on the principals' survey and item 8 on the Union survey in answering this question.

2. What are the standards whereby industrial arts programs can be evaluated and guided? This question is answered through the research and validation procedure described below.

The initial search for standards began with computer searches of a number of data bases and manual searches of books and documents related to both general education standards and industrial arts standards in public and private Christian schools. A comprehensive set of standards for industrial arts had recently been developed by Dr. W. Dugger (1981), and these were used as the initial base for the standards document. Some 
80

standards were deleted from this base while others were added according to their applicability to the seventh-day Adventist educational system.

Pilot study
The standards were pilot-tested on a group of 13 individuals who were familiar with the nature of industrial arts from the aspects of administration and teaching. As a result of the pilot-test, a number of changes that were suggested as contributing to the appeal and adequacy of the standards as a document were made in content and format. The pilot-test participants also suggested that each individual standard be validated by rating on a scale rather than binomially, and that the validation panel be chosen from industrial art teachers, teacher educators, and administrators.

\section{Field Validation Procedures}

A 13-member validation panel was selected according to the criteria outlined by the pilot-test group and according to the degree of willingness to participate. The criteria determined, and suggested by the pilot-test group included a balance in the areas of expertise from which the panel be chosen (teachers, teacher educators, and administrators), the geographic variablilty necessary, interest and willingness, and personal or departmental characteristics such as progress and dynamism.

Computer Iine coples of the standards (see 
81

appendix H) were sent to each individual selected to serve on the validation panel. Included with the standards document was a general cover letter (see appendix I) which was the same for all individuals, and an individualized cover letter designed to suit each person and making mention of any previous contacts with the researcher or the standards project.

Recipients of the standards document were requested to rate each of the 222 standards for industrial arts programs on a scale of one to five, where one Indicated a high degree of unimportance and five a high degree of importance. If a statement was rated unimportant as a standard, the respondent was requested to suggest changes in the statement that would render it more important as a standard.

Nonrespondents received a follow-up phone call and one follow-up letter to remind them of the importance of the evaluation from each expert on the panel. Of the 13 originally chosen, 11 responded, a response rate of 85 percent. The two nonrespondents had expertise in areas which were represented by other panel members, so it was assumed their nonresponse would not have significantly biased the evaluations.

\section{Statistical Validation Procedures}

upon receipt of the evaluations, the ratings for each standard from each respondent were entered into the 
computer. The ratings were utilized to compute a weight for each standard with the following formula:

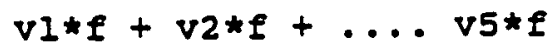

Research indicated that the degree of acceptance by panel members for the purposes of validation varied from 65 to 75 percent (Dugger, 1981; Rozak, 1982; Lucas \& Miles, 1978; stitt, 1978). Utilizing the above formula, a computed rating of 3.75 would approximate the 75 percent acceptance level. It was determined that only those standards which received a rating of 3.75 or above from the validation panel would be acceptable.

\section{Research Questions and Methods}

The methodology outlined above was designed to provide data to answer 31 research questions. These questions are restated below, together with the statistics associated with each question. The questions are organized under the headings of industrial arts students, industrial arts teachers, instructional programs, purposes of industrial arts, resources, facilities, future planning, and standards.

\section{Industrial Arts students}

1. What are some characteristics of industrial 
arts students in the SDA high-school system?

The characteristics described to answer this question are related to the programs of study of industrial arts students, opinions as to whether collegebound students should take industrial arts, the number of students taking industrial arts, and the perceived comparative academic abilities of industrial arts students and other students. These data are presented by calculating relative and absolute frequencies from responses to questions $7,8,9$ and 10 on the principals' survey .

2. Is there a significant difference between the rating of SDA and public-school industrial arts chairmen concerning the academic ability of the SDA and publicschool industrial arts students, respectively?

Null Hypothesis: There is no significant difference between the rating of SDA and public-school industrial arts chairmen concerning the academic ability of the SDA and public-school industrial arts students, respectively.

This question is answered from the responses to item 11 from the chairmen's survey and the hypothesis is tested by carrying out a Mann-Whitney U test to compare these data.

3. Is there a significant difference in the proportion of SDA and public-school students taking industrial arts? 
Null Hypothesis: There is no significant difference in the proportion of SDA and public-school students taking industrial arts.

To answer this question and test the hypothesis, a test of the proportion for two independent samples is carried out on proportions calculated from the response to item 7 on the principals' survey, and comparable data from the public-school system.

Industrial Arts Teachers

4. What are some characteristics of industrial arts teachers in the SDA school system?

The characteristics chosen to answer this question include the number of industrial arts teachers, teaching contracts, supplemental pay, student-teacher ratios, teacher certification, professional involvement, educational levels and experience, and the number of vacant teaching positions. These data are analyzed with relative and absolute erequencies from responses to items 13, 16, 17, and 18 on the principals' survey, $16,17,18$, $19,20,21$, and 22 on the chalrmen's survey, and 1tem 3 on the Union survey.

5. Is a greater or lesser percentage of SDA industrial arts teachers involved in professional educational organizations than public-school industrial arts teachers?

This question is answered by calculating percentages from the responses to Item 22 on the 
85

chairmen's survey and tabulating this information with comparative information from the public-school system.

6. Is there a significant difference between the educational levels of SDA and public-school industrial arts teachers?

Null Hypothesis: There is no significant difference between the educational levels of SDA and public-school industrial arts teachers.

A Mann-Whitney $U$ test carried out on medians from the two groups answers this question and tests the hypothesis. Data for the SDA teachers are derived from item 19 of the chairmen's survey.

7. Is there a significant difference in the proportion of total faculty involved in industrial arts between SDA and public schools?

Null Hypothesis: There is no significant difference in the proportion of total faculty involved in industrial arts between SDA and public schools.

The data from items 17 and 18 of the principals' survey and comparative public-school data are analyzed utilizing the test of proportion for two independent samples to answer this question and test the hypothesis.

\section{Instructional Programs}

8. What are some characteristics of industrial arts instructional programs in SDA secondary schools?

The characteristics that are described relate to 
86

industrial arts facilities, courses, classes, and requirements. The information is derived from items 12 and 13 on the chairmen's survey, and items $1,2,6,14$, and 15 on the principals' survey, and are presented utilizing means, standard deviations, and absolute and relative frequencies.

9. What are the perceived strengths and weaknesses of current industrial arts programs in SDA secondary schools?

This question is answered by computing frequencies from data collected from item 10 on the chairmen's survey. 10. Are the perceived strengths and weaknesses of industrial arts programs in SDA secondary schools significantly different from the perceived strengths and weaknesses of incustrial arts programs in public schools? Null Hypothesis: The perceived strengths and weaknesses of industrial arts programs in SDA secondary schools are not significantly different from the perceived strengths and weaknesses of industrial arts programs in public schools.

The test of chl-square is carried out to answer this question and to test the hypothesis, utilizing the data from item 10 of the chairmen's survey and comparative data from the public-education sector.

11. Is there a difference in the variety of course offerings between SDA and public-school industrial arts programs? 
The difference, if any, is illustrated from responses to item 12 on the chairmen's survey and comparative data for public industrial arts programs.

12. What are considered the characteristics of an exemplary industrial arts program?

13. Are there significant differences among the characteristics of an exemplary industrial arts program as selected by SDA chairmen, principals, and Union education directors?

Null Hypothesis: There are no slgniflcant differences between the characteristics of an exemplary industrial arts program as selected by SDA chairmen, principals, and union education directors.

To answer question 12 , frequencies are computed on the responses to item 3 on the chairmen's survey, item 11 on the principals' survey, and item 9 on the Union survey. The hypothesis (question 13) is tested by computing chisquare values for each of the characteristics in the item.

14. What are considered the major barriers to to having an outstanding industrial arts program?

Frequencies are computed on the responses to item 2 of the chairmen's survey in answering this question.

15. Is there a significant difference between SDA industrial arts chairmen and principals in their perceptions of the programs with which industrial arts is most closely allied?

Null Hypothesis: There is no significant 
difference between SDA industrial arts chairmen and principals in their perceptions of the programs with which industrial arts is most closely allied.

16. Is there a significant difference between SDA and public-school industrial arts chairmen in their perceptions of the programs with which industrial arts is most closely allied?

Null Hypothesis: There is no significant difference between SDA and public-school industrial arts chairmen in their perceptions of the programs with which industrial arts is most closely allied.

17. Is there a significant difference between SDA and public-school principals in their perceptions of the programs with which industrial arts is most elosely allied?

Null Hypothesis: There is no significant difference between SDA and public-school principals in their perceptions of the programs with which industrial arts is most closely allied.

Differences as specified in the above three questions and hypothesis are determined by computing chisquare statistics utilizing the responses to item 1 on the chairmen's survey, item 5 on the principals' survey, and comparative data on the public industrial arts educators perceptions.

Industrial Arts Programs

18. How many SDA schools have advisory committees 
associated with their industrial arts departments?

Absolute and relative frequencies are computed

from the responses to item 8 on the chairmen's survey.

19. What proportion of SDA schools have industrial arts programs?

This proportion is determined from the responses to items 1 and 2 on the Union survey.

20. Is there a significant difference between the proportion of SDA and public secondary schools with industrial arts programs?

Null Hypothesis: There is no significant difference between the proportion of SDA and public secondary schools with industrial arts programs.

To answer this question and test the hypothesis, data from items 1 and 2 of the union survey and comparative data from the public-school sector are analyzed using the test of proportion for two independent samples.

Purposes of Industrial Arts

21. Is there a significant difference between the current and ideal emphasis on the purposes of industrial arts as perceived by SDA industrial arts department chairmen?

Null Hypothesis: There is no significant difference between the current and ideal emphasis on the purposes of industrial arts as perceived by SDA industrial arts department chairmen. 
22. Is there a significant difference between the current and ideal emphasis on the purposes of industrial arts as perceived by SDA principals?

Null Hypothesis: There is no significant difference between the current and ideal emphasis on the purposes of industrial arts as perceived by SDA principals.

To answer the above two questions and test the hypotheses, medians, computed on the responses to item 9 of the chairmen's survey and item 19 of the principals' survey, are compared, utilizing the sign test for dependent samples.

23. Is there a significant difference between the perceptions of SDA chairmen and principals of the ideal emphasis on the purposes of industrial arts?

Null Hypothesis: There is no significant difference between the perceptions of SDA chairmen and principals of the ideal emphasis on the purposes of industrial arts.

To answer the above question and test the hypothesis, medians, computed on the responses to item 9 of the chairmen's survey and item 19 of the principals' survey, are compared utilizing the median test for independent samples.

24. Is there a significant difference between the perceptions of SDA and public-school industrial arts 
91

chairmen on the ideal emphasis on the purposes of industrial arts?

Null Hypothesis: There is no significant difference between the perceptions of SDA and publicschool industrial arts chairmen of the ideal emphasis on the purposes of industrial arts.

The answer to this question would most accurately be determined by utilizing medians because the assumptions of normality when using means may not be met. However, as far as the public-school data are concerned, only means are available, therefore means are compared, utilizing the t-test for independent means.

\section{Resources}

25. What are the general characteristics related to resources in SDA industi ial arts?

26. Do SDA industrial arts departments spend more or less per student on equipment and supplies than publicschool industrial arts departments?

The financial characteristics described relate to equipment and supplies, methods of charging students, and sources of funding. The survey items to be analyzed are items 5,6 and 7 on the chairmen's survey and item 12 on the principals' survey. Means and erequencies, respectively, are utilized.

Facilities

27. Is there a difference between the relative 
92

number and variety of industrial arts general laboratory facilities available in SDA and public schools?

Frequencies are tabulated from the responses to

item 13 on the chairmen's survey and comparative publicschool data.

\section{Future Planning}

28. What are the projections for enrollment and course offerings in industrial arts in SDA schools?

In answering this question, the data from item 14 of the chaimen's survey and from items 3 and 4 of the principals' survey are presented utilizing frequencies and medians respectively.

29. What guidance is given to SDA industrial arts programs by the Union education offices?

The responses to items $4,5,6$ and 7 from the union survey are presented in answer to this question.

\section{standards}

30. What areas of industrial arts should a set of standards cover?

Relative frequencies are computed from the responses to item 4 on the chairmen's survey, item 20 on the principals' survey and item 8 on the Union survey in answering this question.

31. What are the standards whereby SDA industrial arts programs can be evaluated and guided in their development? 
93

This question is answered through a validation procedure separate from the survey instruments referred to above and is discussed in other sections of this dissertation.

\section{Summary}

This chapter began by reviewing applicable research methodology; and by outlining the selection of the sample, the development and administration of the instrumentation, and the general methods of analysis as they relate to the data base. This comprised section one. section two dealt with the standards and the methodology involved in their selection and validation. The chapter concluded by listing the research questions to be answered and the hypotheses to be tested, together with the specific methodologies to be followed. 
CHAPTER IV

PRESENTATION AND ANALYSIS OF DATA

\section{Introduction}

The first three chapters have described the problem, rationale, context, and methodology for this study. This chapter analyzes the methodology in terms of the response rates, outline the analysis of data, and presents the findings of the research.

In the analysis of the data, the statistical methodologies utilized include chi-square goodness of fit, chi-square independent, sign test, median test, test of proportion, Mann-Whitney $U$ test, t-test, and descriptive statistics such as means, medians, and frequencies. In this chapter the data are presented and analyzed in the order of the 31 research questions posited in chapter 3 . Not all of the research questions involved hypotheses; but where applicable, the hypothesis is stated in null form for testing with the appropriate analysis.

This chapter is presented in three sections; the first deals with the response to the survey methodology; section two deals with research questions 1 to 29 using the data gathered from the survey instruments; and section 
95

three covers research questions 30 and 31 proposing standards for industrial arts programs.

\section{Section 1--Analysis of Methodology}

\section{Response Rates}

The response rate of all three populations was 88 percent, computed on a combined population size of 176 . The original population size was assumed to be 180 , but four schools included did not conduct industrial arts programs, thus responses from industrial arts chairmen in these schools could not be expected. This effectively decreased the combined population size to 176.

The response rates, for each population at each stage of the follow-up procedure, are detailed in table 2 . The total population of Union directors returned completed survey forms, a response rate of 100 percent.

TABLE 2

RESPONSE RATES BY PROCEDURE AND POPULATION IN ABSOLUTE AND RELATIVE FREQUENCIES

\begin{tabular}{|c|c|c|c|c|c|}
\hline Procedure & $\begin{array}{c}\text { Unton } \\
N=8 \quad \&\end{array}$ & $\begin{array}{l}\text { Prin } \\
N=86\end{array}$ & $\operatorname{lpals}_{q}$ & $\begin{array}{r}\text { Cha } \\
N=82\end{array}$ & $\underset{q}{\operatorname{rmen}}$ \\
\hline $\begin{array}{l}\text { Postcard reminder } \\
\text { Second reminder } \\
\text { Third reminder } \\
\text { Fourth reminder } \\
\text { Telephone reminder } \\
\text { closure }\end{array}$ & $\begin{array}{rr}1 & 12 \\
1 & 12 \\
7 & 87 \\
8 & 100\end{array}$ & $\begin{array}{l}0 \\
27 \\
66 \\
69 \\
73 \\
78\end{array}$ & $\begin{array}{l}0 \\
31 \\
77 \\
80 \\
85 \\
91\end{array}$ & $\begin{array}{l}0 \\
21 \\
52 \\
54 \\
61 \\
68\end{array}$ & $\begin{array}{l}0 \\
26 \\
63 \\
66 \\
74 \\
83\end{array}$ \\
\hline
\end{tabular}

This response rate was achieved by a fourth reminder, 49 days after the initial mail-out. The 
population of principals achieved the next highest response rate of 91 percent. Chairmen were the most difficult population from which to elicit responses, the response rate at closure being 83 percent.

Cumulative percentage responses are graphically depicted in figure 1. Responses from principals were consistently higher than those from chairmen at each stage of the follow-up schedule, and each reminder produced a larger percentage point increase in returns for principals than for chairmen, with the exception of the fourth reminder.

Figure 1 does not show a typical graph of response rates to general mail surveys because of the slow initial increase in responses. The reason for this lies in the methodology that was used. The initial mail-out was sent at the bulk rate, as previously noted, thereby realizing a significant financial saving of $\$ .30$ on each package. It was not realized at the time that the bulk rate implies delivery delays of over 2 weeks for some areas.

some literature presented a misleading impression on this point. Babbie (1973), for example, stated that "both first class and bulk rate mail seem to move at the same speed through the mails, so this presents no disadvantage for bulk rate mailing" (p. 161). As far as this research was concerned, this delay meant that some potential respondents received the post-card reminder before receiving the initial package. Twelve people 
97

called to request a survey form in response to receiving the post card reminder and it is possible that there were more who did not call. This delay may have adversely affected the response rate.

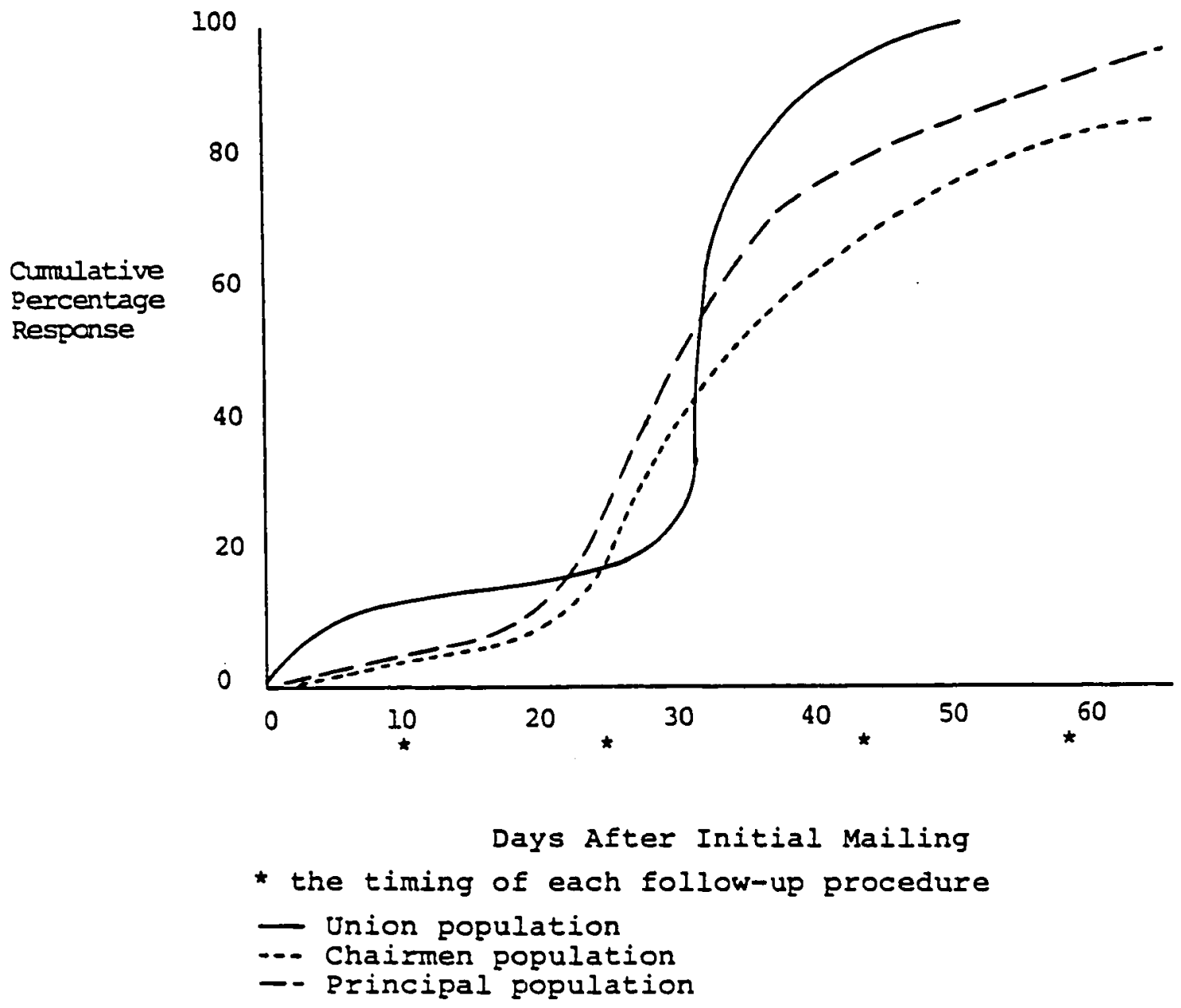

Fig. 1. Cumulative percentage response by population.

An increase in the cumulative response rate shortly after each reminder is not evident in figure 1 graph. One possible exception may be the Union returns 
after the second reminder, but this could be attributed to the initial delay caused by the choice of bulk-rate mailing.

A quick review of the survey literature uncovers a wide range of response rates which would indicate that the response rates achieved by closure in this study were adequate in light of current standards for mall-survey methodology (Babbie, 1973; Erdos, 1957a; Jaeger \& Wolf, 1980; Robinson, 1952).

\section{Nonresponse Bias}

Nonresponse in survey research represents a failure to obtain measurements from some of the units being sampled (Kish,1965, p. 532). Nonresponse results in biased conclusions when persons from whom measurements have been obtained differ substantially from those who have not responded, thereby upsetting the generalizability process from sample to population.

The most common approach to the problem of nonresponse has been to concentrate methodological effort so that as many of the sample are contacted as possible, thereby increasing the response rate. Another approach has been to extrapolate variable values of nonrespondents on the basis of the late respondents. This is based on the assumption that subjects who respond less readily are more like nonrespondents (Armstrong \& Overton, 1977; Daniel, 1975; Filion, 1975; Robinson, 1952; Zimmer, 1956). other research disputes this assumption (Bauer, 1947; 
Frary, Elson, \& Gerken, 1981; Mayer \& Pratt, 1966) and utilizes different methods for estimating the amount of bias in the conclusions due to nonresponse, such as randomly sampling the nonrespondents or weighting the sample results.

A number of mall-survey researchers maintain the opinion, supported by research, that bias due to nonresponse is not signiflcantly present when the response rate is above a certain level. Kerlinger (1973, p. 414) stresses that 80 to 90 percent is desirable. Erdos states:

In an exceptionally favorable instance, when we get a 90 percent response we need not worry about the 10 percent nonrespondents because even if they differ from those who answered, the inclusion of their responses would not overbalance the great preponderance of those who answered. (1957a, p. 30)

Robinson confirms, more liberally, that

In general, it seems safe to conclude that when returns reach the neighborhood of 80 percent, reliability can be given to the findings because nonrespondents would have little effect on the total. (1952, p. 37)

Because of the high response rates in this research, it is concluded that nonresponse bias is minimal, if present.

\section{Section 2--The survey}

This section deals with research questions 1 to 29, and related hypotheses. The data are presented and analyzed, each research question is answered, and conclusions are made regarding the hypotheses. Data relating to the SDA school system has been collected by the procedure outlined in chapter 3 . Data relating to the 
public-school industrial arts programs is from the "Report of Survey Data" (Dugger, 1980C).

\section{Industrial Arts students}

Selected characteristics of industrial arts students, perceptions of the academic abilities of industrial arts students, and the proportion of students taking industrial arts are considered here.

Research Question 1. What are some characteristics of industrial arts students in the SDA high-school system?

The characteristics selected for examination include enrollments, programs of study, and views of the importance of industrial arts for college-bound students.

\section{Student enrollment}

Table 3 contains means of total student enrollment and industrial arts enrollment by grade level. The mean total enrollment for all grades is just less than 40. The mean enrollment in industrial arts courses is highest at the grade 9 level with 15 students (40 percent of the total students in that grade); the number decreases by half at the grade 10 level, and continues to decrease to an average of about six students (15 percent of the total students in that grade) in grade 12 , even though mean total enrollment remains almost constant throughout the four grades. Being a general education course, industrial arts would most likely be taken early in the 
101

student's program, before the student begins to specialize in a particular area.

TABLE 3

TOTAL AND INDUSTRIAL ARTS ENROIIMENTS BY GRADE FOR SDA SCHOOLS

\begin{tabular}{|c|c|c|c|}
\hline Grade & $\begin{array}{c}\text { Mean } \\
\text { Enroliment }\end{array}$ & $\begin{array}{l}\text { Mean } \\
\text { Arts }\end{array}$ & $\begin{array}{l}\text { Industrial } \\
\text { Enrollment }\end{array}$ \\
\hline $\begin{array}{r}9 \\
10 \\
11 \\
12\end{array}$ & $\begin{array}{l}39.16 \\
39.74 \\
39.67 \\
39.67\end{array}$ & & $\begin{array}{r}15.7 \\
7.75 \\
6.92 \\
5.96\end{array}$ \\
\hline
\end{tabular}

\section{Programs of study}

The principals were requested to identify the programs in which the majority of industrial arts students in their schools were enrolled. Table 4 indicates that the majority of industrial arts students are enrolled in general education in the largest number of schools.

TABLE 4

PROGRAMS OF STUDY REPRESENTATIVE OF INDUSTRIAL ARTS STUDENTS

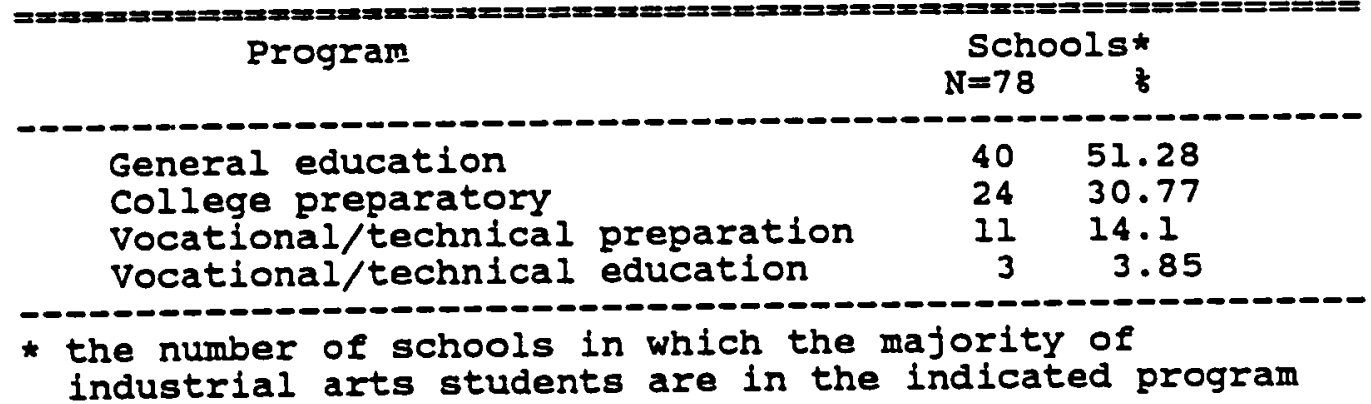


102

This tends to support the popular notion that industrial arts is a general education subject, although it also indicates that industrial arts plays some role for all students no matter what program they are studying.

Industrial arts for students bound for college

Table 5 indicates most high school principals agree that college-bound students should take industrial arts courses. This indication, together with that in Table 4, places the role of industrial arts in the area of general education, applicable for college-bound students.

TABIE 5

SDA PRINCIPAIS' VIEWS REGARDING STUDENTS BOUND FOR COLLEGE TAKING INDUSTRIAL ARTS

\begin{tabular}{|c|c|c|}
\hline Belief & $N=78$ & 8 \\
\hline $\begin{array}{l}\text { YES } \\
\text { NO }\end{array}$ & $\begin{array}{r}76 \\
2\end{array}$ & $\begin{array}{r}97.44 \\
2.56\end{array}$ \\
\hline
\end{tabular}

\section{Academic ability}

Research Question 2. Is there a significant difference between the ratings of SDA and the public-school industrial arts chairmen concerning the academic ability of SDA and public-school industrial arts students, respectively?

Null hypothesis: There is no significant difference between the rating of SDA and public-school industrial arts chairmen concerning the academic ability 
103

of SDA and public-school industrial arts students, respectively.

Table 6 summarizes the perceptions of SDA and public-school chairmen on the academic abilities of industrial arts students. on a scale of one to five, where one represents well below average and five represents well above average, SDA chairmen gave a mean rating of 2.89 , and public-school chairmen 2.59 ; where a mean of three would indicate a perception that industrial arts students have the same ability as the general school population. It seems that both groups rate the academic ability of industrial arts students below that of nonindustrial arts students.

TABIE 6

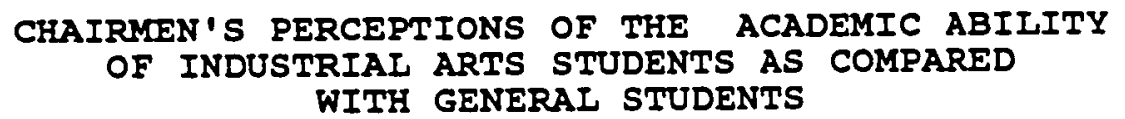

\begin{tabular}{|c|c|c|c|c|}
\hline \multirow[b]{2}{*}{ Ability Category } & \multicolumn{4}{|c|}{ Respondents } \\
\hline & $\begin{array}{r}S \\
\text { Cha } \\
N=68\end{array}$ & $\begin{array}{l}\text { DA } \\
\text { irmen } \\
\frac{7}{8}\end{array}$ & $\begin{array}{r}\text { Public } \\
\text { Chai } \\
N=641\end{array}$ & $\begin{array}{c}\text { Schoo } \\
\text { rmen } \\
\frac{8}{8}\end{array}$ \\
\hline $\begin{array}{l}\text { Well below } \\
\text { Tends to below } \\
\text { Same } \\
\text { Tends to above } \\
\text { Well above }\end{array}$ & $\begin{array}{r}1 \\
14 \\
45 \\
7 \\
1\end{array}$ & $\begin{array}{r}1.47 \\
20.59 \\
66.18 \\
10.29 \\
1.47\end{array}$ & $\begin{array}{r}17 \\
252 \\
346 \\
26 \\
0\end{array}$ & $\begin{array}{l}2.7 \\
39.3 \\
54 \\
4.1 \\
0\end{array}$ \\
\hline Mean rating & & 2.89 & & .59 \\
\hline
\end{tabular}

The null hypothesis stated that there is no significant difference between the rating of the 
respective chairmen concerning the academic ability of SDA and public industrial arts students. A Mann-Whitney $U$ test was carried out, obtaining a 2 -score value of 14.9 (critical $z$ at alpha level $.01=2.58$ ). The null hypothesis, therefore, was rejected, and the conclusion supported that SDA and public-school industrial arts chairmen do differ significantly in their ratings of the academic abilities of industrial arts students, with SDA chairmen rating their students higher.

A plausible explanation of these results could relate to the range of demographic variables such as ability and IQ that are represented in each school system. It is felt that public schools enroll students with a broader range of such variables, whereas SDA schools tend to enroll a narrower range of students, reflective of the largely middle-class church membership; this narrower range could be reflected in the chairmen's perceptions.

The effect size for this hypothesis was postulated to be 0.3 in raw-score terms. The difference between the means exceeded this level, and effect size was computed to be .447 (standardized). Power was computed to be .83 (alpha $=.01)$. This means that the probability of correctly rejecting the null hypothesis when it is actually false is 83 percent.

This researcher has sensed a generally held feeling that industrial arts students possess less academic ability than students who do not take industrial 
arts classes. As a result, industrial arts students, teachers, and programs have been stereotyped accordingly. However, an analysis of the data supplied by the SDA chairmen does not confirm this notion. A t-test obtained a score of -1.4 (critical $t$ at alpha level .05 $=2.0$ ) in comparing the mean rating of the academic ability of industrial arts students with general students as perceived by industrial arts chairmen.

\section{proportion taking industrial arts}

Research Question 3. Is there a significant difference in the proportion of SDA and public-school students taking industrial arts?

Null hypothesis: There is no significant difference in the proportion of SDA and public-school students taking industrial arts.

The proportion of SDA students taking industrial arts was .229 , the proportion of public-school students taking industrial arts was .285 . A test of proportion for two independent samples was carried out, and a z-score of .77 (critical $z$ at alpha level .05 = 1.96) was calculated. As a result, the null hypothesis that there is no significant difference between the proportion of SDA students and the proportion of public-school students who take industrial arts was retained.

Industrial Arts Teachers

This group of questions examines selected 
demographic characteristics of industrial arts teachers relating to the professional involvement of teachers, their educational levels, and the proportion of total teachers involved in industrial arts.

Research Question 4. What are some characteristics of industrial arts teachers in the SDA school system?

The demographic characteristics to be described are teacher contracts, supplemental pay, student-teacher ratios, teacher certification, years of experience, and positions vacant.

\section{Teacher contracts}

Table 7 illustrates the absolute and relative frequencies for SDA industrial arts teachers employed on 10-month and 12-month contracts. This reflects what is felt to be the common situation in SDA schools, namely that most teachers are employed only while school is in session.

\section{TABLE 7}

LENGTH OF SDA INDUSTRIAL ARTS TEACHERS' CONTRACTS

\begin{tabular}{|c|c|c|c|}
\hline Length & of Contract & $N *$ & 8 \\
\hline $\begin{array}{l}10 \\
12\end{array}$ & $\begin{array}{l}\text { Months } \\
\text { Months }\end{array}$ & $\begin{array}{l}65 \\
16\end{array}$ & $\begin{array}{l}80.25 \\
19.75\end{array}$ \\
\hline
\end{tabular}




\section{Supplemental pay}

of the 12 sources of supplemental pay listed in table 8 , the data revealed that few teachers received any form of supplemental pay. Those who did were in the areas of school assembly, school maintenance, and bus duty. It should be noted that the percentage frequencies in table 8 total more than 100 percent. This indicates an intersection of sets, where some teachers receive supplemental pay from more than one source.

It is this researcher's experience that industrial arts teachers in SDA schools, particularly boarding schools, are involved in many activities other than teaching. Table 8 probably does not reflect a lack of involvement in these other activities; it simply reveals that supplemental pay is not received for such activity.

TABIE 8

ACTIVITIES FOR WHICH SDA INDUSTRIAL ARTS TEACHERS RECEIVE SUPPLEMENTAL PAY

\begin{tabular}{lcc} 
Activity & N=70 & (3) \\
\hline Athletic contests & 0 & 0 \\
Industrial arts club & 0 & 0 \\
School club advisor & 0 & 0 \\
School grounds supervisor & 0 & 0 \\
Field trips & 0 & 0 \\
Student council advisor & 0 & 0 \\
Year book advisor & 0 & 0 \\
Study supervision & 0 & 0 \\
Class advisor & 0 & 0 \\
School assemblies & 1 & 1 \\
Maintenance & 9 & 13 \\
Bus duty & 4 & 6 \\
None & 59 & 84 \\
\hline
\end{tabular}


student-teacher ratio

Seventh-day Adventist industrial arts chairmen were asked their opinion related to the maximum studentteacher ratio and the actual average student-teacher ratio in industrial arts classes. The mean maximum ratio was determined to be 12.72 students per teacher, and the mean actual ratio was 10.92 students per teacher. This means that there are fewer students in industrial arts classes than chairmen consider the maximum.

\section{Teacher certification}

Table 9 presents a summary of the types of teaching certification held by SDA industrial arts teachers as reported by industrial arts chatrmen.

TABLE 9

TYPE OF CERTIFICATION HELD BY SDA INDUSTRIAL ARTS TEACHERS

\begin{tabular}{|c|c|c|}
\hline Type of certification & $\begin{array}{r}\text { Tea } \\
N=68\end{array}$ & $\begin{array}{r}\text { ers } \\
q\end{array}$ \\
\hline $\begin{array}{l}\text { Denominational } \\
\text { Basic } \\
\text { Standard } \\
\text { Professional }\end{array}$ & $\begin{array}{l}17 \\
28 \\
41\end{array}$ & $\begin{array}{l}25 \\
41.2 \\
60.29\end{array}$ \\
\hline $\begin{array}{l}\text { istate } \\
\text { Industrial Arts }\end{array}$ & 37 & 54.42 \\
\hline
\end{tabular}

The chairmen were asked to consider the three levels of denominational certification as well as state certification for industrial arts. of all the industrial arts teachers, 60 percent were certificated by the 
denomination at the professional level, and 54 percent held state certification in the area of industrial arts. The frequencies in table 9 indicate that some teachers possess more than one type of certification.

Teacher experience

The years of experience for industrial arts teachers in SDA schools in the United states varied from 1 to 33 years. The median length of experience was 8 years and the semi-interquartile range was 4.75 years. This distribution of years of experience was skewed (skewness = 1.22) toward the lower/negative end, possibly indicating that most of the industrial arts teachers have not made a career of teaching industrial arts for the SDA school system.

\section{Teacher vacancies}

one of the questions directed to the Union education directors related to the number of vacant positions for industrial arts teachers. of the eight Union education directors in the United states, three responded that they had industrial arts teaching positions vacant at the beginning of the 1983-84 school year. Two unions had one vacancy each, and one Union had two vacancies, a total of four industrial arts vacancies for the SDA high-school system in the United states. This compares favorably with the shortages of industrial arts 
110

teachers in the public schools, in that there were relatively fewer vacancies in the SDA system.

Professional organization involvement

Research Question 5. Is a greater or lesser percentage of SDA industrial arts teachers involved in professional educational organizations than public-school industrial arts teachers?

Table 10 presents an answer to this question by showing the percentages of SDA and public-school teachers belonging to professional industrial arts organizations. An examination of the percentages indicates that more public-school industrial arts teachers belong to a greater variety of professional organizations than do SDA industrial arts teachers. A number of reasons such as lack of time, lack of initiative, or lack of provided opportunity may explain these data.

The two most popular professional organizations for SDA industrial arts teachers were local educational associations and state industrial arts associations. The figures indicate that the only organization to which a higher percentage of SDA teachers belong than state teachers are local teachers unions. This seems unusual in the light of the tendency for SDAs not to join trade unions. A more plausible explanation of these figures would be that respondents understood the term 'Union' to relate to that element of the SDA church structure known as the Union. 
TABLE 10

\section{RELATIVE FREQUENCIES OF INDUSTRIAL ARTS TEACHERS' MEMBERSHIP IN PROFESSIONAL ORGANIZATIONS}

\begin{tabular}{lcc} 
Organization & $\begin{array}{c}\text { SDA } \\
\text { Teachers }\end{array}$ & $\begin{array}{c}\text { Public } \\
\text { Teachers }\end{array}$ \\
\hline Local education association & 19.32 & 70 \\
State industrial arts association & 22.73 & 54.3 \\
National Education Association & 6.82 & 62.2 \\
American Federation of Teachers & 0 & 9.8 \\
Local teachers union & 3.41 & 0 \\
Local industrial arts association & 5.68 & 31.7 \\
State education association & 2.27 & 54.3 \\
American Industrial Arts Association & 13.64 & 21.9 \\
American Vocational Association & 3.41 & 8.7 \\
Epsilon Pi Tau & 0 & 14.9 \\
Iota Lambda Sigma & 0 & 2.2 \\
None & 60.23 & 5.6 \\
- & &
\end{tabular}

\section{Educational levels}

Research Question 6. Is there a significant difference between the educational levels of SDA and publicschool industrial arts teachers?

Null hypothesis: There is no significant difference between the educational levels of SDA and public-school industrial arts teachers.

The percentages of teachers possessing various educational degrees are shown in table 11. In relative terms, there are more SDA industrial arts teachers with no degree than public-school teachers, while at the bachelors degree level, the situation is reversed. To test the hypothesis regarding a significant difference between the educational levels of the two groups, a Mann-Whitney U test was carried out. A $z$-score value of 0.65 was 
computed (critical 2 at alpha level .05 $=1.96$ ), resulting in the retention of the null hypothesis that there is no significant difference between the two groups on educational levels.

TABLE 11

EDUCATIONAL DEGREES HELD BY INDUSTRIAL ARTS TEACHERS

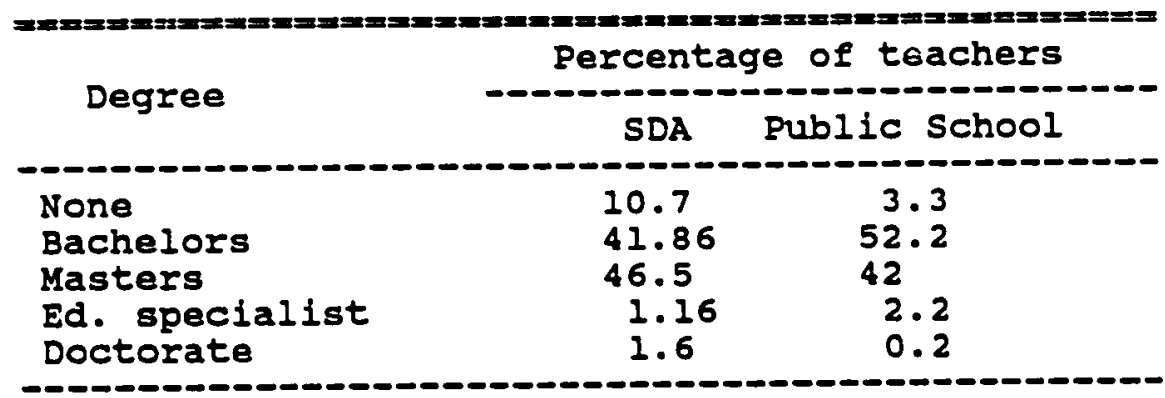

\section{Proportion of faculty}

Research Question 7. Is there a significant difference in the proportion of total faculty involved in industrial arts between SDA and public schools?

Null hypothesis: There is no significant difference in the proportion of total faculty involved in industrial arts between SDA and public schools.

While the number of faculty per school is much larger for the public-school system, table 12 reveals that the proportion of industrial arts teachers to total faculty seems to be higher for SDA schools. This proportion was computed from the ratio of mean total teachers per school to mean industrial arts teachers per 
school. With the application of the test of proportion for independent samples, however, the difference was found to be not statistically significant $(z-s c o r e=1.87$, critical $z$ at alpha level $.05=1.96$ ), resulting in the retention of the null hypothesis that there is no significant difference between the two proportions.

TABLE 12

\section{PROPORTION OF INDUSTRIAL ARTS TEACHERS TO TOTAL FACULTY}

\begin{tabular}{|c|c|c|}
\hline & SDA & Public \\
\hline Number of schools & 78 & 576 \\
\hline $\begin{array}{c}\text { Industrial arts teachers } \\
\text { per school* }\end{array}$ & 1.56 & 2.77 \\
\hline Faculty per school* & 14.17 & 51.12 \\
\hline Proportion & 0.11 & 0.054 \\
\hline
\end{tabular}

Instructional Programs

The aspects of instructional programs that are examined include the perceived strengths and weaknesses of industrial arts programs, the variety of course offerings, the characteristics of exemplary industrial arts programs, the major barriers to outstanding programs, and the program with which industrial arts is most closely allied. Research Question 8 . What are some characteristics of industrial arts instructional programs in SDA secondary schools? 


\section{Courses}

The industrial arts course conducted by the largest number of schools is Auto Mechanics, followed in order by General woods, General Shop, Welding, and Photography. Table 13 ranks all courses that are offered in SDA industrial arts programs, together with mean figures for the number of sections per year for each course, the grade level in which it is offered, the amount of time allocated to lecture or laboratory work, and the mean enrollment per section. The number of sections per year ranges from one to four; courses are offered in all high school grades, although most commonly in grades 9 and 10, and the enrollment varies from two to 40, although most class sizes are approximately ten. As previously stated, the mean student-teacher ratio is 10.9 .

\section{Laboratories}

Tables 14 and 15 contain details of the types of industrial arts laboratories in SDA schools. As would be expected, the most common types of laboratories parallel the most common courses that are offered--Auto Mechanics, General Woods, and General Industrial Arts. The types of laboratories were divided into general (multiple area) and unit (single area) facilities. Because these terms were not explicitly defined in the survey instrument, it is possible that they were interpreted in slightly different ways. However, a broad plcture of the number and types of laboratories in SDA schools is presented. 
TABLE 13

DATA RELATED TO INDUSTRIAL ARTS COURSES OFFERED IN SDA SCHOOIS

\begin{tabular}{|c|c|c|c|c|c|c|}
\hline Course & $\begin{array}{c}N=68 \\
\text { chools }\end{array}$ & $\begin{array}{l}\text { Sect/ } \\
\text { Year }\end{array}$ & $\begin{array}{l}\text { Mean } \\
\text { Grade }\end{array}$ & $\stackrel{8}{\text { Lect }}$ & $\begin{array}{c}8 \\
\text { Lab }\end{array}$ & $\begin{array}{l}\text { Enroll } \\
\text { /sect }\end{array}$ \\
\hline $\begin{array}{l}\text { Auto mechanics } \\
\text { General woods } \\
\text { General shop } \\
\text { Welding } \\
\text { Photography } \\
\text { Other } \\
\text { Graphic arts } \\
\text { Arch. drafting } \\
\text { Ceramics } \\
\text { Mech. drawing } \\
\text { Drafting } \\
\text { other mechanics } \\
\text { Home mechanics } \\
\text { General metals } \\
\text { Electronics } \\
\text { Printing } \\
\text { Crafts } \\
\text { Power mechanics } \\
\text { Wood technology } \\
\text { Art metal } \\
\text { Electricity } \\
\text { other woods } \\
\text { Leather } \\
\text { Photolithography } \\
\text { other crafts } \\
\text { Plastics } \\
\text { other graphics } \\
\text { Indust. materials } \\
\text { Indust. mat. proc. } \\
\text { Manufacturing } \\
\text { Numerical cont. } \\
\text { Exploring tech. } \\
\text { Foundry } \\
\text { other metals } \\
\text { Construction } \\
\text { Comm tech. } \\
\text { Service indust. } \\
\text { Drafting tech. }\end{array}$ & $\begin{array}{r}53 \\
43 \\
28 \\
22 \\
22 \\
17 \\
15 \\
15 \\
11 \\
12 \\
12 \\
9 \\
8 \\
7 \\
6 \\
6 \\
5 \\
5 \\
5 \\
4 \\
3 \\
3 \\
3 \\
2 \\
2 \\
2 \\
2 \\
1 \\
1 \\
1 \\
1 \\
1 \\
1 \\
1 \\
1 \\
1 \\
1 \\
1\end{array}$ & 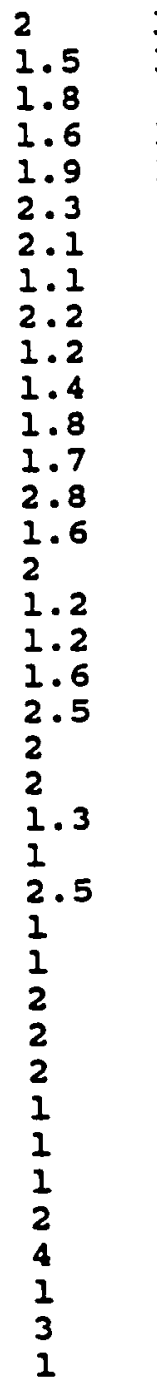 & $\begin{array}{r}10.9 \\
10.3 \\
9.3 \\
10.5 \\
10.6 \\
10.1 \\
10.6 \\
10.7 \\
10.6 \\
10.3 \\
9.8 \\
11.2 \\
10.5 \\
10.2 \\
10.9 \\
90.2 \\
10.2 \\
10.3 \\
10.2 \\
10.2 \\
10.5 \\
10.4 \\
10.3 \\
10.1 \\
10.8 \\
10.5 \\
10.1 \\
10.7 \\
10.5 \\
\quad 8\end{array}$ & $\begin{array}{l}37.3 \\
27 \\
30.7 \\
21.9 \\
30.5 \\
17.9 \\
30.5 \\
20.6 \\
13.1 \\
27 \\
31.6 \\
25 \\
43.1 \\
30.4 \\
34 \\
31.6 \\
22 \\
52 \\
27 \\
28.3 \\
30 \\
28 \\
26 \\
50 \\
7.5 \\
29 \\
27.5 \\
50 \\
5 \\
10 \\
0 \\
40 \\
40 \\
50 \\
20 \\
20 \\
50 \\
25\end{array}$ & $\begin{array}{l}62.7 \\
73 \\
69.3 \\
78.1 \\
69.5 \\
82.1 \\
69.5 \\
79.4 \\
86.9 \\
73 \\
68.4 \\
75 \\
56.9 \\
69.6 \\
66 \\
68.4 \\
78 \\
48 \\
73 \\
71.7 \\
70 \\
72 \\
74 \\
50 \\
92.5 \\
71 \\
72.5 \\
50 \\
95 \\
90 \\
900 \\
100 \\
60 \\
60 \\
50 \\
80 \\
80 \\
50 \\
75\end{array}$ & $\begin{array}{r}12 \\
11.2 \\
14.3 \\
9.5 \\
10.4 \\
8.4 \\
9.5 \\
9.8 \\
15.6 \\
11 \\
13.5 \\
13.3 \\
11.2 \\
11.1 \\
12.6 \\
10.5 \\
12.3 \\
10.2 \\
5.8 \\
13 \\
12 \\
7.6 \\
17.6 \\
14 \\
9.5 \\
20 \\
\quad 6.5 \\
5\end{array}$ \\
\hline
\end{tabular}


TABLE 14

ABSOLUTE AND REIATIVE FREQUENCIES OF INDUSTRIAL ARTS GENERAL LABORATORIES IN SDA SCHOOLS

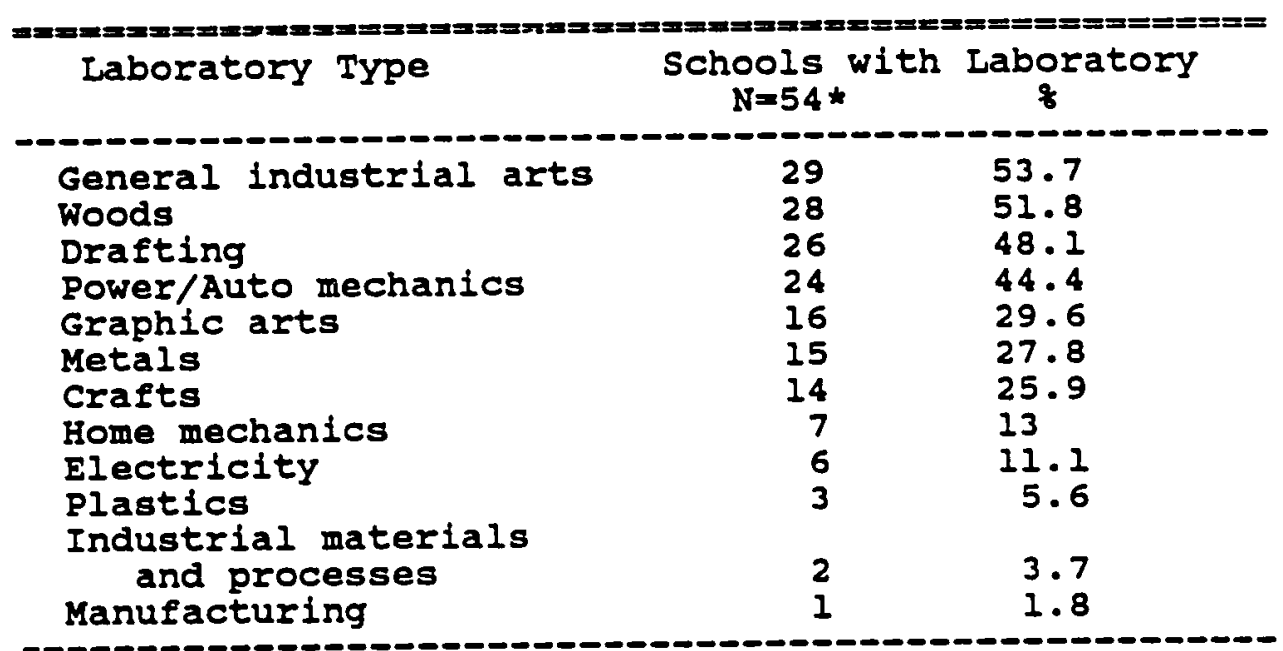

* N = 54 because not all schools have general laboratories 
TABIE 15

\section{ABSOLUTE AND REIATIVE FREQUENCIES OF INDUSTRIAI ARTS UNIT IABORATORIES IN SDA SCHOOIS}

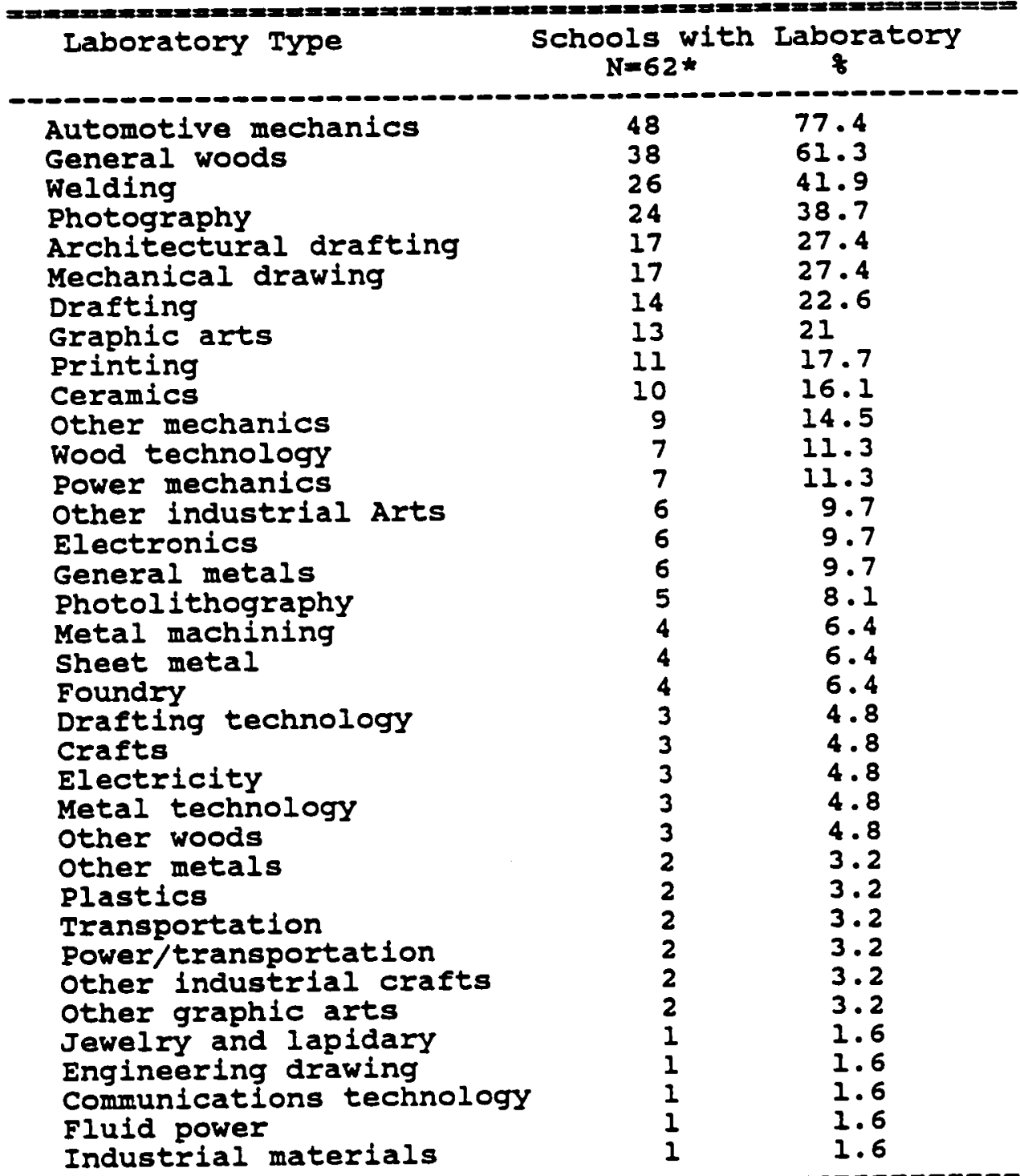

$\star N=62$ because not all schools have unit laboratories 
Table 14 ranks the 12 types of general laboratories. Table 15 ranks a list of the 38 types of unit laboratories that exist in SDA schools in the United states.

\section{Course requirements}

Table 16 contains a list of the number of schools requiring specific numbers of industrial arts courses. The majority of schools require one industrial arts course for all students. Eleven schools have no industrial arts requirement for students. The number of required courses vary from school to school, and range from zero to nine. It is possible that those respondents indicating 9 or even 6 industrial arts courses being offered in some way misinterpreted the question, either by assuming too broad a definition for "industrial arts", or referring to all the courses available from which students could choose the industrial arts requirement/s.

TABLE 16

ABSOLUTE AND RELATIVE FREQUENCIES OF SDA SCHOOIS REQUIRING INDUSTRIAL ARTS COURSES

\begin{tabular}{|c|c|c|}
\hline $\begin{array}{l}\text { Number of } \\
\text { Required Courses }\end{array}$ & $\begin{array}{c}\text { Number } \\
N=78\end{array}$ & of Schools \\
\hline $\begin{array}{l}0 \\
1 \\
2 \\
3 \\
4 \\
5 \\
6 \\
9\end{array}$ & $\begin{array}{r}11 \\
47 \\
12 \\
4 \\
1 \\
1 \\
1 \\
1\end{array}$ & $\begin{array}{l}14.1 \\
60.26 \\
15.38 \\
5.13 \\
1.28 \\
1.28 \\
1.28 \\
1.28\end{array}$ \\
\hline
\end{tabular}


Data regarding the grade levels at which required industrial arts courses are most likely to be taken are shown in table 17. Most schools schedule their required industrial arts courses in grade 9, though in some schools they can be taken in any grade. The higher the grade, the fewer the number of schools requiring industrial arts.

Most SDA principals expressed the opinion that industrial arts should be a requirement for all high school students. of the 77 princlpals responding to this question, 65 (84 percent) indicated an affirmative opinion, while 12 ( 16 percent) Indicated that they did not believe all students should have to take industrial arts. These proportions are possibly reflected in table 16, where it was noted that 14.1 percent of schools do not require any industrial arts courses.

\section{TASLE 17}

ABSOLUTE AND RELATIVE FREQUENCIES OF SDA SCHOOIS REQUIRING INDUSTRIAL ARTS COURSES IN SPECIFIC GRADES

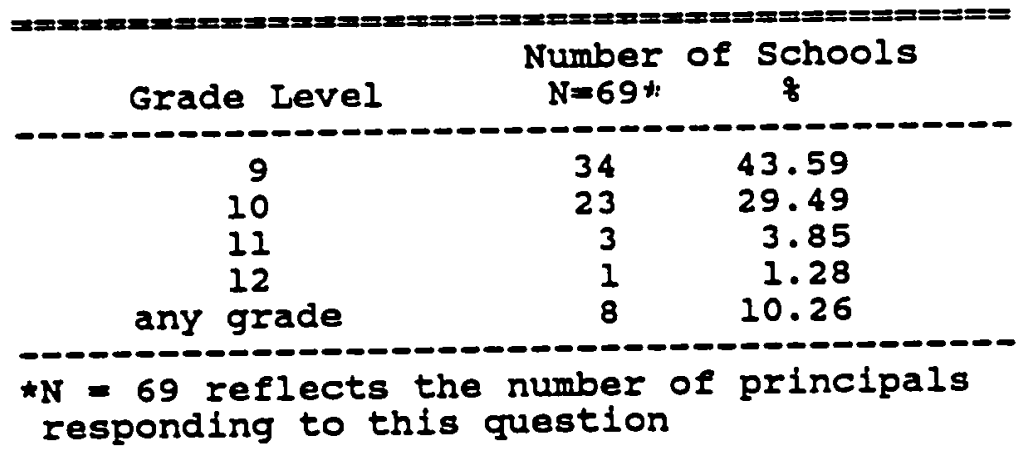




\section{Classes}

The number of industrial arts classes conducted per week in schools varied from one to 40 . This distribution was heavily skewed; the median number was five and skewness was 1.53. The length of an industrial

arts class period also varied greatly, from 33 minutes to 100 minutes, though median class length was 45 minutes. The distribution was bi-modal, with five schools conducting classes that lasted for 100 minutes or more.

\section{Strengths and weaknesses}

Research Question 9. What are the perceived strengths and weaknesses of current industrial arts programs in SDA secondary schools?

The strengths and weaknesses as perceived by chairmen of industrial arts programs are summarized in table 18. This table summarizes perceptions of both SDA and public-school chairmen. As far as the SDA chairmen are concerned, the two strengths that seem to stand out from the rest are course content and staffing. Three items seem to stand out as weaknesses--being chosen by the largest number of chairmen: enrollment, administrative support, and funding, in that order.

Research Question 10. Are the perceived strengths and weaknesses of industrial arts programs in SDA secondary schools significantly different from the perceived strengths and weaknesses of industrial arts programs in public schools? 
TABLE 18

\section{RELATIVE FREQUENCIES OF THE STRENGTHS AND WEAKNESSES OF INDUSTRIAI ARTS AS PERCEIVED BY CHAIRMEN}

\begin{tabular}{|c|c|c|c|c|}
\hline Item & \multicolumn{2}{|c|}{ strengths } & $\begin{array}{l}\text { Wea } \\
\text { SDA }\end{array}$ & $\begin{array}{l}\text { esses } \\
\text { Public }\end{array}$ \\
\hline $\begin{array}{l}\text { Course content } \\
\text { Facilities } \\
\text { Enrollment* } \\
\text { Administrative support* } \\
\text { Staffing } \\
\text { Methodology } \\
\text { Resources } \\
\text { Funding }\end{array}$ & $\begin{array}{r}25 \\
11 \cdot 8 \\
4 \cdot 4 \\
10 \cdot 3 \\
29 \cdot 4 \\
11 \cdot 8 \\
2 \cdot 9 \\
1 \cdot 5\end{array}$ & $\begin{array}{l}45 \\
28 \cdot 6 \\
28 \cdot 6 \\
31 \cdot 5 \\
33 \cdot 2 \\
21 \cdot 6 \\
13 \cdot 6 \\
11 \cdot 7\end{array}$ & $\begin{array}{r}1 \cdot 5 \\
11 \cdot 8 \\
22 \cdot 1 \\
20 \cdot 6 \\
8 \cdot 8 \\
4 \cdot 4 \\
7 \cdot 4 \\
17 \cdot 7\end{array}$ & $\begin{array}{l}7 \cdot 5 \\
35 \\
16 \cdot 2 \\
12 \cdot 4 \\
16 \cdot 7 \\
10 \cdot 1 \\
20 \cdot 1 \\
43 \cdot 6\end{array}$ \\
\hline
\end{tabular}

* items on which there are significant differences $(p<.05)$ in perception between SDA and public-school chairmen

Null Hypothesis: The perceived strengths and weaknesses of industrial arts programs in SDA secondary schools are not significantly different from the perceived strengths and weaknesses of industrial arts programs in public schools.

A chi-square test of independence applied to the perception of SDA and public-school industrial arts chairmen (table 18) revealed that only on the items of enrollment (computed chi-square $=14.98$, critical chisquare at alpha level .01 = 6.63) and administrative support (computed chi-square $=10.85$, critical chi-square at alpha level $.01=6.63$ ) was there any significant difference, with SDA chairmen perceiving both items more as weaknesses than did the public-school chairmen. conversely, public-school chairmen perceived both enrollment and administrative support more as strengths 
than did SDA chairmen. As a result of this test, the null hypothesis was rejected on two of the items: enrollment and administrative support. Within both groups, more agree with the notion of course content and staffing as strengths. The largest groups of SDA chairmen perceive administrative support and enrollment as weaknesses, whereas public-school chaimen perceive funding and facilities as such.

\section{Variety of courses}

Research Question 11. Is there a difference in the variety of course offerings between SDA and public-school industrial arts programs?

Forty-two different courses are offered in industrial arts programs in SDA schools in the United states, 13 of them in only one school each (see table 13). The public schools offer 59 different courses. Of the three courses offered by the largest number of schools, General woods is the only course the two systems have in common. Including General woods, the top three courses in the SDA system are Auto Mechanics and General Shop: in the public system they are General Metals and Mechanical Drawing. When ranked in order of the most frequently offered courses, the SDA courses have no drawing or drafting in the top six, while the third, fourth, fifth and sixth courses for public-school industrial arts programs relate to drawing or drafting. Apart from the 
broader variety of public-school industrial arts course offerings, there seems to be a different emphasis.

\section{Exemplary orograns}

Research Question 12. What are considered characteristics of an exemplary industrial arts program?

Table 19 contains a list of the characteristics together with the percentage for each group selecting that characteristic. Industrial arts department chairmen, principals, and Union education directors agreed that the two most important characteristics were dedicated, prepared teachers and well-equipped laboratories.

Research Question 13. Are there significant differences among the characteristics of an exemplary industrial arts program as selected by SDA chairmen, principals, and Union education directors?

Null hypothesis: There is no significant difference between the characteristics of an exemplary industrial arts program as selected by SDA chaimen, principals, and union education directors.

Chi-square values were computed on the number in each group selecting the stated characteristics of exemplary programs. Indicated in table 19 are the five characteristics on which significant differences were found. on the first listed characteristic, 'relevant to industry,' the difference was not between chairmen and principals, but between those two groups and Union 
education directors. Chairmen and principals considered relevance to industry more important than did union directors.

TABLE 19

REIATIVE FREQUENCIES OF RESPONDENTS SELECTING CHARACTERISTICS OF EXEMPIARY INDUSTRIAL

\section{ARTS PROGRAMS}

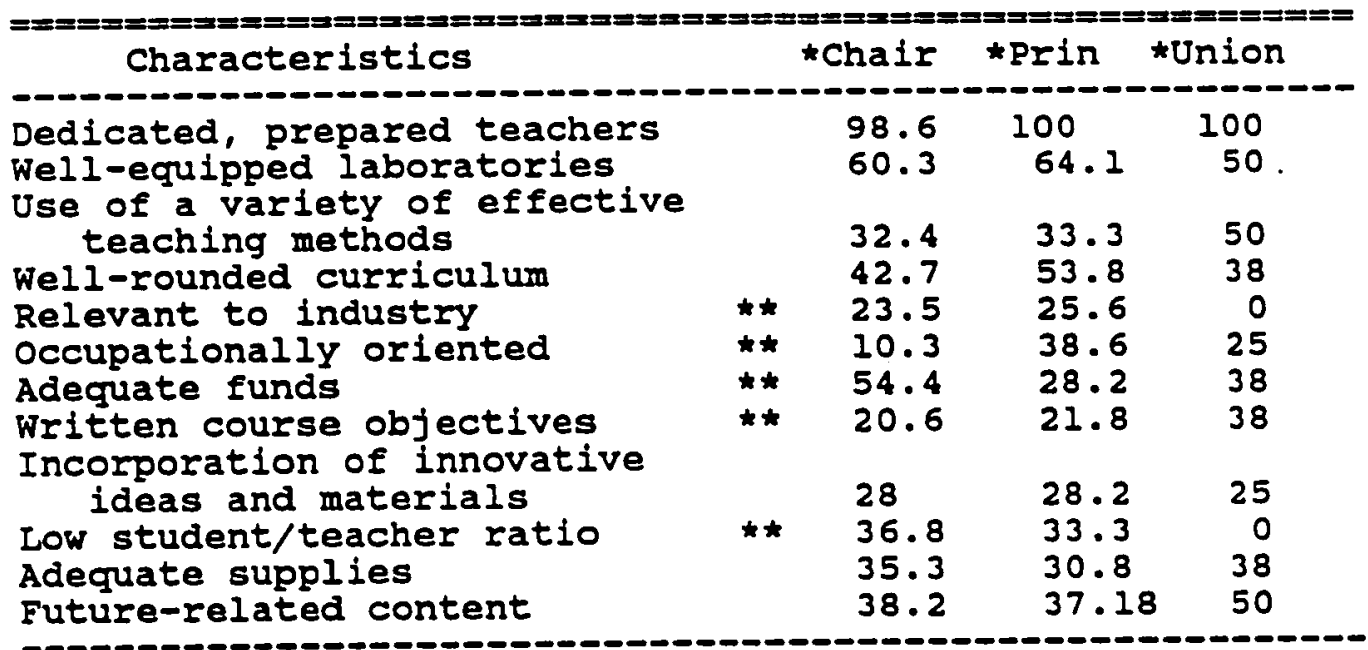

* percentages of respondents choosing that characteristic as exemplary

** characteristics on which significant differences were found $(p=<.05)$

on the characteristic of the occupational orientation of industrial arts courses, a larger percentage of principals selected this as a characteristic of exemplary programs than did Union directors, while a smaller percentage of chairmen viewed it as important. For the characteristic of adequate funds, there was no significant difference between the selections of principals and union directors, but more chairmen chose 
the adequacy of funding as an important characteristic of exemplary programs.

The next characteristic on which a significant difference was found was written course objectives; few chairmen and principals selected this, while a larger percentage of Union education directors chose it.

The final characteristic on which significant disagreement was found was a low student-teacher ratio. Approximately equal numbers of chaimen and principals chose this, while no unton directors were included in this category.

\section{Barriers}

Research Question 14. What are considered the major barriers to having an outstanding industrial arts program?

Table 20 ranks the absolute and relative frequencies for the SDA industrial arts chairmen responses to each barrier. Industrial arts chairmen most frequently cited limited supplies and equipment as being a major barrier, while relevant content was of least concern as a barrier.

\section{Program alliance}

Research Question 15. Is there a significant difference between SDA industrial arts chairmen and principals in their perceptions of the programs with which industrial arts is most closely allied? 
TABLE 20

\section{ABSOLUTE AND RELATIVE FREQUENCIES OF CHAIRMEN'S PERCEPTIONS ON THE MAJOR BARRIERS TO OUTSTANDING INDUSTRIAL ARTS PROGRAMS IN SDA SCHOOIS}

\begin{tabular}{lcc} 
Barriers & $\begin{array}{c}\text { Responses } \\
\mathrm{N}=68\end{array}$ \\
\hline Iimited supplies and equipment & 41 & 60.3 \\
Lack of understanding of industrial & 22 & 32.4 \\
arts programs by other faculty & 20 & 29.4 \\
Lack of pupil interest & 18 & 26.5 \\
Poor facility & & \\
Lack of understanding of industrial & 17 & 25 \\
arts programs by administrators & 4 & 5.9 \\
Lack of relevant content &
\end{tabular}

Null hypothesis: There is no significant difference between SDA industrial arts chairmen and principals in their perceptions of the programs with which industrial arts is most closely allied.

The alternatives from which the respondents could choose to answer this question were general education, college preparatory education, preparation for vocational/technical education, and vocational/technical education. Respondents cholces are listed in table 21.

There were no significant differences between the responses of SDA chairmen and principals in allying industrial arts with these programs. In both groups the majority chose general education. Vocational/technical preparation was the next most frequent choice followed by vocational/technical education and, finally, college preparation. 
TABLE 21

RELATIVE FREQUENCY OF SDA CHAIRMEN'S AND PRINCIPAIS' PERCEPTIONS OF PROGRAMS WITH WHICH INDUSTRIAI ARTS IS MOST CLOSELY ALLIED

\begin{tabular}{lcc} 
Programs & Chairmen & Principals \\
\hline General education & 67.7 & 61.5 \\
College preparatory & 4.4 & 3.8 \\
Vocational/technical prep & 23.5 & 25.6 \\
Vocational/technical ed & 4.4 & 8.9 \\
\hline
\end{tabular}

Research Question 16. Is there a significant difference between SDA and public-school industrial arts chairmen in their perceptions of the programs with which industrial arts is most closely allied?

Null hypothesis: There is no significant difference between SDA and public-school chairmen in their perceptions of the programs with which industrial arts is most closely allied.

The frequencies in table 22 indicate that the order in which the alternatives were chosen was similar for both groups; general education was the most frequent choice followed by vocational/technical preparation.

Equal numbers of SDA chairmen chose the alternatives of college preparation and vocational/technical education; whereas, among public-school chaimen, more chose vocational technical education than college preparation. A chi-square test revealed that this latter category, college preparation, was the only category in 
which a significant difference was found (computed chisquare $=3.84$, critical chi square at alpha level $.05=$ 3.82 ) between SDA and public-school chairmen, resulting in the rejection of the null hypothesis for this category only. This finding may indicate that SDA industrial arts chairmen are more oriented toward college preparation than public-school chairmen, who feel a closer affinity for the vocational-technical area.

TABLE 22

RELATIVE FREQUENCY OF SDA AND PUBIIC SCHOOL CHAIRMEN'S PERCEPTIONS ON PROGRAMS WITH WHICH INDUSTRIAL ARTS IS MOST CLOSELY ALIIED

\begin{tabular}{|c|c|c|}
\hline \multirow[b]{2}{*}{ Programs } & \multicolumn{2}{|c|}{ Chairmen } \\
\hline & SDA & Puliclic \\
\hline $\begin{array}{l}\text { General education } \\
\text { College preparatory } \\
\text { Vocational/technical prep } \\
\text { Vocational/technical ed }\end{array}$ & $\begin{array}{r}67.7 \\
4.4 \\
23.5 \\
4.4\end{array}$ & $\begin{array}{l}53.6 \\
0.2 \\
36 \\
10.2\end{array}$ \\
\hline
\end{tabular}

Research Question 17. Is there a significant difference between SDA and public-school principals in their perceptions of the programs with which industrial arts is most closely allied?

Null hypothesis: There is no significant difference between SDA and public-school principals in their perceptions of the programs with which industrial 
arts is most closely allied.

Table 23 contains a list of the frequencies across groups and categories.

No public-school principal chose the categorles of college preparation or vocational technical education, while SDA principals were spread across all four categories. A chi-square test (computed chi square $=.322$, critical chi-square at alpha level .05 $=3.82$ ) identified that the only category on which the null hypothesis of no significant difference should be retained was that of general education, even though the second largest category was vocational/technical preparation for both groups.

TABIE 23

RELATIVE FREQUENCY OF SDA AND PUBLIC SCHOOL PRINCIPALS' PERCEPTIONS ON PROGRAMS WITH WHICH INDUSTRIAL ARTS IS MOST CLOSELY ALLIED

\begin{tabular}{|c|c|c|}
\hline \multirow[b]{2}{*}{ Programs } & \multicolumn{2}{|c|}{ Principals } \\
\hline & SDA & Public \\
\hline $\begin{array}{l}\text { General education } \\
\text { College preparatory } \\
\text { vocationai/technical prep } \\
\text { vocational/technical ed }\end{array}$ & $\begin{array}{r}61.5 \\
3.8 \\
25.6 \\
8.9\end{array}$ & $\begin{array}{cc} & 55.4 \\
* & 0 \\
* & 44.6 \\
* & 0\end{array}$ \\
\hline
\end{tabular}

The most significant finding for the above three questions was that across all groups, general education was the program choice with which industrial arts is most closely allied. 
Industrial Arts Programs

\section{Advisory committees}

Research Question 18. How many SDA schools have advisory committees associated with their industrial arts departments?

When SDA chairmen were asked if there is an advisory committee associated with their department, only six responded affirmatively. This means that a large majority of industrial arts chairmen do not utilize advisory committees in guiding their department, a potentially valuable source of guidance, both philosophically and financially.

Proportion of schools with industrial arts programs

Research Question 19. What proportion of SDA schools have industrial arts programs? Union education directors provided the data for this question, stating that of the 93 secondary schools in the eight union conferences of the United states, 85 had industrial arts programs. This represents 91.4 percent of SDA secondary schools. (This research contacted 86 of the secondary schools, but found that only 82 had industrial arts programs; replies were recelved from 78 of the principals and 68 of the chairmen. The discrepancy of three schools may be a result of these schools cutting out their industrial arts departments and not registering such action with the Union.) 
131

Research Question 20. Is there a significant difference between the proportion of SDA and public secondary schools with industrial arts programs?

Null hypothesis: There is no significant difference between the proportion of SDA and public secondary schools with industrial arts programs.

The data displayed in table 24 show the total number of secondary schools and the number of secondary schools with industrial arts programs for both the SDA and public-school systems.

The proportion of SDA schools with industrial arts programs is .914, while that for public schools is .757 . A test of proportion for two independent samples, when applied to these data, result in the rejection of the null hypothesis (computed $z=3.52$, critical $z$ at alpha level $.01=2.58$ ) and the acceptance of the research hypothesis that there is a significant difference between these two proportions; a greater proportion of SDA schools have industrial arts departments.

The effect size in this hypothesis was postulated to be 0.15 in raw-score terms. The difference between the proportions exceeded this level, and the computed effect size was .366 . Using this effect size, the sample size, and the alpha level, power was computed at.99. This means that the probability of correctly rejecting the null hypothesis when it is actually false is 99 percent. 
TABLE 24

\section{PROPORTION OF SDA AND PUBLIC SCHOOIS WITH INDUSTRIAI ARTS PROGRAMS}

\begin{tabular}{|c|c|c|}
\hline & SDA & Public \\
\hline $\begin{array}{l}\text { Total number of schools } \\
\text { Schools with industrial }\end{array}$ & 93 & 20,230 \\
\hline arts departments & 85 & 15,315 \\
\hline Proportion & .914 & .757 \\
\hline
\end{tabular}

Purposes of Industrial Arts

Seventh-day Adventist industrial arts chairmen and school principals were asked to rate 12 purposes of industrial arts according to the perceived current and ideal emphasis for each of those purposes. A three-item scale of "high", "medium", and "low" was used for rating. For the purposes of analysis, a high was given a value of three, a medium a value of two, and a low a value of one. Means and medians were computed for each group on each purpose.

Research Question 21. Is there a significant difference between the current and ideal emphasis on the purposes of industrial arts as perceived by SDA industrial arts department chairmen?

Null hypothesis: There is no significant difference between the current and Ideal emphasis on the purposes of industrial arts as perceived by SDA department chairmen.

Medians and means were computed on the responses 
by department chairmen, and a sign test for dependent samples was computed. Table 25 contains the means, medians, and results of the test for significance. It can be seen that there were only two purposes for which there is no significant difference between current and ideal emphasis. For all other purposes, it was indicated that chairmen perceive the current and ldeal emphasis to be significantly different and the null hypotheses were rejected. The two purposes on which no discrepancies were perceived related to the development of skill in the use of common tools and machines and the development of worthy leisure-time interests.

Research Question 22 . Is there a significant difference between the current and ldeal emphasis on the purposes of industrial arts as perceived by SDA principals?

Null hypothesis: There is no significant difference between the current and ideal emphasis on the purposes of industrial arts as perceived by SDA principals. Means and medians, as descriptive measures, and a sign test for dependent samples computed on the principals' perceptions of the current and ideal emphasis on the purposes of industrial arts. These are listed in table 26. Principals perceived a significant discrepancy between the current and ideal emphasis placed on all except one of the stated purposes, resulting in the rejection of the null hypothesis at the .01 level. 
TABLE 25

CURRENT AND IDEAL EMPHASIS ON PURPOSES OF INDUSTRIAL ARTS AS PERCEIVED BY SDA CHAIRMEN

\begin{tabular}{|c|c|c|c|c|c|}
\hline \multirow{3}{*}{ Purposes } & \multicolumn{5}{|c|}{ Emphasis } \\
\hline & \multicolumn{2}{|c|}{ current } & \multirow[b]{2}{*}{ DIFF } & \multicolumn{2}{|c|}{ Ideal } \\
\hline & $m \Omega$ & md & & $\operatorname{mn}$ & md \\
\hline $\begin{array}{l}\text { To develop an understanding } \\
\text { of our technical culture }\end{array}$ & 1.9 & 2 & * & 2.5 & 3 \\
\hline $\begin{array}{l}\text { To discover and develop creative } \\
\text { talents in students }\end{array}$ & 2.4 & 3 & $\star$ & 2.8 & 3 \\
\hline $\begin{array}{l}\text { To develop an understanding of } \\
\text { the application of science } \\
\text { and math }\end{array}$ & 1.7 & 2 & * & 2.3 & 2 \\
\hline $\begin{array}{l}\text { To develop skills in the use } \\
\text { of common tools and machines }\end{array}$ & 2.7 & 3 & & 2.8 & 3 \\
\hline $\begin{array}{l}\text { Io provide pre-vocational } \\
\text { experiences for those interested } \\
\text { in technical work }\end{array}$ & 1.8 & 2 & * & 2.4 & 3 \\
\hline $\begin{array}{l}\text { To provide vocitional training } \\
\text { to those who would otherwise not } \\
\text { have the opportunity }\end{array}$ & 1.8 & 2 & * & $2 \cdot 3$ & 2 \\
\hline $\begin{array}{l}\text { To provide general technical } \\
\text { knowledge and skills }\end{array}$ & 2.2 & 2 & $\star$ & 2.6 & 3 \\
\hline $\begin{array}{l}\text { To develop worthy leisure- } \\
\text { time interests }\end{array}$ & 2.2 & 2 & & $2 \cdot 4$ & 2.5 \\
\hline To develop consumer knowledge & 2.1 & 2 & $\star$ & 2.5 & 3 \\
\hline To develop problem-solving skills & 2.3 & 2 & * & 2.8 & 3 \\
\hline $\begin{array}{l}\text { To develop an understanding of } \\
\text { the nature of technology }\end{array}$ & 1.8 & 2 & * & 2.3 & 2 \\
\hline $\begin{array}{l}\text { To help students make informed } \\
\text { educational and occupational } \\
\text { choices }\end{array}$ & 2.1 & 2 & * & 2.6 & 3 \\
\hline
\end{tabular}


TABLE 26

\section{CURRENT AND IDEAI EMPHASIS ON PURPOSES OF INDUSTRIAL ARTS AS PERCEIVED BY SDA PRINCIPAIS}

\begin{tabular}{|c|c|c|c|c|c|}
\hline \multirow{3}{*}{ Purposes } & \multicolumn{5}{|c|}{ Emphasis } \\
\hline & \multicolumn{2}{|c|}{ Current } & \multirow[b]{2}{*}{ DIFF } & \multicolumn{2}{|c|}{ Ideal } \\
\hline & $\operatorname{mn}$ & md & & $m n$ & md \\
\hline $\begin{array}{l}\text { To develop an understanding } \\
\text { of our technical culture }\end{array}$ & 1.8 & 2 & * & 2.3 & 2 \\
\hline $\begin{array}{l}\text { To discover and develop creative } \\
\text { talents in students }\end{array}$ & 2 & 2 & $\star$ & 2.6 & 3 \\
\hline $\begin{array}{l}\text { To develop an understanding of } \\
\text { the application of science } \\
\text { and math }\end{array}$ & 1.7 & 2 & * & 2.2 & 2 \\
\hline $\begin{array}{l}\text { To develop skills in the use } \\
\text { of common tools and machines }\end{array}$ & 2.6 & 3 & & 2.8 & 3 \\
\hline $\begin{array}{l}\text { To provide pre-vocational } \\
\text { experiences for those interested } \\
\text { in technical work }\end{array}$ & 1.9 & 2 & $\star$ & 2.4 & 2 \\
\hline $\begin{array}{l}\text { To provide vocational training } \\
\text { to those who would otherwise not } \\
\text { have the opportunity }\end{array}$ & 2 & 2 & $\star$ & 2.5 & 3 \\
\hline $\begin{array}{l}\text { To provide general technical } \\
\text { knowledge and skills }\end{array}$ & 2 & 2 & * & 2.5 & 2 \\
\hline $\begin{array}{l}\text { To develop worthy leisure- } \\
\text { time interests }\end{array}$ & 2 & 2 & $\star$ & 2.4 & 2 \\
\hline To develop consumer knowledge & 1.6 & 2 & $\star$ & 2.2 & 2 \\
\hline To develop problem-solving skills & 1.8 & 2 & $\star$ & 2.4 & 2 \\
\hline $\begin{array}{l}\text { To develop an understanding of } \\
\text { the nature of technology }\end{array}$ & 1.6 & 2 & * & 2.1 & 2 \\
\hline $\begin{array}{l}\text { To help students make informed } \\
\text { educational and occupational } \\
\text { choices }\end{array}$ & 2 & 2 & $\star$ & 2.6 & 3 \\
\hline
\end{tabular}


The one purpose on which no discrepancy was perceived related to the development in each student of a measure of skill in the use of common tools and machines.

It is significant to note in tables 25 and 26 that on almost all of the stated purposes of industrial arts, both SDA principals and chairmen see a discrepancy between the ideal and current emphasis. This may indicate that it is not the principals or the chairmen that control the emphasis that is placed on the various aspects of industrial arts.

other factors that may exert more influence include finances, enrollment, facilities, and other administrators. A reason for the influence of these factors may be that SDA industrial arts programs have had no consistent guidance and direction and, as a result, have been influenced by other pressures.

Research Question 23. Is there a significant difference between the perceptions of SDA chairmen and principals on the ideal emphasis on the purposes of industrial arts?

Null hypothesis: There is no significant difference between the perceptions of SDA chairmen and principals on the ideal emphasis on the purposes of industrial arts.

The data associated with the perception of SDA chairmen and principals on the ideal emphasis of the 
purposes of industrial arts are presented in table 27 . As a result of completing a median test for independent samples on these two groups, it was discovered that a significant difference existed on three of the purposes, leading to the rejection of the null hypothesis that there is no significant difference between the perceptions of these two groups. The first purpose on which there was a significant difference related to the development of an understanding of indigenous technical culture, with chairmen rating it higher than principals.

The second puxpose on which a significant difference of perception was found related to developing consumer knowledge and appreciation and use of industrial products; again chairmen rated this higher than principals.

The last purpose on which a difference was found and rated as ideally more important by chairmen, concerned developing problem-solving skills relating to materials and processes. On all the other purposes of industrial arts the ideal ratings of chairmen and principals did not differ significantly.

Research Question 24. Is there a significant difference between the perceptions of SDA and public-school industrial arts chatrmen of the ldeal emphasis or the purposes of industrial arts? 
TABLE 27

IDEAL EMPHASIS ON PURPOSES OF INDUSTRIAL ARTS AS PERCEIVED BY SDA CHAIRMEN AND PRINCIPAIS

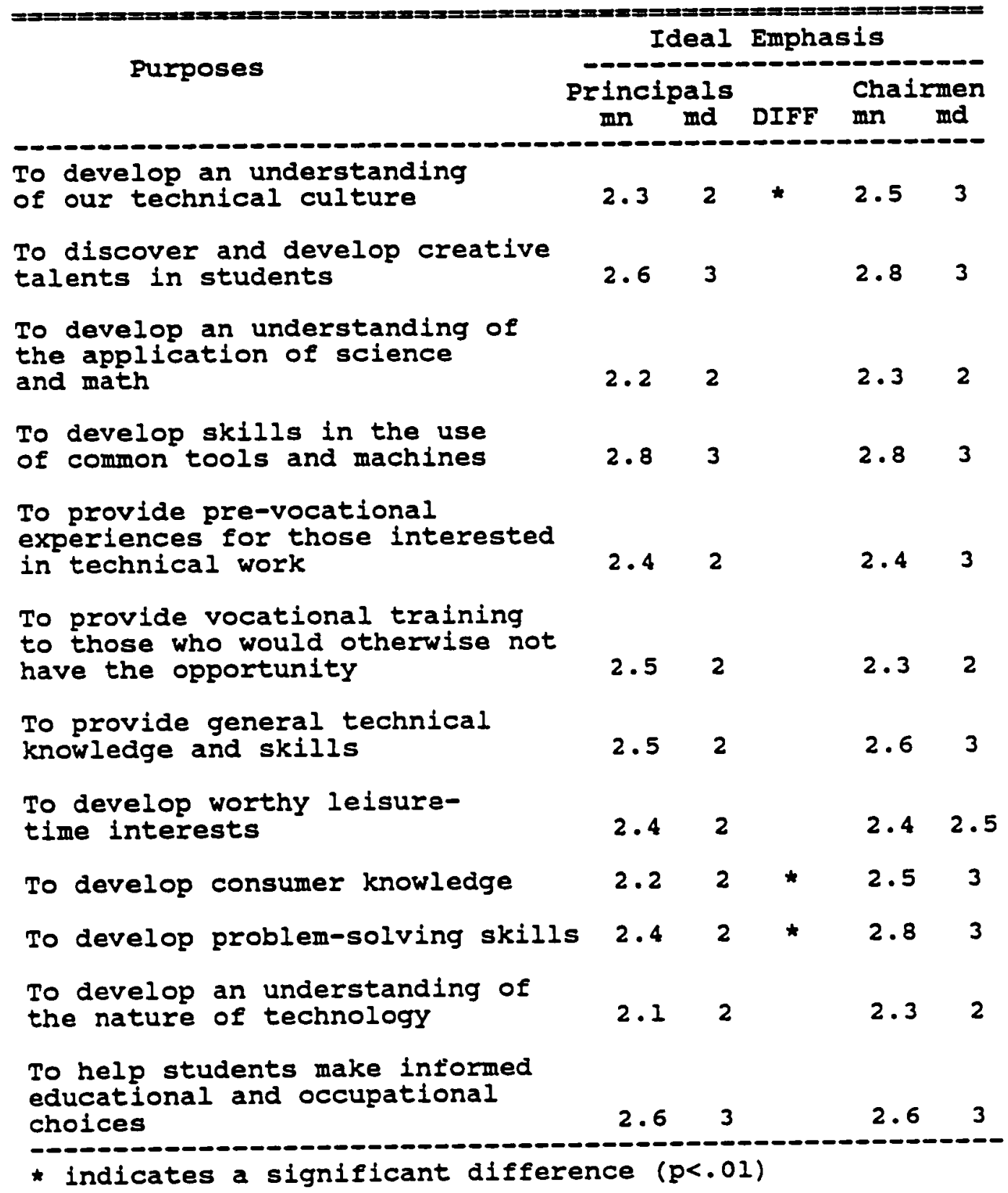


139

Null hypothesis: There is no significant difference between the perceptions of SDA and publicschool industrial arts chairmen of the ldeal emphasis on the purposes of industrial arts.

A t-test for independent means computed on the perceptions of SDA and public-school industrial arts chairmen regarding the ideal purposes of industrial arts programs revealed that the two groups did not differ significantly on any of the stated purposes. The mean data and results are listed in Table 28.

\section{Resources}

The characteristics of industrial arts program resources to be considered in this question relate to equipment and supplies and sources of funding.

Research Question 25. What are the general characteristics related to resources in industrial arts?

\section{Equipment and supplies}

Seventh-day Adventist chairmen responded to a question or the survey form dealing with the average amount of money spent annually for equipment and supplies. Table 29 contains descriptive data on the amounts spent. The median amount spent annually for equipment was $\$ 600$ and for supplies, $\$ 1000$. 
TABLE 28

IDEAL EMPHASIS ON PURPOSES OF INDUSTRIAL ARTS AS PERCEIVED BY SDA AND PUBLIC SCHOOL INDUSTRIAL ARTS CHAIRMEN

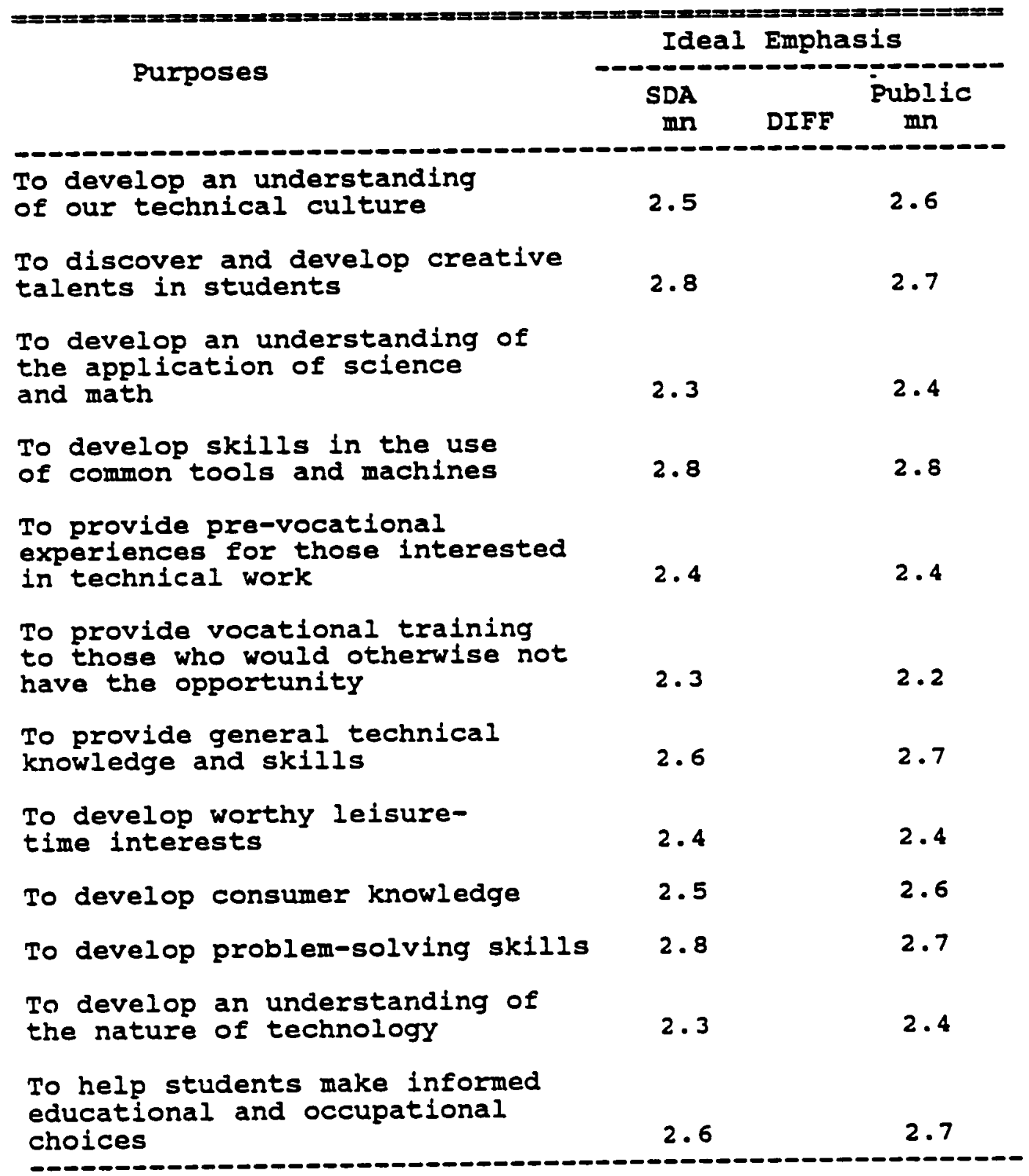

There are no significant differences. 
TABLE 29

\section{SDA INDUSTRIAL ARTS DEPARTMENTS' AVERAGE ANNUAI EXPENDITURES ON EQUIPMENT \\ AND SUPPIIES}

\begin{tabular}{|c|c|c|}
\hline & Equipment & Supplies \\
\hline $\begin{array}{l}\text { Median } \\
Q \\
\text { Range }\end{array}$ & $\begin{array}{c}\$ 600 \\
\$ 600 \\
\$ 100-10,000\end{array}$ & $\begin{array}{c}\$ 1000 \\
\$ 600 \\
\$ 150-15,000\end{array}$ \\
\hline
\end{tabular}

Teachers use a number of different methods to provide students with expendable supplies. Chairmen were asked to check the method they used, together with the method they considered ideal. The most common method employed was requiring students to pay for the materials they used, while the method considered most ideal was to charge students a standard minimum fee. Table 30 contains a list of the methods used and indicates the frequency with which SDA chaimen choose each method in ideal and actual categories.

TABIE 30

IDEAL AND ACTUAL PROCEDURES USED FOR PROVIDING EXPENDABIE SUPPIIES BY SDA INDUSTRIAL ARTS DEPARTMENTS

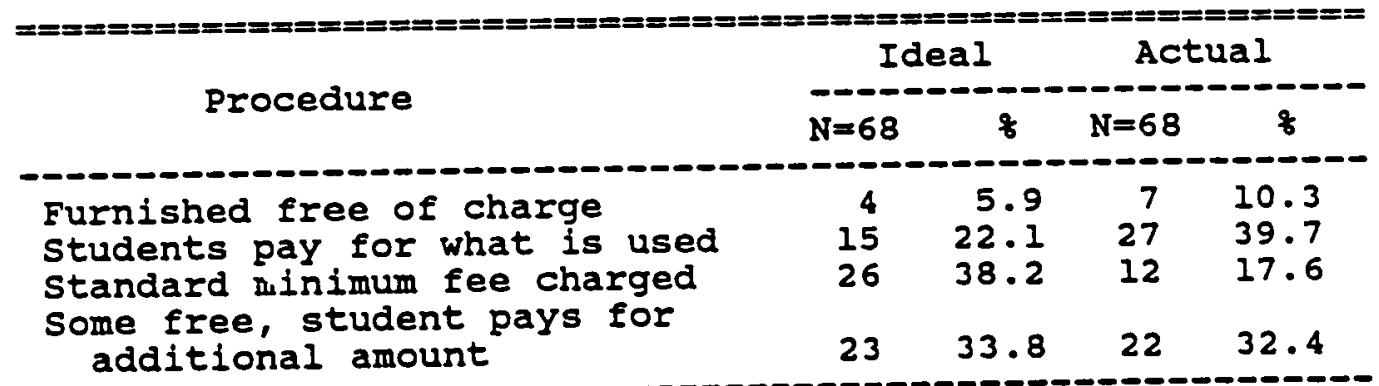


Sources of funding

SDA principals were requested to identify sources of funding for various industrial arts courses. Table 31 lists the industrial arts courses, the three sources of funding (individuals, industry, government), and the number of schools recieving such funding.

The most common course receiving funding from these sources was Power/Automotive Mechanics, followed by woods. The most common source of funding was individuals, followed by industry.

Expenditure per student

Research question 26. Do SDA industrial arts departments spend more or less per student on equipment and supplies than public-school industrial arts departments?

Data in table 32 indicate that SDA industrial arts departments spend more per student on both equipment and supplies than do public-school industrial arts departments. These figures were computed from mean school expenditures and mean industrial arts students per school.

A plausible reason for this is that regardless of how few students there are, it requires a certain amount of equipment and supplies for an industrial arts program to function; beyond that limit, economy of scale begins to operate, costing little more for more students. 
TABLE 31

SOURCES OF FUNDING FOR SDA INDUSTRIAL ARTS COURSES $($ Schools $=78)$

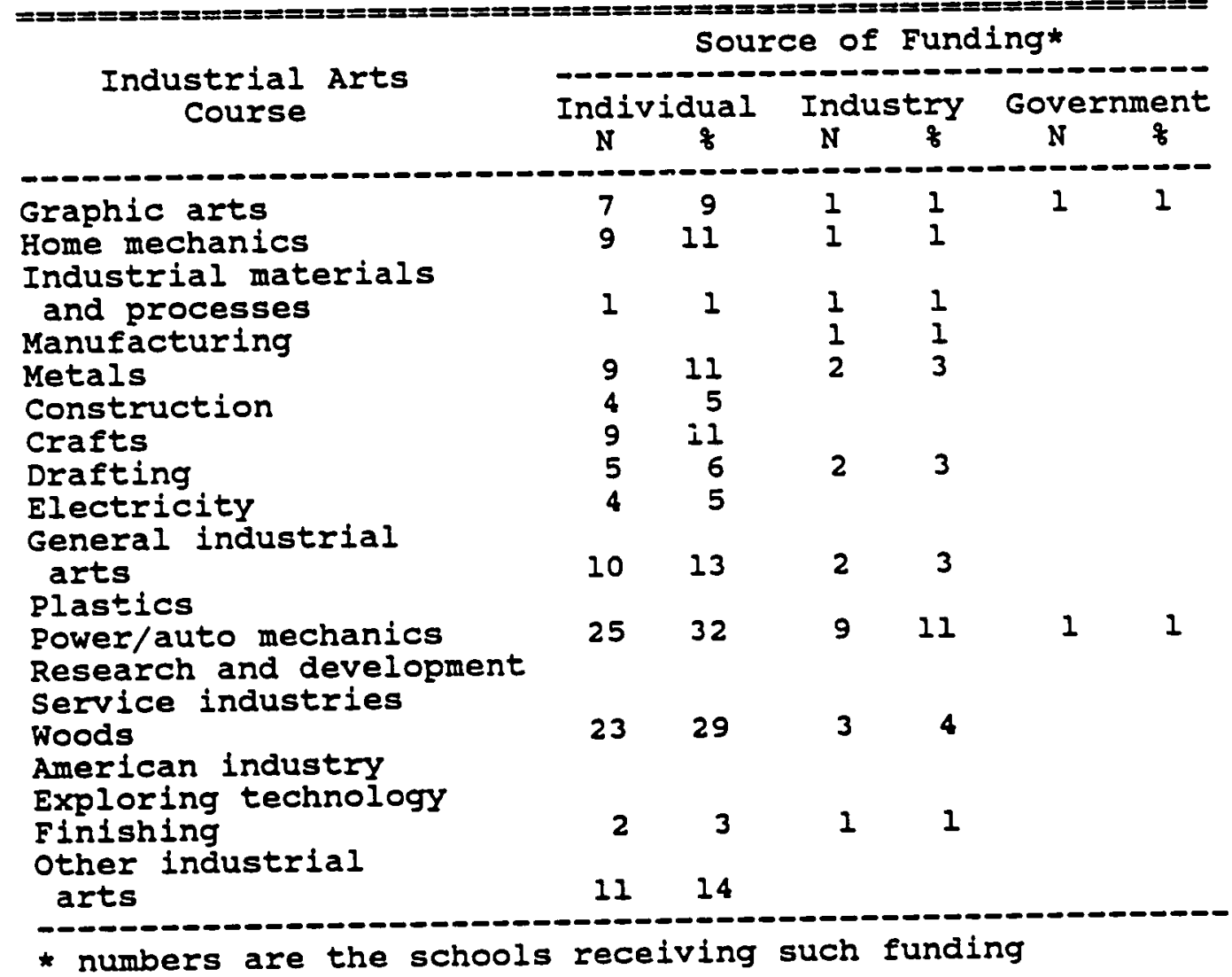


Seventh-day Adventist industrial arts departments spend slightly more (\$4.00 per student) on supplies than equipment, while public-school industrial arts departments spend almost twice as much on supplies (\$29.61) than on equipment $(\$ 16.79)$. The reason for this may be that the supply budget for SDA schools is relatively more stringent than for public schools.

TABIE 32

INDUSTRIAL ARTS DEPARTMENT EXPENDITURES BY SCHOOL AND BY STUDENT ON EQUIPMENT AND SUPPLIES

\begin{tabular}{|c|c|c|}
\hline & $\begin{array}{r}\text { SDA } \\
N=78\end{array}$ & $\begin{array}{l}\text { Public } \\
\mathrm{N}=719\end{array}$ \\
\hline $\begin{array}{c}\text { By school expenditures } \\
\text { Equipment * } \\
\text { Supplies * }\end{array}$ & $\begin{array}{l}1563 \\
1731\end{array}$ & $\begin{array}{l}2134 \\
3762\end{array}$ \\
\hline $\begin{array}{c}\text { Industrial Arts students } \\
\text { per school } * \star\end{array}$ & 36.33 & 127.04 \\
\hline $\begin{array}{c}\text { By student expenditures } \\
\text { Equipment } \\
\text { Supplies }\end{array}$ & $\begin{array}{l}43.02 \\
47.64\end{array}$ & $\begin{array}{l}16.79 \\
29.61\end{array}$ \\
\hline
\end{tabular}

Facilities

Research Question 27. Is there a difference between the relative number and variety of industrial arts general laboratory facilities available in SDA and public schools?

A general laboratory is one in which a number of different activities can be conducted. Table 33 contains 
a list of the 15 types of industrial arts general laboratories that are represented in public schools. Woods laboratories are the most common, followed by drafting, metals, and general industrial arts. SDA schools have 12 different types of general laboratories, the most common being general industrial arts, followed by woods, drafting, and power/auto mechanics. It appears from these data that public schools generally have more variety in their general industrial arts laboratories and that specific public schools tend to have more general laboratories than do SDA schools.

The data in table 33 indicate that the third most common general laboratory in SDA schools is drafting, though the data in table 13 rank drafting as below the seventh most common course. This may indicate that drafting laboratories are often used for classes other than drafting.

\section{Future Planning}

Research Question 28. What are the projections for enrollment and course offerings in industrial arts in SDA schools?

\section{Courses}

In an endeavor to project future trends, SDA chairmen were requested to note the courses they planned to add or delete from their industrial arts program within the next five years. Tabie 34 contains a list of the 
courses that are planned for addition or deletion. Chairmen indicated that they plan to add 25 and to delete nine different courses. Two courses seem to stand out from the others--as far as the number of schools planning to add them is concerned--General Metals and those related to electricity/electronics. Apart from those, it is difficult to discern a trend, except to say that chairmen plan to add more courses than they plan to delete, and this correlates positively with projected enrollment trends.

\section{Enroliment}

Principals were requested to project future enrollment by indicating enroliment trends for their schools and for industrial arts. Projections for the two areas were very similar. principals were asked to rate their projections on a three-point scale from decline to increase; decline was given a value of one and increase a value of three. The mean school enrollment trend is 2.19 (s.d. $=.604)$, while industrial arts is 2.18 (s.d. = .639). From these profections it can be stated that principals profect slight increases in enrollment both for their schools and for industrial arts.

\section{Union education office}

Research question 29. What guidance is given to SDA industrial arts programs by the union education offices? 
TABIE 33

\section{RELATIVE FREQUENCIES OF GENERAL IABORATORY FACIIITIES AVAILABLE IN SDA AND PUBLIC SCHOOLS}

\begin{tabular}{|c|c|c|}
\hline General Laboratory & $\begin{array}{c}\text { SDA } \\
N=57 \\
f\end{array}$ & $\begin{array}{c}\text { Public } \\
N=501 \\
\&\end{array}$ \\
\hline $\begin{array}{l}\text { Construction } \\
\text { Crafts } \\
\text { Drafting } \\
\text { Electricity } \\
\text { General Ind Arts } \\
\text { Graphic Arts } \\
\text { Home Mechanics } \\
\text { Materials and Processes } \\
\text { Manufacturing } \\
\text { Metals } \\
\text { Plastics } \\
\text { Power/Auto Mechanics } \\
\text { Research and Development } \\
\text { Service Industries } \\
\text { Woods }\end{array}$ & $\begin{array}{l}0 \\
24.6 \\
45.6 \\
10.5 \\
50.9 \\
28 \\
12.3 \\
3.5 \\
1.7 \\
26.3 \\
5.3 \\
42.1 \\
0 \\
0 \\
49.1\end{array}$ & $\begin{array}{r}29.7 \\
27.3 \\
56.1 \\
33.1 \\
49.3 \\
21.6 \\
9.8 \\
5.6 \\
9.3 \\
55.7 \\
16 \\
29.1 \\
1 \\
0.6 \\
61.5\end{array}$ \\
\hline
\end{tabular}

TABIE 34

ABSOIUTE FREQUENCY OF SDA SCHOOLS PLANNING ADDITIONS AND DEIETIONS IN INDUSTRIAL ARTS COURSES

\begin{tabular}{|c|c|c|c|c|c|}
\hline Course & Add & Del & Course & Add & Del \\
\hline $\begin{array}{l}\text { Auto mechanics } \\
\text { General woods } \\
\text { Welding } \\
\text { Photography } \\
\text { other } \\
\text { Graphic arts } \\
\text { Arch drafting } \\
\text { Ceramics } \\
\text { Mech drawing } \\
\text { Drafting } \\
\text { Other mechanics } \\
\text { Home mechanics } \\
\text { General metals }\end{array}$ & $\begin{array}{l}3 \\
2 \\
3 \\
3 \\
2 \\
1 \\
3 \\
3 \\
1 \\
2 \\
2 \\
3 \\
5\end{array}$ & $\begin{array}{l}1 \\
3\end{array}$ & $\begin{array}{l}\text { Electronics } \\
\text { Printing } \\
\text { Crafts } \\
\text { Power mechanics } \\
\text { Wood technology } \\
\text { Electricity } \\
\text { Leather } \\
\text { Plastics } \\
\text { Manufacturing } \\
\text { Finishing } \\
\text { Metal technology } \\
\text { Foundry } \\
\text { Drafting tech }\end{array}$ & $\begin{array}{l}3 \\
4 \\
2 \\
1 \\
2 \\
1 \\
1 \\
1 \\
1\end{array}$ & $\begin{array}{l}2 \\
1\end{array}$ \\
\hline
\end{tabular}


This question was designed to assess the role of the Union education offices in industrial arts programs. Information was sought from the Union education directors which related to scope and sequence plans, curriculum guides, evaluations, and certification requirements. These questions, together with response frequencies are given in table 35. There is no unanimity on any of these items for the eight Unions.

TABLE 35

UNION EDUCATION OFFICE INVOLVEMENT IN SDA INDUSTRIAL ARTS PROGRAMS

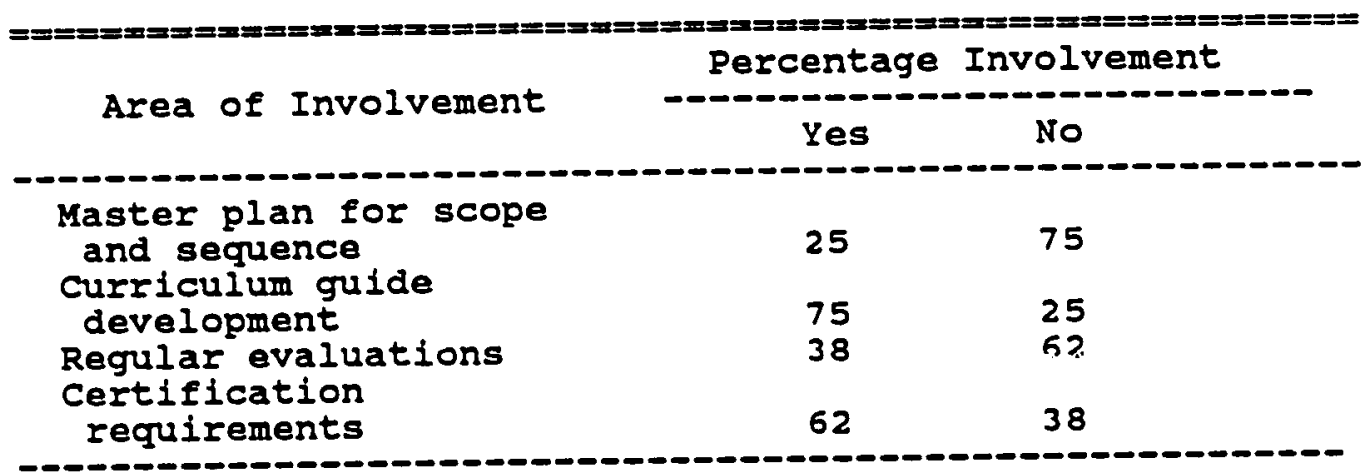

Two Unions have scope-and-sequence plans for industrial arts, six have developed curriculum guides, three have regular and systematic evaluations, and five have specific certification requirements for industrial arts teachers beyond that required for other teachers. At least in these areas of involvement, the data indicate a lack of consistent union guidance and involvement in SDA industrial arts programs across the U.S. 
Section 3--The standards

Research Question 30. What areas of industrial arts should a set of standards cover?

All three populations were requested to check elements they thought should be included in a statement of standards for industrial arts. The frequency of choice by population for each element is listed in table 36. All three groups--principals, industrial arts chairmen, and Union education directors-most often chose philosophy and course content as being important elements in a statement of standards. one notable difference across the three groups relates to funding. of chairmen, 61.8 percent (rank=3) consider it important, while only 50 percent of the principals (rank=7) and 25 percent of Union respondents (rank=8.5) consider it important. Because chairmen are the ones to operate the budget, presumably they have more concern in this area.

The only element on which there was a consistently low rating by all groups was enrollment. As a result, this was not izcluded in the standards document.

Research Question 31. What are the standards whereby SDA industrial arts programs can be evaluated and guided in their development?

The methodology followed to answer this question is discussed in chapter 3. It involved a literature review, initial selection of standards, a pilot test, validation panel ratings, and final statistical selection 
150

of the validated standards related to all areas of industrial arts programs.

The ratings for each standard as given by the validation panel were statistically weighted utilizing the following formula:

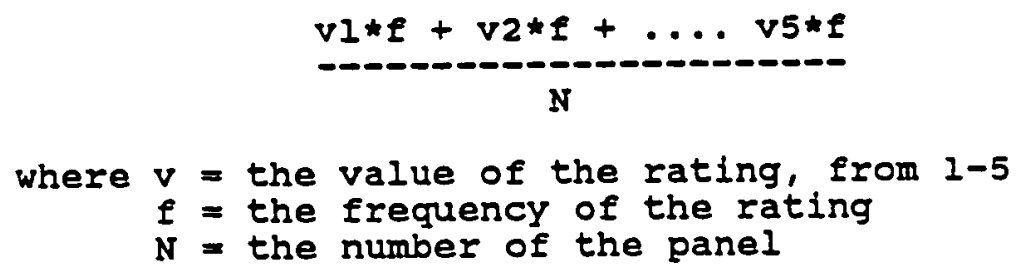

A computed rating of 3.75 was considered the minimum; standards below this level were not considered valid.

TABLE 36

ELEMENTS TO BE INCLUDED IN A STATEMENT OF STANDARDS FOR INDUSTRIAL ARTS

\begin{tabular}{|c|c|c|c|c|c|c|}
\hline Element & \multicolumn{2}{|c|}{$\begin{array}{l}\text { Principals } \\
\text { rank }\end{array}$} & \multicolumn{2}{|c|}{$\begin{array}{l}\text { Chairmen } \\
\text { rank \& }\end{array}$} & \multicolumn{2}{|c|}{ Union } \\
\hline $\begin{array}{l}\text { Philosophy } \\
\text { Course content } \\
\text { Funding } \\
\text { Administrative }\end{array}$ & $\begin{array}{l}1 \\
2 \\
7\end{array}$ & $\begin{array}{l}97.4 \\
93.6 \\
50\end{array}$ & $\begin{array}{l}1 \\
2 \\
3\end{array}$ & $\begin{array}{l}85.3 \\
78 \\
61.8\end{array}$ & $\begin{array}{l}2 \\
1 \\
8.5\end{array}$ & $\begin{array}{r}88 \\
100 \\
25\end{array}$ \\
\hline $\begin{array}{l}\quad \text { support } \\
\text { Facilities } \\
\text { Staffing } \\
\text { Resources } \\
\text { Methodology } \\
\text { Enrollment }\end{array}$ & $\begin{array}{l}8 \\
3 \\
6 \\
4 \\
5 \\
9\end{array}$ & $\begin{array}{l}44.9 \\
73.1 \\
61.5 \\
69.2 \\
66.7 \\
28.2\end{array}$ & $\begin{array}{l}4 \\
5 \\
6 \\
7 \\
8 \\
9\end{array}$ & $\begin{array}{l}50 \\
47 \\
39.7 \\
36.8 \\
30.9 \\
17.7\end{array}$ & $\begin{array}{l}6.5 \\
3 \\
4 \\
6.5 \\
5 \\
8.5\end{array}$ & $\begin{array}{l}38 \\
75 \\
62 \\
38 \\
50 \\
25\end{array}$ \\
\hline
\end{tabular}

This computation indicated eight standards below the acceptable level. No suggestions were made as to changes that would render these standards acceptable. The 
151

final document contains 214 standards (see appendix J). The eight standards that were not rated sufficiently high are listed in appendix $\mathrm{K}$.

\section{Summary}

This chapter has presented the analysis of the data and the findings. The order of presentation followed the order of the 31 research questions, prefaced by an analysis of the methodology in terms of response rates. The research questions were divided under the areas of industrial arts students, industrial arts teachers, instructional programs, industrial arts programs, purposes of industrial arts, resources, facilities, future planning, and the standards. 
CHAPTER V

SUMMARY, CONCLUSIONS AND RECOMMENDATIONS

\section{Introduction}

This chapter presents a summary of the study, outlining chapters one to four. Conciusions, implications, general recommendations and recommendations for further research drawn from the study are also presented.

\section{Summary}

The technological revolution has left industrial arts teachers in a quandary which can be summarized by the question: Is industrial arts filling the most appropriate role possible given its historical background and the current context of learners in a technological society?

Apart from the implications of technological revolutions, the SDA industrial arts system was confronted with a number of factors which further confused the decision as to which role industrial arts should fill. These factors include the diversity of the constituencies that many SDA schools serve, the attempt to follow specific counsel written around the turn of the century without considering the context, and the lack of a unified approach to the area of industrial arts. 
The statement of the Problem

Two problems which were the concern of this study were identified. The first was that, at the time of this writing, there existed no comprehensive data describing the number, nature, and status of SDA industrial arts programs.

The second problem was that there were no comprehensive criteria for the evaluation and guidance of industrial arts programs.

\section{The Purpose of the study}

The purpose of the study directly addressed the two problems as stated above. Descriptive and comparative data were gathered and analyzed, and validated goals and standards were developed.

\section{Related Iiterature and Research}

Industrlal arts began developing in schools toward the end of the nineteenth century. The roots of the movement were seen by two opposing groups as developing either from the already existing manual arts movement, or from the social reform movements generated by the shift from an agrarian to an industrial society.

The literature seemed to be in general agreement that a technological revolution has occured during the 1970's and 1980's, and that industrial arts classes have the potential to prepare students for the technological society in which they must live. 
The Present state of Industrial Arts

The present industrial arts curriculum was viewed in most of the professional literature as out-of-date, and out-of-touch with the current dynamics of society. Most industrial arts teachers orient their curriculum to project construction, a very limited approach "because students were not provided with broad experiences that will assist them in living in a highly technical society (Copeland, 1982, p. 11). Confusion and stagnation were two terms that were often used in describing the practicing profession. A dichotomy existed between the propositions and developmental tasks of the professionals and the reality of what was happening in the schools.

The Research Methodology

This study was oriented around 31 research questions. The questions were grouped under the headings industrial arts students, industrial arts teachers, instructional programs, industrial arts programs, purposes of industrial arts, resources, facilities, future, and standards. There were two separate methodologies utilized to answer the research questions. One related to the development, administration and analysis of the survey, and the other to the development and validation of standards for industrial arts.

subjects who participated in the survey were 68 SDA industrial arts chairmen, 78 SDA high-school principals and eight SDA Union education directors. One 
instrument for each of the three populations was designed, validated, pilot-tested, and administered. The surveys were mailed to the subjects, 88 percent of whom responded. The responses were computer-analyzed and the resulting data formed the basis of the answers to the research questions.

standards for industrial arts were compiled from computer searches and other sources, before being pilottested with a group of 13 industrial arts administrators and teachers. The resulting 222 standards were submitted for validation by a panel of 11 who rejected eight of the standards as not being valid.

\section{Findings of the study}

The following points summarize the mafor findings of this study of industrial arts in SDA schools in the United states. It should be noted that some of the findings are descriptive of the SDA school system, and others comparative with the public-school system.

1. Of the high school grades 9-12, grade 9 was the focus of the industrial arts program as far as both numbers of students taking industrial arts and the numbers of courses offered. Forty percent of students in grade 9 take industrial arts, 20 percent in grade 10, decreasing to 15 percent in grade 12 .

2. Most principals (62 percent) perceived industrial arts as a general education program (as distinct from vocational education), and that it had a role to play 
in the instructional program of college-bound students. Eighty-four percent believe that industrial arts should be a requirement for all students.

3. Both SDA and public-school industrial arts chairmen rated the academic ability of industrial arts students as below that of other students. Public-school chaimen rated their students as signiflcantly less than SDA chairmen rated their students. Where a rating of three would represent the same degree of academic ability for both groups, SDA chaimen rated their students at 2.89 and public-school chairmen rated theirs at 2.59 .

4. Fifty percent of industrial arts teachers serve on a 10-month contract, the remaining 20 percent have a 12 -month contract.

5. The proportion of students taking industrial arts in SDA academies was about 23 percent. This was not significantly different from the situation in public schools, which was 28 percent.

6. Most SDA industrial arts teachers did not receive supplemental pay for activities beyond that of teaching.

7. The mean student-teacher ratio of 10.92 students per teacher for SDA industrial arts classes was acceptable to chairmen, who considered 12.72 students per teacher to be the maximum for industrial arts classes.

8. Seventh-day Adventist industrial arts teachers were less involved in professional organizations than were 
157

public-school industrial arts teachers. Relatively more SDA industrial arts teachers ( 60.23 percent) do not belong to any professional organization than public-school industrj.al arts teachers ( 5.6 percent).

9. The level of education at which there was the largest difference between SDA and public-school industrial arts teachers was "no degree"; 10.7 percent of SDA teachers had no degree while 3.3 percent of publicschool teachers fall in this category. The differences between the two groups, however, were found to be not significant.

10. The most common industrial arts courses taught in SDA schools were, in order: auto mechanics (taught in 78 percent of schools), general woods (taught in 63 percent of schools), and general industrial arts (taught in 41 percent of schools). The types of laboratories also reflected this emphasis.

11. In SDA schools, 11 percent of the faculty were industrial arts teachers and in public school, the figure was 5.4 percent. Although this absolute difference was large, it was not significantly different because of the large N (576 public schools) involved in the computation. 12. Most ( 60 percent) SDA secondary schools had at least one industrial arts course as a requirement. Fourteen percent did not require any courses, and 15 percent required two courses.

13. Seventh-day Adventist and public-school 
industrial arts chairmen agreed that the two most important strengths of industrial arts were course content and stafing, but disagreed on the weaknesses. Seventhday Adventist chairmen indicated enroliment and administrative support whlle public-school chairmen identified funding and facilities as weaknesses.

14. Public-school industrial arts programs offered more different types of courses and had a stronger emphasis on drawing than SDA industrial arts programs, which proportionally tended to emphasize auto mechanics. 15. Union education directors, industrial arts chairmen, and principals, agreed that the two most important characteristics for exemplary industrial arts programs were dedicated and prepared teachers, and wellequipped laboratories.

16. Of SDA principals, 60 percent perceived limited supplies and equipment as the major barrier to outstanding industrial arts programs.

17. Seventh-day Adventist principals (6I percent) and industrial arts chairmen (68 percent) allied industrial axts most closely with general education. public-school chairmen (46 percent) placed more emphasis on the alliance of industrial arts with vocationaltechnical areas than did SDA chairmen (28 percent), though the relative difference was determined not to be significant.

18. Nine percent of SDA industrial arts 
departments had advisory comittees associated with them.

19. A significantly larger proportion of SDA schools had industrial arts programs than public schools. Ninety-one percent of all SDA schools had industrial arts programs, while the frequency of public schools was 76 percent.

20. Seventh-day Adventist chairmen perceived a significant difference between the current and ideal emphasis on all except one of the stated purposes of industrial arts, as did principals. Apart from three purposes, it was found that there was no significant difference between SDA chairmen and principals perceptions of the ideal emphasis given to the remaining purposes. on the ideal emphasis given to the stated purposes by SDA and public-school chairmen, no significant differences were found.

21. Different procedures were ut1lized by schools in providing students with expendable industrial arts supplies, and it appeared that many schools were not using what they considered to be the ideal procedure. The most common method was that students pay for the material they use, but it was felt that the ldeal procedure would be to charge all students a minimum fee.

22. Apart from tuition, schools recelved funding for their industrial arts departments from Individuals, industry, and government. Auto mechanics and woods were 
the courses that most commonly received funding from these three latter sources.

23. Seventh-day Adventist industrial arts departments spent more per student on equipment $(\$ 43.02$ compared to $\$ 16.79)$ and supplies $(\$ 47.64$ compared to $\$ 29.61$ ) than did public-school industrial arts departments. The larger size of the public schools permitted more favorable economies of scale.

24. It was projected by SDA chairmen that 25 new courses would be added within the next five years in the schools surveyed, and that nine courses would be deleted. Accompanying this expansion of courses, principals projected a slight increase in both industrial arts (18 percent) and total enrollment (19 percent) in the future. 25. It was found that there were 214 out of 222 standards that were considered valid for SDA industrial arts programs. The valid standards relate to all aspects of SDA industrial arts programs.

\section{Conclusions}

This study collected data from 78 principals, 68 industrial arts chairmen, and the eight union education directors in the SDA educational system in the United states. The following conclusions were made from the data collected.

The evidence seems to indicate that SDA industrial arts programs are not following the latest curriculum developments in the area of industrial arts and technology 
161

education. The trend in curriculum and program development is toward consolidation of courses. A survey of the courses to be added and deleted within the next five years indicates that SDA industrial arts chairmen as a group are planning on diversifying their course offerings, but the types of courses to be added are not in the areas being recommended or developed by the industrial arts profession.

Those standards that were deleted from the final standards document (Appendix $K$ ) are a further indication of the degree to which SDA chairmen are out of touch with the latest trends. of the 222 original standards, eight were deleted because they were not rated above the validation level. One of the standards deleted summarized the current thrust of industrial arts curriculum development, that of relating it to courses in manufacturing, construction, transportation, communication and energy.

A plausible reason for this lag in the SDA industrial arts curriculum is because chairmen are not aware of what is happening in this area. Professional organizations are an important source of curriculum ideas, yet SDA industrial arts teachers are not as heavily involved in these organizations as their public school counterparts.

Seventh-day Adventist industrial arts chairmen are generally content with their courses; they rated 
"methodology and course content" more as a strength than a weakness, and considered "lack of relevant content" as the least important barrier to outstanding industrial arts programs. So even though they are "behind the times" as far as course content is concerned, they do not perceive the situation as such, nor as detrimental.

Industrial arts was generally perceived to be closely allied with the general education curriculum, to be an important component in the educational program of college-bound students, and to be a requirement for all students. The data tend to indicate that with regard to the courses offered in SDA and public schools, there are many similarities, but with a notable exception in the slightly different focus taken by the two systems. At the risk of over-simplification, this course focus can be compared as an emphasis upon auto mechanics in SDA schools and drawing in the public industrial arts system.

The SDA industrial arts emphasis on auto mechanics most likely is not based on current philosophical imperatives, but rather on an historical confusion between industrial arts and vocational education as alluded to in Chapter 1. This researcher feels that the auto technologies are viewed as more in alliance with vocational than general education, and for that reason are common courses. This is in spite of the fact that SDA industrial arts chairmen ranked "occupational orientation" as the least important characteristic of an exemplary 
industrial arts program. This discrepancy may correlate with an idea mentioned below, that industrial arts chairmen are not really in control of their industrial arts programs.

Apart from the difference mentioned above, there are few signiflcant differences between the SDA and the public-school industrial arts programs. of the nine hypothesis tested in this study which related to SDApublic school comparisons, significant differences were found on five, but on three of those only sub-sections of the null hypotheses were rejected. For the ideal emphasis on all the purposes of industrial arts listed, there was no significant difference between the perceptions of SDA and public-school industrial arts chairmen. This would indicate philosophical agreement between these two groups on the purposes mentioned.

Neither SDA principals nor chairmen seem to be content with the current emphasis given to the purposes of industrial arts. This may indicate that they are not in control of the industrial arts program, that there are other forces that exert more influence on the direction of the program than either principals or chairmen exert, such as history, finances, facilities, or curriculum guides developed by higher authorities.

The implied discontent is not the result of differences between principals and chaimen guiding programs in different directions; they agree on the ideal 
emphasis that should be given to all except three of the stated purposes. It is interesting to note that the only purpose on which both SDA principals and industrial arts chairmen discerned no significant discrepancy between the current and ideal emphasis was related to developing skill in the use of common tools and machinery. This was the major purpose of industrial arts according to national surveys in 1962 and 1981 (Dugger, 1980c, p.168). This may indicate that long lasting and static purposes in industrial arts outside of the SDA school system have the effect of minimizing the differences between the perceived current and ideal emphases toward SDA industrial arts.

It appears that SDA industrial arts chairmen differentiate between the emphasis given to purposes of industrial arts, with which they express discontent, and course content, with which they are comfortable. A plausible explanation may be that chairmen have more control over the course content and so can shape it to their philosophy, whereas the emphasis that is placed upon the various nurposes of industrial arts is beyond their control.

Seventh-day Adventist chairmen do not sense strong administrative support for their programs. The situation is the opposite for public-school industrial arts chairmen. This may be, in part, a result of the lack of 
consistent guidance in the area of industrial arts received from the Union education departments.

Seventh-day Adventist industrial arts chairmen place more importance on adequate funding than do SDA principals o:: Union education directors. More industrial arts chairmen perceive funding to be a weakness than those who perceive it as a strength. This is understandable as it is the chairmen who are restricted by the budget. Chairmen also consider limited supplies and equipment a major barrier to outstanding industrial arts programs. Most chairmen, however, do not utilize advisory committees which might be a potential source of income.

Seventh-day Adventist schools spend more per industrial arts student on both equipment and supplies than do public schools. More students in SDA industrial arts courses would produce more favorable economies of scale, costing progressiveiy less for each additional student.

Adequate facilities exist for more students in SDA industrial arts programs; enrollments are perceived as a weakness, presumably implying that enrollment is currently too low. Although there is no significant difference in the proportion of students taking industrial arts in SDA and public schools, the smaller size of SDA schools is reflected in a smaller enrollment in industrial arts programs. Because the actual student-teacher ratio is less than the maximum desirable ratio, more students could 
be accommodated in these programs. One way of alleviating some problems of industrial arts would be to enroll more students.

\section{Implications}

The following implications are perceived by this researcher as a result of the findings and conclusions outlined above.

Because SDA industrial arts programs lag behind the "state of the art" as far as technological orientation is concerned, and because the nature of society is changing rapidly from industry to technology, students will perceive SDA industrial arts programs as being increasingly irrelevant to their needs in the societal context. This will exacerbate the problems currently faced by SDA industrial arts educators relating to enrollment and finances.

Given that SDA industrial arts programs are outof-date and that industrial arts teachers are not aware of this, the implication is that teachers are not in contact with the sources, such as professional literature and organizations, from which they could gain an awareness of general trends and current activities.

The differences between the SDA and public-school industrial arts programs are not great, and could be even less than they are currently. The implication of this similarity as it relates to curriculum development is that curriculum guides for SDA industrial arts programs could 
be based on material developed by public-school systems or other organizations rather than an entire developmental process by the SDA educational system.

Both chairmen and principals consistently observed a discrepancy between the current and ideal emphasis placed on the purposes of industrial arts. This implies that there are other forces which exert more influence on the nature of industrial arts than do chairmen and principals.

\section{Recommendations}

\section{General Recommendations}

Based on the findings of this study or the observations of the researcher, it is recommenued that:

1. Because industrial arts is perceived as a component of the general education curriculum, and of value to all students regardless of their educational program, it be a required course in all SDA secondary schools.

2. Opportunities be provided for industrial arts teachers to become more involved in professional activities and organizations which will enable them to keep in touch with the latest developments in the area of industrial and technology education.

3. The SDA philoscphy of industrial arts be expanded to accommodate new technologies; specifically that the curriculum be reoriented from a skill-and-project focus to a broad view of technology in the suggested areas of manufacturing, transportation, construction, 
communication and energy utilization and the effects on society. This would enable the area of industrial arts to be re-established as a vital and relevant component of high school general education for all students.

4. Consideration be given to the role of the SDA high school in the provision of vocational education, and as a result, clarification be made regarding that role.

5. Industrial arts teachers be conscious of the need to attract more students into their programs by portraying them as relevant, worthwhile, and up to date, and by appealing to a more representative cross-section of the total student population. This will help solve a number of the problems related to finances.

6. The standards developed and validated in this study be utilized in a regular and systematic way in evaluating and modifying existing industrial arts programs and in guiding the establishment of new industrial arts programs in SDA schools.

7. Seventh-day Adventist industrial arts curriculum guides be based on material developed by publicschool systems or other organizations rather than as a developmental process exclusively by the SDA educational system. This will avoid the duplication of the past that has occured because of minimal differences between SDA and public-school industrial arts programs. 
169

Recommendations for Further Research

Based upon the findings of this study and the observations of the researcher, it is recommended that:

1. The standards developed and validated in this study be updated to reflect current trends in the area of industrial and technology education.

2. This study be utilized as a base with which to compare replications, and to determine trends and changes in the area of SDA industrial arts education.

3. The forces that shape the nature of industrial arts programs in SDA schools be determined through research, and subsequent consideration be given to the desirability of the relationships thereby isolated.

4. The unique Christian bias in the philosophy of SDA industrial arts be studied to determine the imperative consequences on course content of such bias. 
APPENDIX A

SURVEY INSTRUMENTS

(pp. 171-182, inclusive) 


\section{SDA Industrial Arts Standards Project}
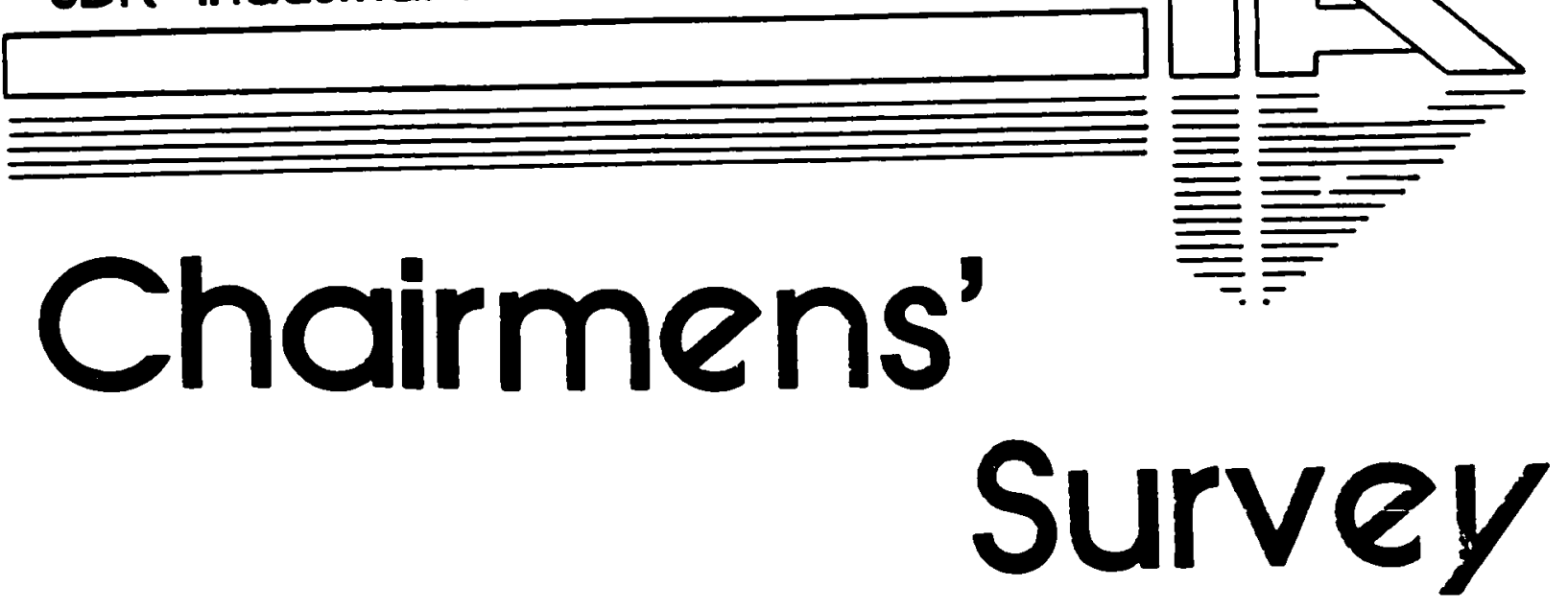

PURPOSE

The purpose of thls survey is to collect data on industrial arts programs in Seventh-day ifventist schools in North Amertca. This data will serve as a basis for the fevelopment of standards for improving and evaluating industrial arts.

\section{OIRECTIONS}

The industrial arts department is asked to complete this form and return it ulthin five(5) days in the enclosed pre-addressed stamped envelope. Answers to raturn some of the questions may require that you check with the other

1

In your opinton industrial arts is most nearly allied with which one of the following programs? (Mark one)

O GENERAL EDUCATIOH

O COLLEGE PREPARATORY EDUCATION

O PREPARATION FOR VOCATIONAL/ TECHNICAL EDUCATION

O VOCATIONAL/TECHMICAL EDUCATION

\section{2} please indicate which of the following represent major barriers to having an outstanding industrial arts program in your school. (Mark as many as apply)

tack of understanding of industrial arts program by Eaculty other than

industrial arts teachers

Lack of understanding of induserial arts program by administrators

Limited supplies and equipment

Lack of relevant content

C Lack of pupil interest

P poor facility. 
3

Mark tige of the folowing that you consider are most important characteristics of an exemplary program in industrial arts?

0 Dedicated and prepared teachers

O Well equipped laboratories nethods

Relevant to industry

0 Occupationaliy or lented

$\bar{O}$ Adequate funds

Written course objectives

Ideas and matertals

0 Low student/teacher ratlo

- Adequate supplies

0 Content related to the Euture use of a varlety of effective teaching

Well counded curriculum

- Incorporation of innovative

Other (please list)

5

Mark one procedure you most often use, and one procedure you think should be used in providing your students with expendable supplies?

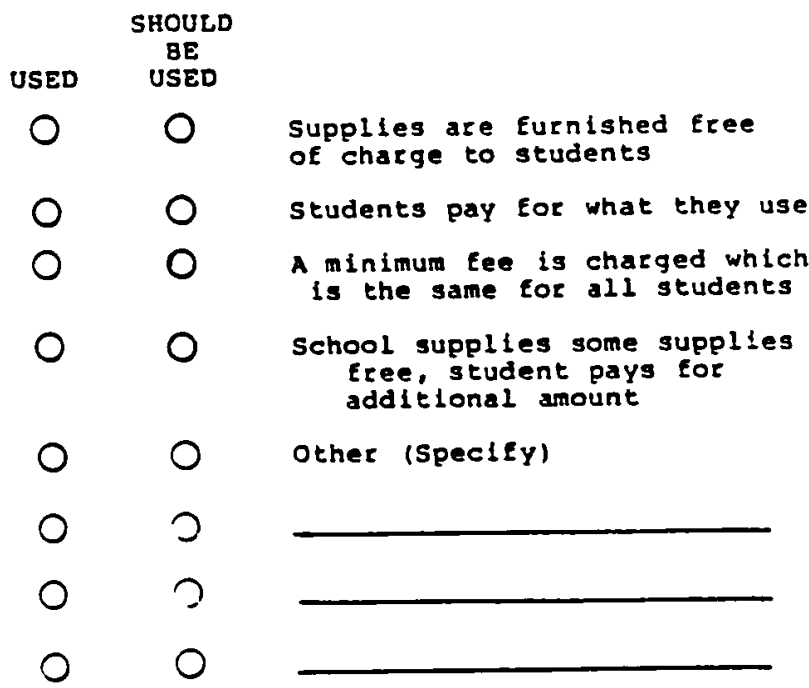

6 Indicate the average amount (over 3 years) spent annualiy for equipment in your industrial departnent lMark in the dollar amount arts department.
starting with the last digit in the far sight
columnl

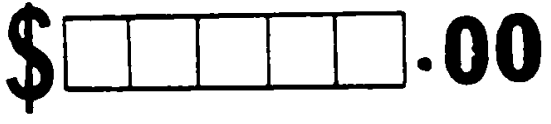

Check as many of the elements jelow that you s.zlnk snouid se included $1 \mathrm{n}$ a statement of stancards for industrlal ares? (Mark as many as apol:?

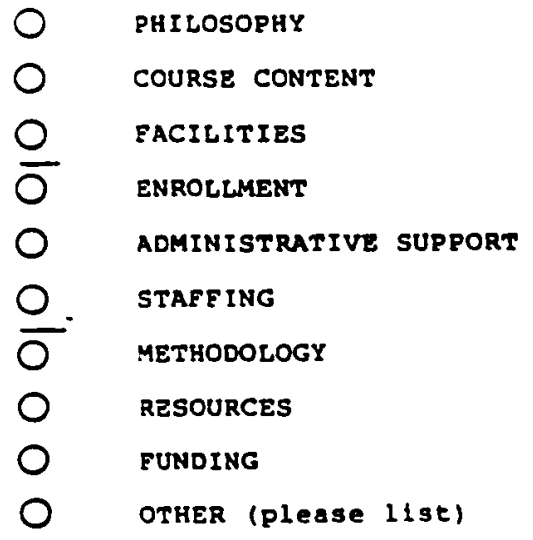

Indicate the average amount (over 3 years) spent annually for supplies annually in your industrial arts department. IMark in the

dollar amourt gtarting with the last digit in the far right column!

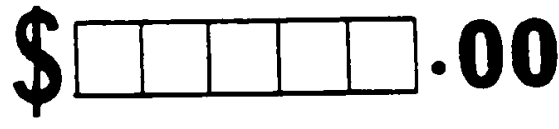

8

is there an industrlal arts advisory comnlttee assoclated with the incusisial arts department?
YES
No

Credit for questions and design ideas for this survey goes to the Standards for Industrial arts Programs. Virginia Polytechnic and State University. 
Please Indlcate the relative degree of emphasis you attach to each of the potential purposes of industrlal arts by darkening one clrcle in the column marked "current" and one circle In the column marked "ideal" Lor each purpose statement.

\section{CURRENT DEGREE OF EMPEASIS}

High Med. Low

○ 0

a. To develop an understanding of our technical eulture.

00 b. To discover and to develop

creative talents in students.

c. To develop an understanding of the application of sceince and. math.

d. To develop in each student a measure of skill in the use of common tools and machines.

e. To provide prevocational expertence of an intensifled nature for

those students

interested in technlcal work.

E. To proulde vocational

training for students who would not otherwise have this opportunity.

9. To proulde genéral allaround technical knowledge and skilis.

h. To develop wor thy lelsure tine interests.

1. To develop consuner knowledge and appreclation and use of

Industrial products.
IDEAL DEGREE OF EMPHASIS High Med. Low

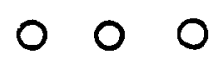
O 00
$k$. To develop an understanding of the nature of technology.

000

000

1. To halp students make informed educatlonal and occupational cholces.

j. To develop problen-solving skills relating to materials and processes.

IDEAL DEGREE OP EMPHASIS

High Med. Low
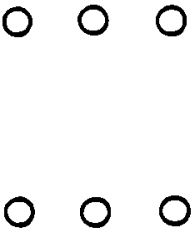

10

In your opinion, what is the greatest strength and weakness of the industrial arts program in your school? (Mark only one Item in each colunn!

STRENGTH

MEAKNESS

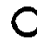

0

Course content

O Facllities

0

Onrollment

0

O Adninistrative support

O

O staffing

0

O Methodology

0

O Resources

0

0 Funding

Other (specify)

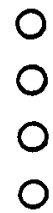

C

0

O

0

11

In your opinion, how would you rate the academle ablilties of those students who take Industrial arts courses in comparison to the general school population?

$\begin{array}{cllll} & \text { TEND } & & \text { TEND } & \\ \text { WELL } & \text { TO BE } & & \text { TO BE } & \text { WELL } \\ \text { BELOW } & \text { BELOW } & \text { SAME } & \text { ABOVE } & \text { ABOVE }\end{array}$




\section{4}

12 Pleage provide information for each of the industrial arts courses taught in your scnool in the spaces provided in the table at the botem of tris page. List tne courses whicn most broadly represent course offerings at your school. Utilize the four digit course codes beiow to laentify the courses.

(Mark as many as apply)

0100 CONSTRUCTION

\section{CRAPTS}

(INDUSTRIAL ARTS)

$\begin{array}{lll}02 & 01 & \text { Art Metals } \\ 02 & 02 & \text { Ceramics } \\ 02 & 03 & \text { Crafts (Industrial) } \\ 02 & 04 & \text { Leather } \\ 02 & 06 & \text { Text1les } \\ 02 & 07 & \text { Jewelry and Lapldary } \\ 02 & 99 & 0 t h e r \text { Industrial erafts }\end{array}$

\section{DRNTING}

0301 Architectural drafting

0302 Descriptive Geometry

0304 Deafting

0305 Drafting Technology

0306 Englneering Drawing

0307 Mechanical Drawing

0308 Technical Illustration

0399 Other Drafting

\section{ELECTRICITY}

0401 Electricity

0402 Electronics

0499 other Electrlelty

0600 GENERAL

INDUSTRIAC ARTS

(Formerly General shop)
GRAPRIC ARTS

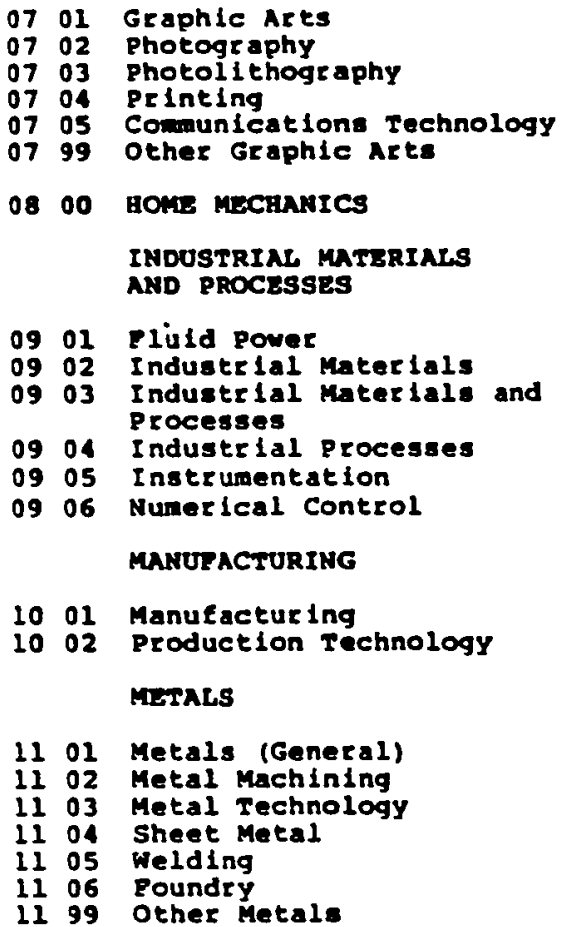

PEASTICS

1201 Plagtics

1202 Plastics Technology

1203 other plastics

\section{POWER/AUTONOTIVE} MEchaisco

1301 Automotive Mechenics

1302 Power Mechantce

1303 Transportation

13 o4 Power/Transportation

1399 Other Mechanlcs

1400 RESEARCa AND DEVELOPMERT

15 OO SERVICB INDUSTRIES WOODS

1601 Woods (General)

1602 Woods Technology

1699 Other Moods

1700 MHERICAN INDUSTRY

1800 EXPLORING TECHMOLOCY

1900 PINISAING matzriLs AND MTSTRODS

9900 OTHER INDUSTRIAL ARTS

\begin{tabular}{|c|c|c|c|c|c|c|}
\hline \multicolumn{4}{|c|}{ GENERAL INYORMATION } & \multicolumn{2}{|c|}{ METHOD } & \multirow{2}{*}{$\begin{array}{c}\text { ENROLLMENT } \\
\text { TOTAL } \\
\text { ENROLMENT } \\
\text { PER SECTION } \\
\end{array}$} \\
\hline COURSE & $\begin{array}{l}\text { COURSE } \\
\text { CODES }\end{array}$ & $\begin{array}{l}\text { OF } \\
\text { SECTIONS } \\
\text { PER YEAR }\end{array}$ & $\begin{array}{l}\text { MAIN } \\
\text { GRADE } \\
\text { LEVEL }\end{array}$ & LECTURE & LAB & \\
\hline 1 & & & & & & \\
\hline 2 & & & & & & \\
\hline 3 & & & & & & \\
\hline 4 & & & & & & \\
\hline 5 & & & & & & \\
\hline 6 & & & & & & \\
\hline 7 & & & & & & \\
\hline 8 & & & & & & \\
\hline 9 & & & & & & \\
\hline
\end{tabular}




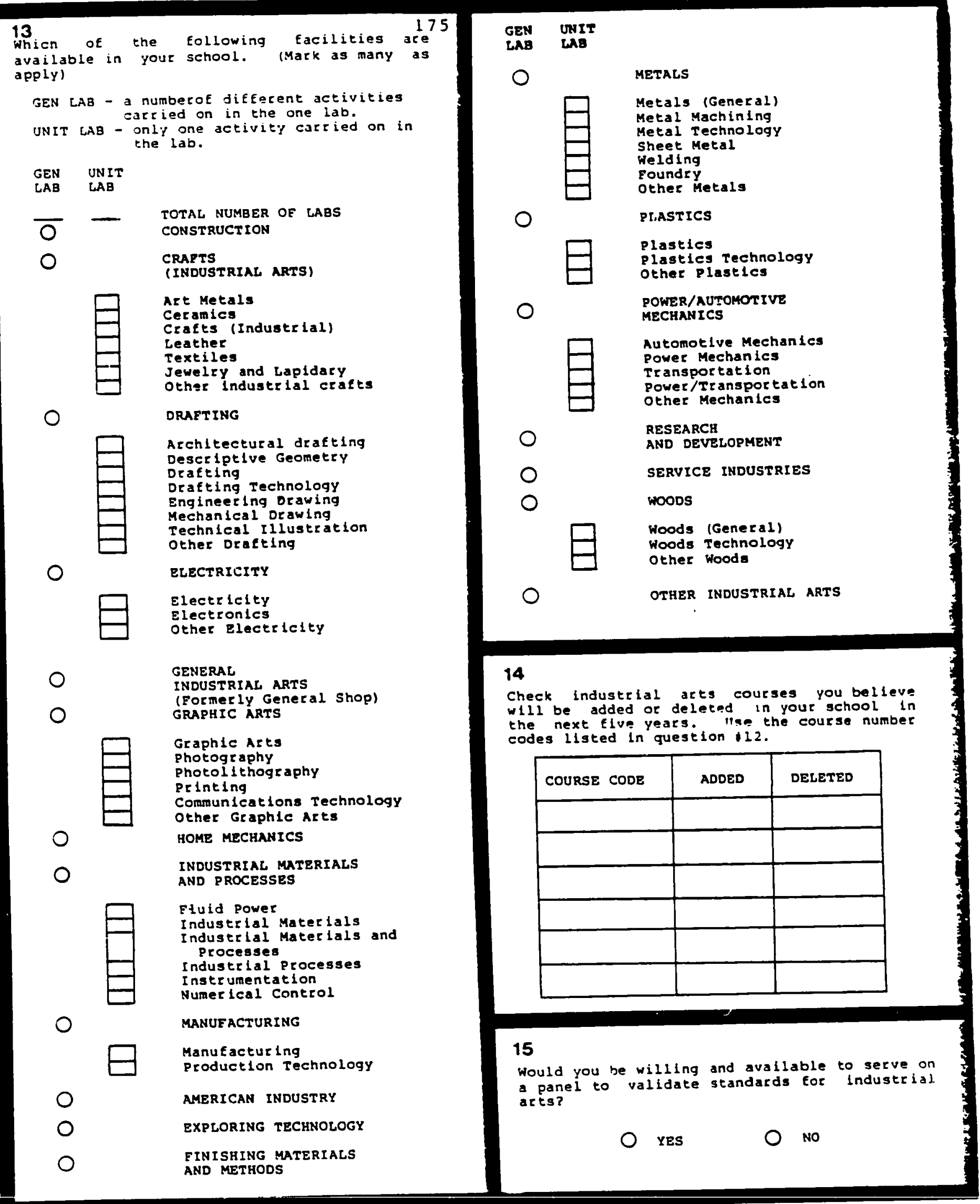


16

What do you think should be the maximum

student/teacher ratio tor Industrial arts laboratory courses?

STUDENTS PER TEACHER

\section{7}

What is the average student/teacher ratio for industrial arts laboratory courses in your department?
20

In your opinion, how do industrlal arts teachers in your school compare in terms of professional involvement with respect to other teachers in the school? (e.g. serve on committees. run for professional office, etc.l

MORE INVOLVED ABOUT THE LESS INVOLVED PROFESSIONALLY SAME RROEESSIONALLY

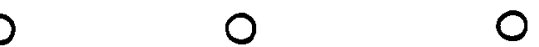

How many total years of teaching experience do you and each of the Industrial arts teachers have, including all of the schools in which experlence has been gained? (Rate yourself as (1)

Please indicate below the type of certification held by each person in your department. (rate yourself as il)

\begin{tabular}{|l|l|l|l|l|}
\hline \multirow{2}{*}{ CERTIFICATION } & \multicolumn{3}{|c|}{ IEACHERS } \\
\cline { 2 - 5 } & 1 & 2 & 3 & 4 \\
\hline $\begin{array}{c}\text { DENOMINATIONAL } \\
\text { Basic }\end{array}$ & & & & \\
\hline Standard & & & & \\
\hline Professlonal & & & & \\
\hline $\begin{array}{c}\text { STATE } \\
\text { Certifled for } \\
\text { Indugtial arts }\end{array}$ & & & & \\
\hline
\end{tabular}

\section{9}

Below, mark the highegt educational degree that you and each of the industrial arts teachers in your department has earned. (Mark one degree for each teacher, yourself as 11

\section{TEACHERS}

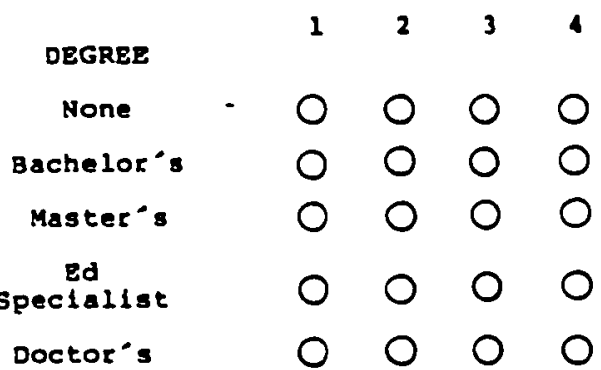

22

Please indicate the professional educational organizations to which you and the teachers in your department belong? (Rate yourselt is teacher (1)

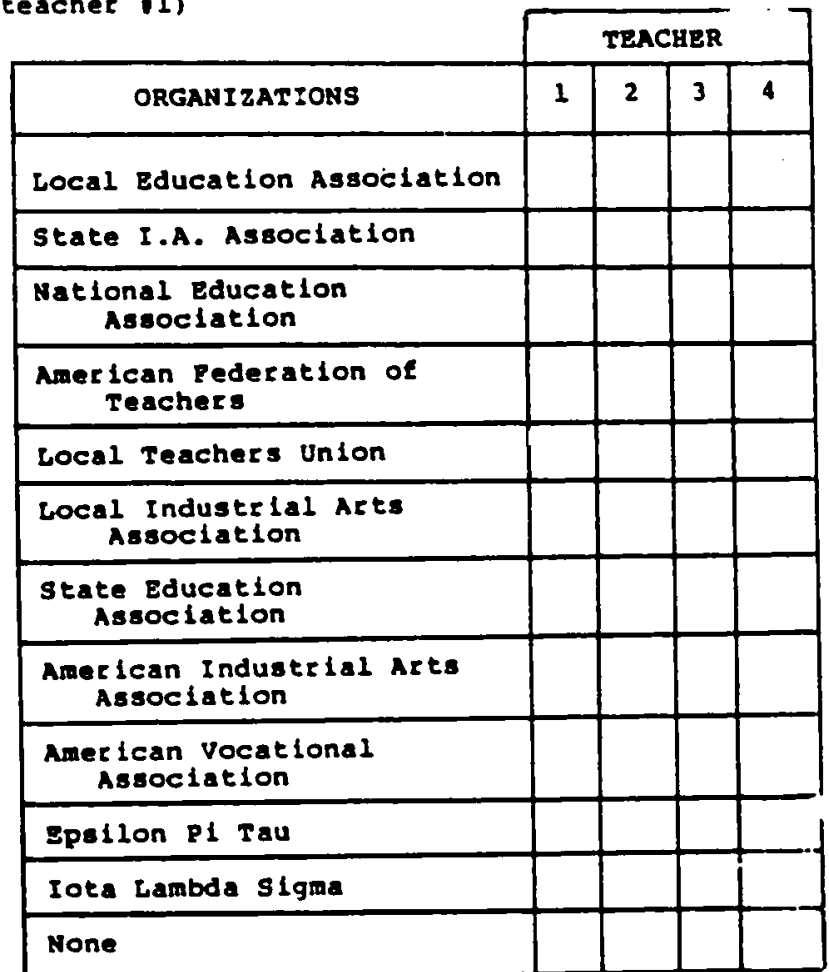




\section{SDA Industrial Arts Standards Project}
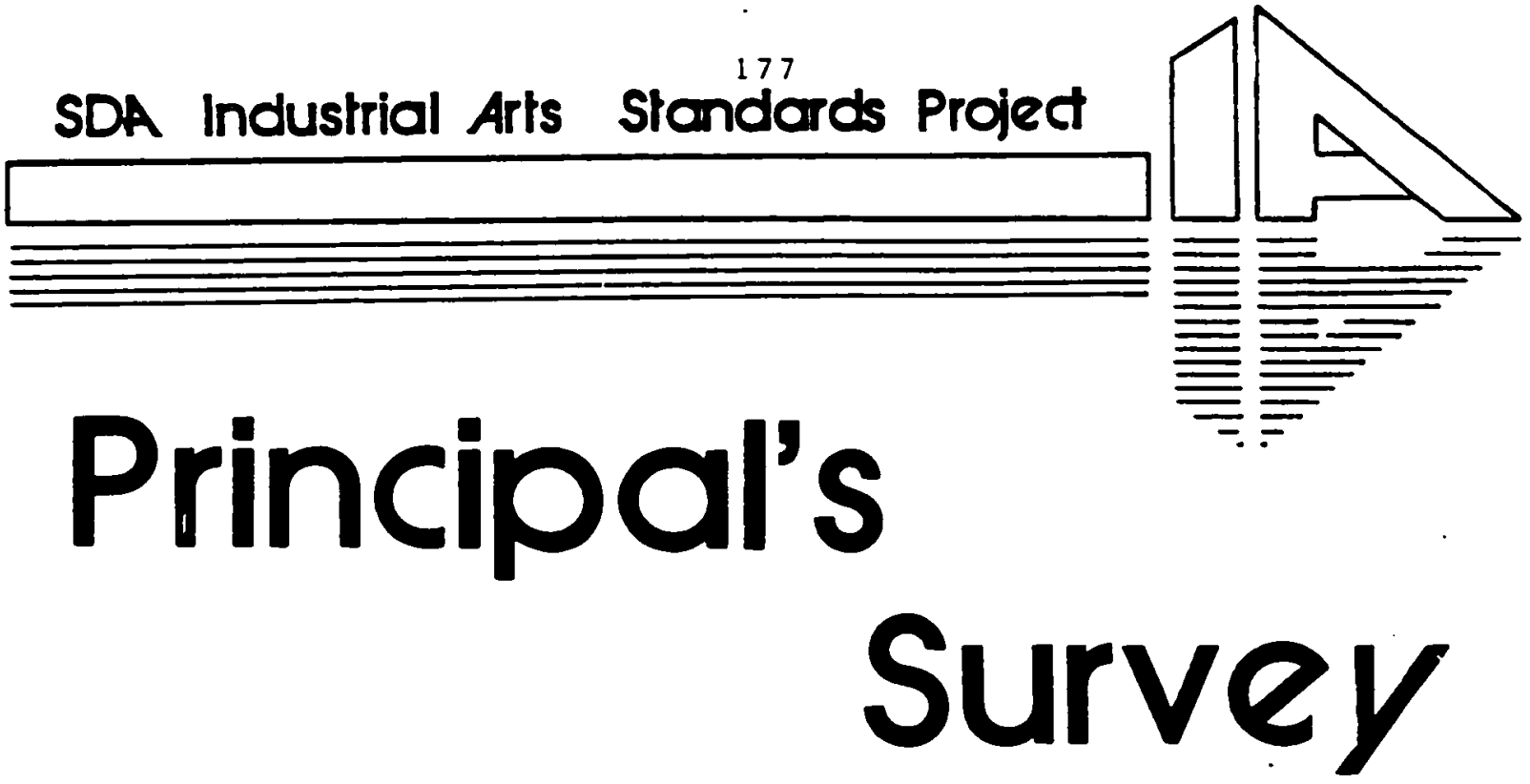

PURPOSE

The purpose of this survey is to collect data on industrial arts programs in seventh-day Adventigt schools in North America. This data will serve as a basis for the development of standards for improving and evaluating industrial arts.

\section{DIRECIONS}

The principal is asked to complete this form and ceturn it within tive (5) days in the pre-addressed postage-paid envelope.

Credit for questions and design ideas for this survey Virginia Polytechnic and State University.

1 in your school? goes to the Standards for Industrial Arts Prograns. How many industrlal arts courses are required
2

In what grade levels are students most likely to take the required courses?

\section{3}

Please indicate the profected total enroliment trends in your achool in the next three years. (Mark one)

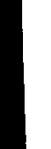

INCREASE

SAME

DECLINE

O

0

O

4 Please indlcate the profected enrollment trends in industrial arts in your school in the next three years. (Mark one)

INCREASE

SAME

DECLINE

$\begin{array}{lllllll}6 & 7 & 8 & 9 & 10 & 11 & 12\end{array}$

$0 \quad 0$

0 
5

In your opinion. Industrial arts is most closely aliled with which of the following programs? (Mark one)

O GENERAL EDUCATION

O COLLEGE PREPARATORY EDUCATION

O PREPARATION FOR VOCATIONAL/TECHNICAL EDUCATION

O VOCATIONAL/TECHNICAL EDUDATION

\section{9}

The majority of students in your school who take industrial arts courses beyond any required. are in which program? (Mark one)

O GENERAL EDUCATION

C COLLEGE PREPARATORY

O PREPARATION FOR VOCATIONAL/TECHNICAL EDUCATION

VOCATIONAL/TECHNICAL EDUCATION

\section{6}

In your opinion, should Industrial arts be required tor all students in your school? (Mark one)

YES $O$ No $O$

7

Please indicate the total encollment, and the number of students enrolled in at least one industrial arts course, by grade level in your school.

\begin{tabular}{|c|c|c|}
\hline Grade & $\begin{array}{c}\text { Total } \\
\text { Students }\end{array}$ & $\begin{array}{c}\text { Ind Arts } \\
\text { Students }\end{array}$ \\
\hline 6 & & \\
\hline 7 & & \\
\hline 8 & & \\
\hline 9 & & \\
\hline 10 & & \\
\hline 11 & & \\
\hline 12 & & \\
\hline
\end{tabular}

\section{8}

How would you cate the academic abilities of i:hose students who take industrial arts courses in comparison to the general population in your school? (Mark one)

$\begin{array}{rrrl}\text { WELL TEND TO BE } & \text { TEND TO BE WELL } \\ \text { BELOW } & \text { ABOVE }\end{array}$
BELON

SAME
11

Mack five of the folowing that you consider are most important characteristics of an exemplary progran in industrial arts?

0 Dedicated and prepared teachers

O Well equipped laboratorlee

Use of a varlety of effective teaching methods

Well rounded curgiculum

O Relevant to Induntry

O Occupationally ortented

Adequate cunds

0 Written course objectives

O Incorporation of innovative ldeas and mater lals

Low student/teacher ratio

Adequate supplies

Content related to the future other (please $118 t$ ) 
12

please indicate any industrial arts courses taught in your school that receive or have received funds from government, industry or individuals. (See list and mark as many as applyl

INDUSTRIAL ARTS COURSES

179

$I$
$N$
$D$
$I$
$V$
$I$
$D$
$U$
A
I
14

Indicate the average number of classes (indluding lab) per week that the industrial arts courses meet in your school.

\section{CLASSES PER WEER}

15

Indicate the average number of minutes per class that the Industrial arts courses meet in your school.

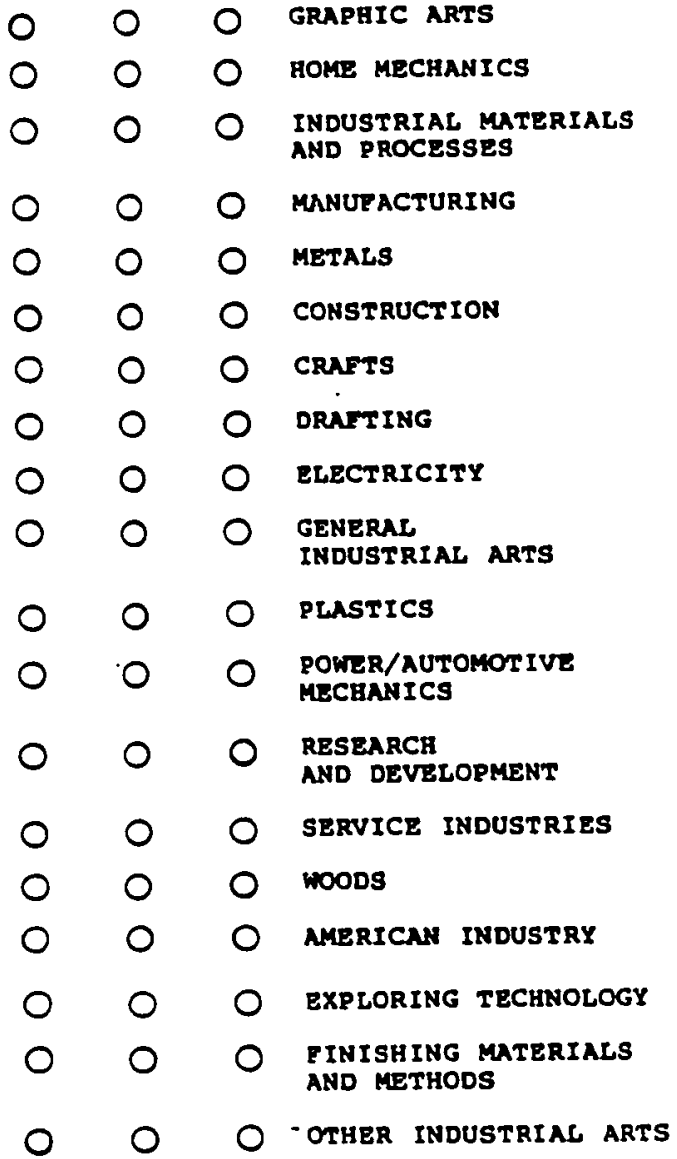

16

For which of the foliowing actlulties do the industrial arts teachers in your school recelve supplemental pay? (Mack as many as are appropilatel

O ATHLETIC CONTESTS

O INDUSTRIAL ARTS CLUB

O sCHOOL CLUB ADVISOR

O SUPERVISION OF SCHOOL GROUNDS

O FIELD TRIPS

O STUDENT COUNCIL ADVISOR

Y YEAR BOOK ADVISOR

STUDY SUPERVISION

C cuss aDVIsor

SCHOOL ASSEMBLIES

O MAINTENANCE

O Bus DUTY

O NONE
17

How many Industrial arts teachers do you have in your school?
13

How many of your industrlal arts teachers have the following types of teaching contracts? (Ligt the chaliman of the depaltment as (1)

\begin{tabular}{|l|l|l|l|l|}
\hline \multirow{2}{*}{ CONTRACT } & \multicolumn{4}{|c|}{ TEACHER } \\
\cline { 2 - 5 } & 1 & 2 & 3 & 4 \\
\hline 10 MONTH & & & & \\
\hline 12 MONTH & & & & \\
\hline
\end{tabular}

TORAL I. A. EACULTY

18

please indicate the number of full time professional faculty employed in your school. TORAL FACULTY 
19

Please indicate the relative degree of emphasis you attach to each of the potential purposes of industrial arts by darkenting one circle in the column marked "current" and one circle in the column marked "ideal" for each purpose statement.

$\begin{array}{cc}\text { CURRENT } & \text { PURPOSES } \\ \text { DEGREE OF } & \text { OF } \\ \text { EMPHASIS } & \text { INDUSTRIAL } \\ & \text { ARTS }\end{array}$

Bigh Med. Low

000

00

000

○ 0

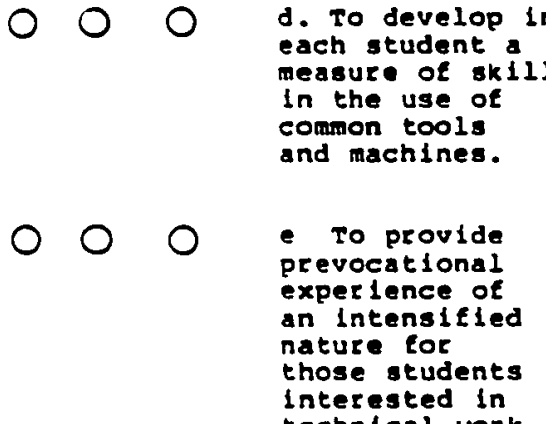

technical work.

$\bigcirc \bigcirc \bigcirc$

E. To provlde

vocational

training for

students who

would not other-

wise have this

oppor tunity.

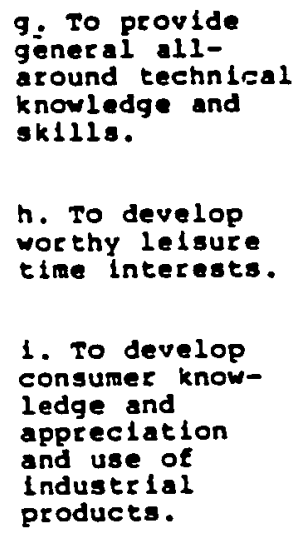

9. To provide general allaround technleal knowledge and sk111s.

000

h. To develop worthy lelsure

1. To develop consumer knowledge and appreclation

products.

DEGREE OE
CURRENT

DEGREE OE

EMPHASIS

High Med. Low

PURPOSES
OR
INDUSTRIAL
ARTS

j. To develop problem-solving sklils relating to mater lals and processes. EMPHASIS

High Med. Low

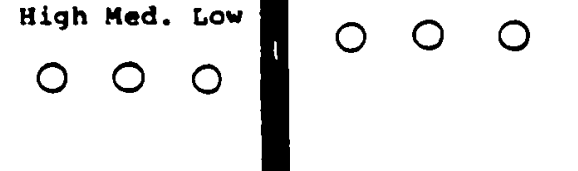

k. To develop

an understanding

of the nature

and character 1 stics

of technology.

1. To help

students

make informed

educational and

and occupational

cholces.
IDEAL

DEGREE OF

EMPHASIS

Hlgh Med. Low
20

check as many of the elements below that you think should be included in a statement of standards for industrial arts? (Mark as many as applyl

$\begin{array}{ll}0 & \text { PHILOSOPHY } \\ 0 & \text { COURSE CONTENT } \\ 0 & \text { FACILITIES } \\ 0 & \text { ENROLLMENT } \\ 0 & \text { ADMINISTRATIVE SUPPORT } \\ 0 & \text { STAYTING } \\ 0 & \text { METHODOLOGY } \\ 0 & \text { RPSOURCES } \\ 0 & \text { FUNDING } \\ 0 & \text { OTHER (Please 11st) }\end{array}$

\section{1}

Would you be willing and avallable to serve $c$ a panel to validate standards for Industrial arts?
YES
0 no 


\section{SDA Industrial Arts Standards Project}
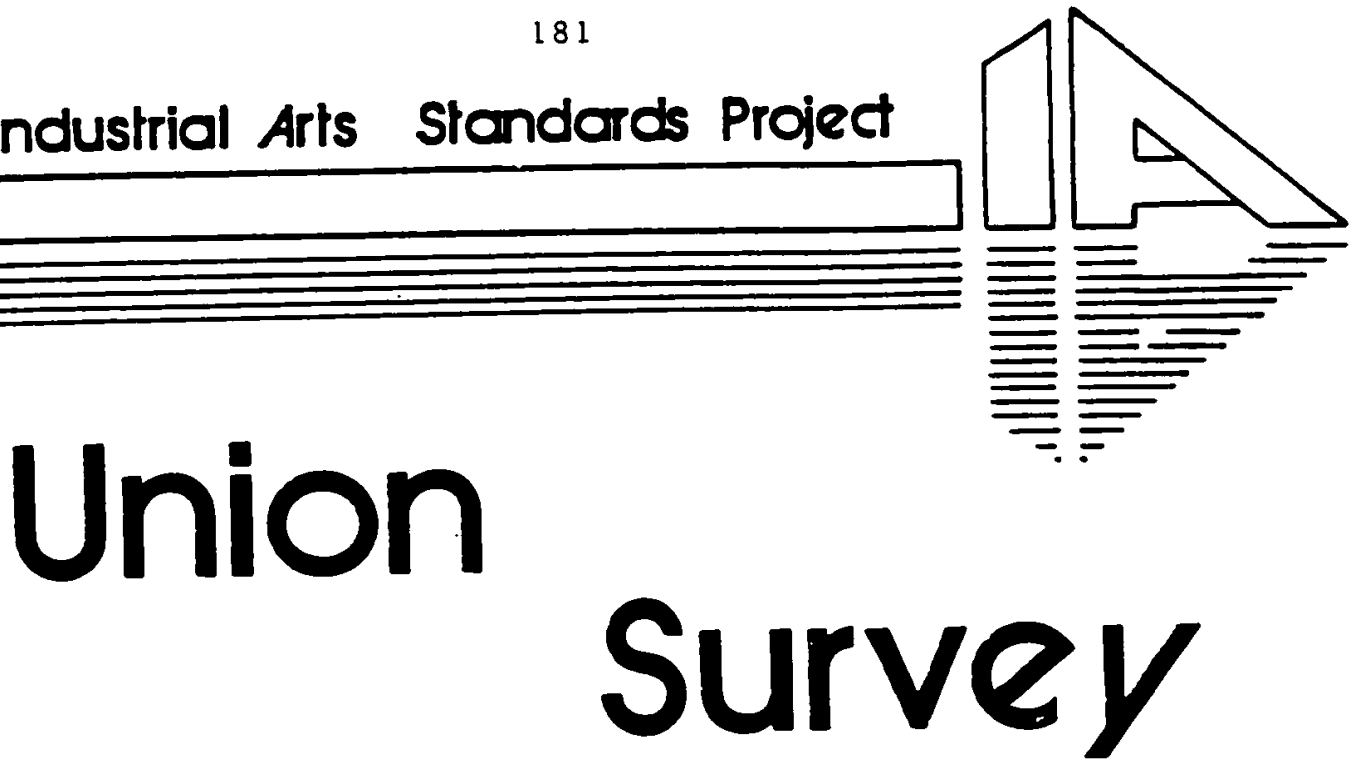

PURPOSE

The purpose of this suryey is to collect data on induserial arts programs in seventh-day this data wil serve as a basis for the development of seandards for lmproving and evaluating industrial arts.

\section{DIRECIIONS} The union education office is asked to complete this form and return it within tive(5) days in the pre-addressed postage-paid envelope pur pour best estimate based on the latest information available to you.

1
Uow many secondary schools are there in your
union?
SECONDARY scroors

Credte for questions and design ideas for this survey goes to the Standards for Industrial Arts Programs. Virginia Polytechnic and State University.

2

How many secendary schools in your unton offer Industrial arts courses?

SECONDARY SCHOOLS
4

Has your union developed a master plan for the scope and sequence of Industrial arte courser?
Y YES
0 No

\section{5}

Has your union developed an Industrial arts cure lculum guide?
YES
No 
6

Does the union have regular and systematic evaluations of industrial arts?
O YES
ก No

7

Does your unton have spectelc certiflcation requirements for industrial arts teachers beyond that required for other reachers?

$$
\text { Y YES } O \text { No }
$$

8

Check as many of the elements below that you think should be included in a statement of standards for industrial arts? (Mark as many as apply)

$\begin{array}{ll}0 & \text { PHILOSOPHY } \\ 0 & \text { COURSE CONIENT } \\ 0 & \text { FACILITIES } \\ 0 & \text { ENROLLMENT } \\ 0 & \text { ADMINISTRATIVE SUPPORT } \\ 0 & \text { STAFFING } \\ 0 & \text { METHODOLOGY } \\ 0 & \text { RESOURCES } \\ 0 & \text { EUNDING } \\ & \text { OTHER (PleASE 11St) }\end{array}$

Mark five of the folowing that you consider dee most lmportant chatacteristics of af exemplary program in industrial arts?

0 Dedicated and prepared teachers

0 well equipped laboratorles

0 Use of a var lety of effective teaching methods

O Well rounded curriculum

Relevant to Industry

O Occupationally or lented

0 Adequate Eunds

O Written course objectives

0 Incorporation of innovative

tdeas and mater lals

Low student/teacher ratlo

O Adequate supplies

O Content related to the futura

other (please 1lst)

10

Would you be willing and avallable to serve on Would you be walldate standards for Industrial arts?

YES $O$ no 
APPENDIX B

BUSINESS REPLY MAII ENVELOPE

Reproduced with permission of the copyright owner. Further reproduction prohibited without permission. 


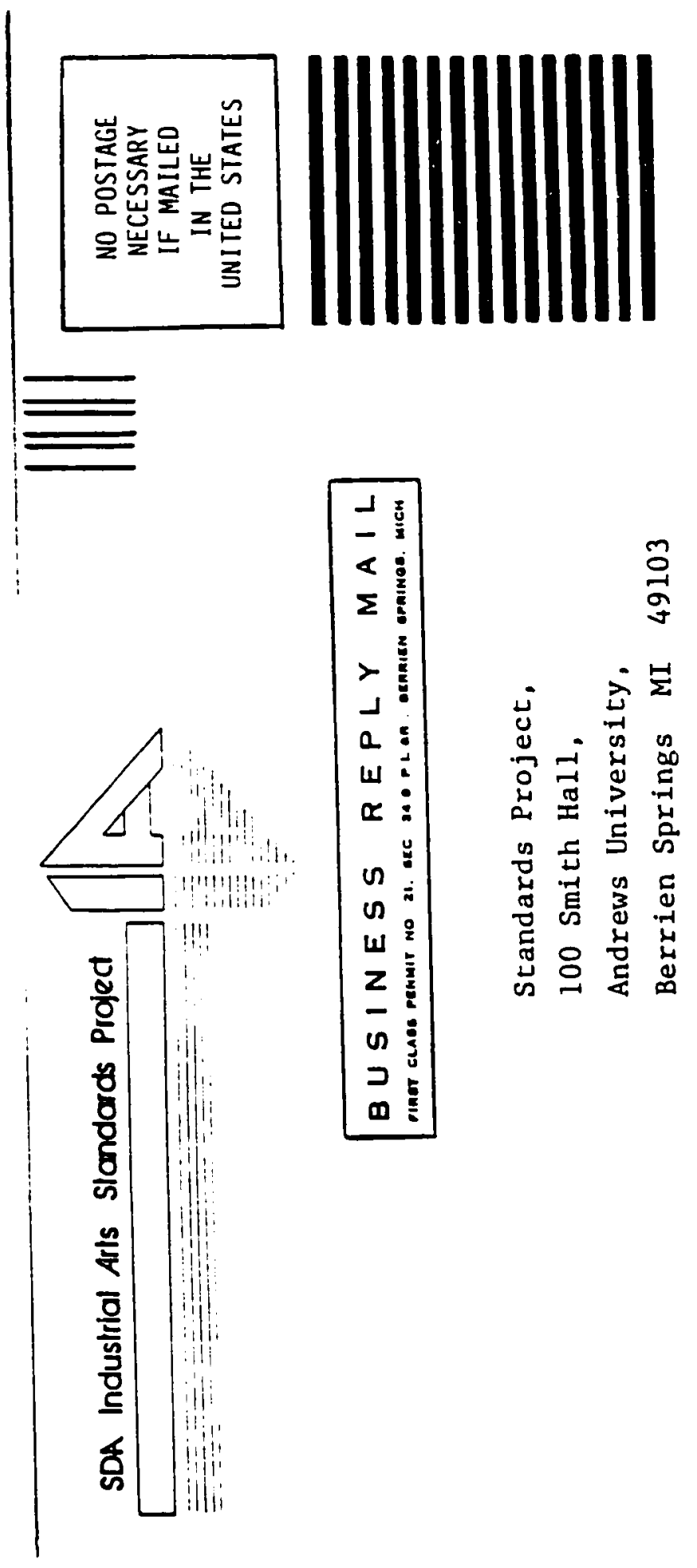


APPENDIX C

INITIAL MAIL-OUT COVER IETTER

Reproduced with permission of the copyright owner. Further reproduction prohibited without permission. 


\section{SDA Industrial Arts Standards Project}

Standards Project, 100 Smith Hall, Andrews University,

Berrien Springs, MI 49104

April 1, 1984

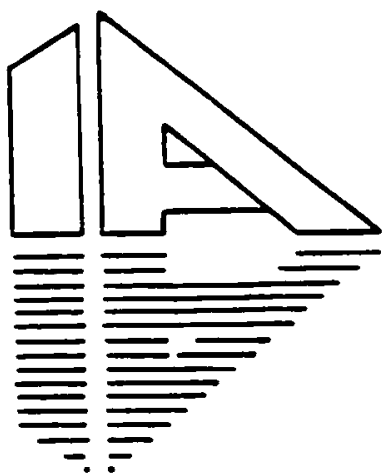

Alan Anderson

Ind. Arts

Andrews Academy

BERRIEN SPGS, MI 49104

Dear Alan Anderson,

planning for industrial arts takes place at all levels of the educational structure, and all planning eventually impacts on the school situation. However many of the people who do the planning do not have a knowledge of what the situation is at the school level.

You are one of the teachers selected to contribute to this national project on industrial arts by providing data on your department. In order for the results to truely represent the situation in the United States, it is important that each questionnaire be completed and returned. Union educational directors and principals are also requested to participate in this project.

You may be assured of complete confidentiality. The questionnaire is identified for mailing purposes only. This is so that your name can be checked off the mailing list when your questionnaire is returned.

The North American Division Office of Education which, in 1985, will be revising the industrial arts curriculum guide, has expressed interest in the results of this project. It will be made available to them, and to any interested person or group. You may receive a sumnary of the results by writing "copy of results requested" together with your name and address on the back of the return envelope.

I would be most happy to answer any questions you might have. please write or call. The telephone number is (616) 4713450 .

Thank you for your assistance.

sincerely,

P. John Williams.

Project Director. 
APPENDIX D

POST CARD REMINDER 


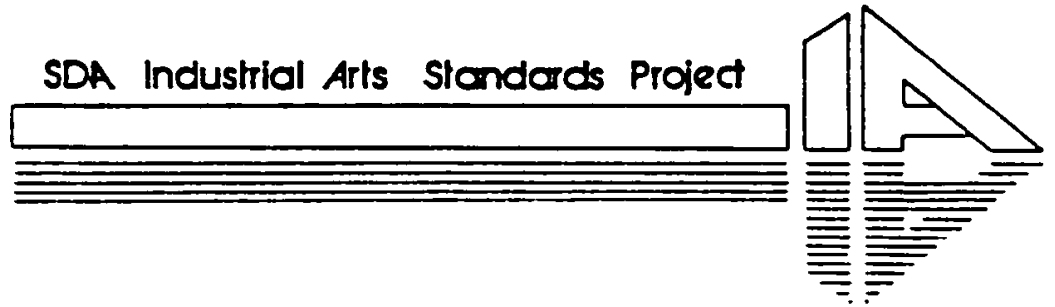

April 12, 1984

Thank you for participating in the standards for Industrial Arts Project. Last week a questionnaire seeking some details related to industrial arts was mailed to you. If you have already completed and returned it please accept our sincere thanks. If not, please do so today. It is extremely important that yours be included in the study if the results are to accurately represent the industrial arts situation in our schools today.

If by some chance you did not receive the questionnaire, or it got misplaced, please call me right now, collect $\left(\begin{array}{lll}616 & 471 & 3450\end{array}\right)$ and I will send another immediately.

Sincerely,

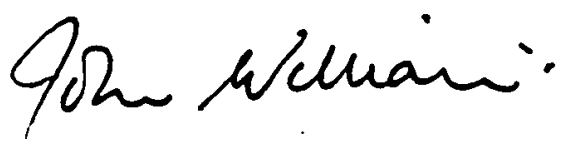

P. John Williams

Project Director 


\section{APPENDIX E}

\section{SECOND COVER LETTER}

Reproduced with permission of the copyright owner. Further reproduction prohibited without permission. 


\section{SDA Industrial Arts Standards Project}

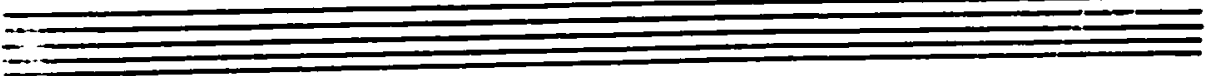

gdards Project, 100 Smith Hall, Andrews University,

- Trien Springs, MI 49104

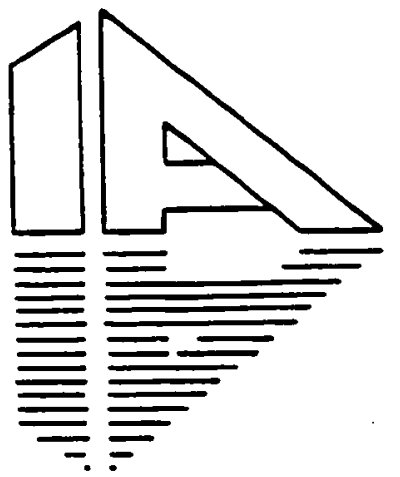

April 27, 1984

$\therefore$ lan Andersor.

1.nd. Arts

Andrews Academy

:RFRRIEN SPGS, MI 49104

tar Alan Anderson,

About four weeks ago I wrote to you seeking your input on latters related to your industrial arts department. As of today we have not received your completed questionnaire.

This projert has been undertaken in the belief that a valid base - it empirical data is necessary for effective planning, policy

ormation, evaluation, and guidance.

$i$ am writing to you again because of the significance each questionnaire has to the usefulness of this study. In order for the results to be truly representative of the industrial arts $\therefore$ ituation in the onited states, it is essential that each person ceturn their questionnaire.

j.r. the event that your questionnaire has been misplaced, a i. eplacement is enclosed.

your cooperation is greatly appreciated.

Cordially,

P. John Williams.

Project Director. 


\section{APPENDIX F}

THIRD COVER LETTER

Reproduced with permission of the copyright owner. Further reproduction prohibited without permission. 


\section{SDA Industrial Arts Standards Project}

Standards Project, $100 \mathrm{Smith}$ Hall, Andrews University,

Berrien Springs, MI 49104

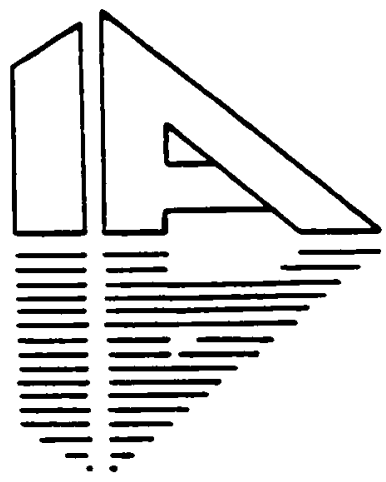

May 15,1984

Alan Anderson

T.nd.Arts

Andrews Academy

BERRIEN SPGS, MI 49104

Dear Alan Anderson,

I am writing to you about our study of Industrial Arts. We have not yet received your completed questionnaire.

The large number of questionnaires returned is very encouraging. But whether we will be able to describe accurately the industrial arts situation throughout the nation depends on the response from Andrews Academy.

rhis is the first nation wide study of this type that has ever been done. Therefore the results are of particular importance to those planners and policy makers who determine how best to meet the needs of those involved in industrial arts. The usefulness of the results depends on how accurately we are able to describe the nature of industrial arts.

It is for these reasons that I am sending another reminder. In case our other correspondence did not reach you, a replacement questionnaire is enclosed. May I urge you to complete and return it as soon as possible.

I'll be happy to send you a copy of the results if you want one. simply put your name, address and "copy of results requested" on the back of the return envelope. We expect to have them ready to send out within a few months.

Your contribution to the success of this study will be appreciated greatly.

Most sincerely, 
APPENDIX G

FOURTH COVER LETTERS 


\section{SDA Industrial Arts Siandards Project}

Standards Project, $100 \mathrm{Smith} \mathrm{Hall,} \mathrm{Andrews} \mathrm{University,}$

Berrien Springs, MI 49104

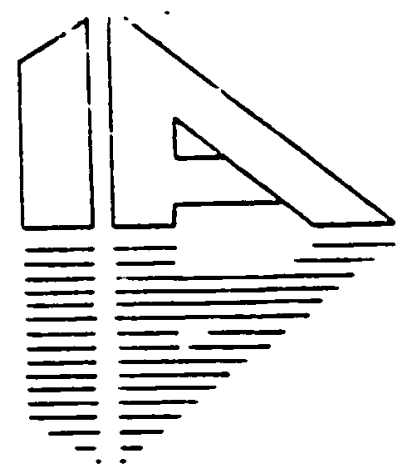

May 21,1984

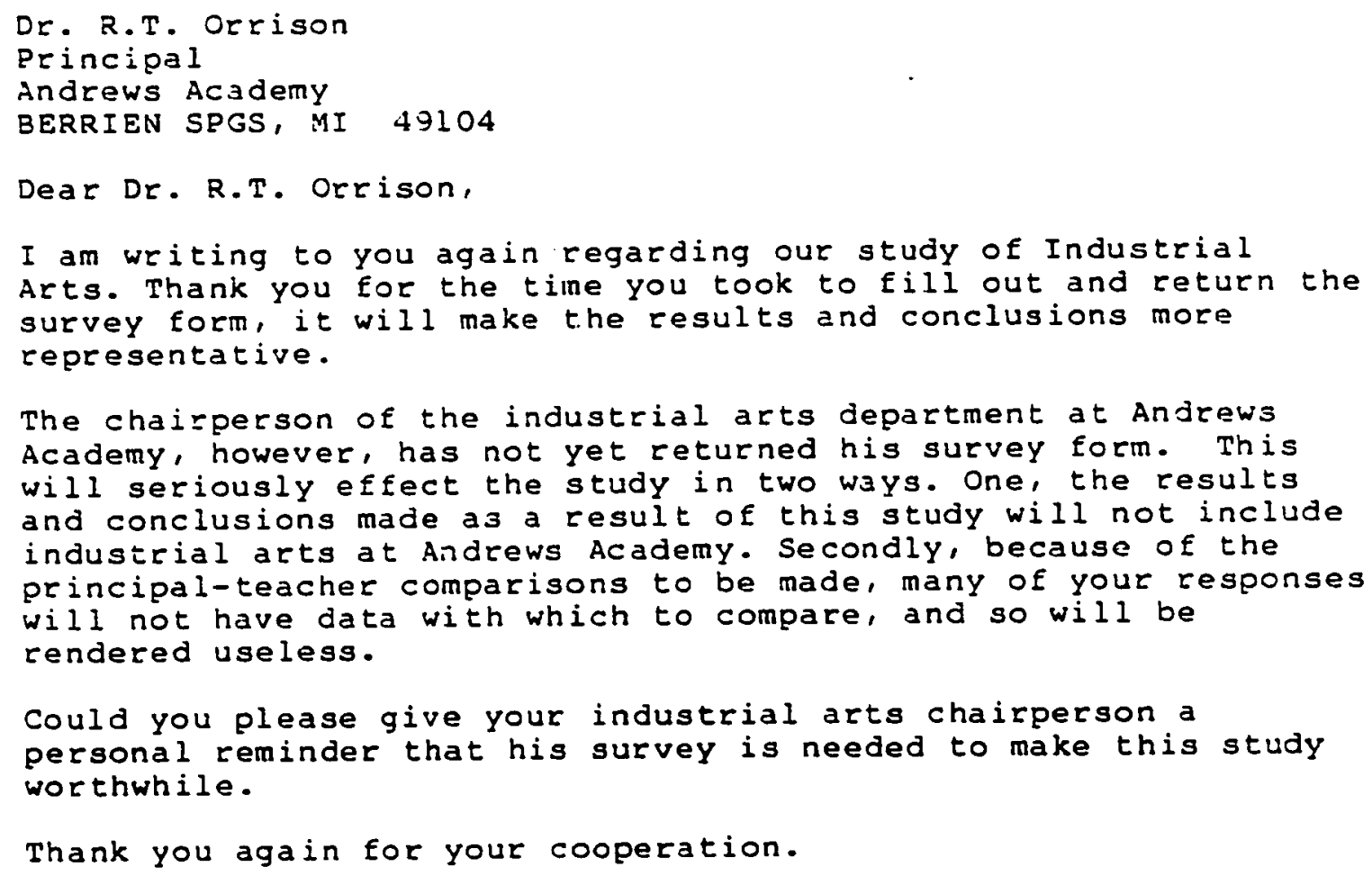




\section{SDA Industrial Arts Standards Project}

jrandards Project, 100 Smith hall, Andrews University,

rerrien Springs, MI 49104

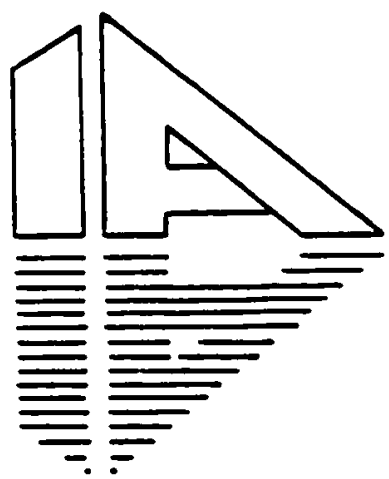

MaY 21, 1984

Alan Anderson

Ind. Arts

Andrews Academy

HERRIEN SPGS, MI 49104

Dear Alan Anderson,

[ am writing to you again regarding our study of Industrial Arts. Thank you for the time you took to fill out and return the survey form, it will make the results and conclusions more representative.

The principal at Andrews Academy, however, has not yet returned ils survey form. This will seriously effect the study in two ways. One, the results and conclusions made as a result of this study wili not include Andrews Academy. Secondly, because of the principal-teacher comparisons to be made, many of your responses will not have data with which to compare, and so will be rendered useless.

Could you please give your principal a personal reminder that his survey is needed to make this study worthwhile.

Thank you again for your cooperation.

Most sincerely,

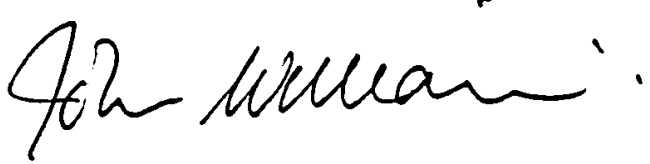

P. John Williams.

Project Director. 
APPENDIX H

\section{STANDARDS FOR RATING}

(pp. 197-228, inclusive) 
SDA INDUSTRIAL ARTS STANDARDS PROJECT

\author{
STANDARDS FOR INDUSTRIAI ARTS
}

\author{
P. JOHN WIILIAMS
}


STANDARD 10 EVALUATION

10.1 Establishing an Evaluation System . . . . . . 30

10.2 Collecting and Analysing Data... . . . . . . 30

10.3 Reporting.................... . 31

10.4 Decision Making . . . . . . . . . . . . . . 31 
STANDARDS FOR INDUSTRIAL ARTS

DIRECTIONS FOR RATING

Please read each statement carefully and decide which statements are important as standards for Industrial Arts Programs in Seventh-day Adventist secondary schools in North America. Respond to each statement according to the following scale criteria :

5 -- indicates that this standard is very important

4 -- Indicates that this standard is important

3 -- indicates that this standard is of uncertain importance

2 -- indicates that this standard is unimportant

1 -- indicates that this standard is very unimportant

Circle the appropriate number. 


\section{STANDARD 1 PHIIOSOPHY}

The statements contained within this standard topic concern the philosophy of an industrial arts program. A philosophy is a statement of fundamental beliefs which reflect a value system. It serves as a foundation and framework for elements of a program.

\subsection{DEVELORMENT}

A philosophical statement for including industrial arts as an integral part of the school curriculum is developed.

1. The philosophical statement is developed as a joint effort of a number of contributors.

$\begin{array}{llllll}1 & 2 & 3 & 4 & 5 & a\end{array}$. Industrial arts teachers are involved in developing the philosophical statement.

$123 \quad 345$

b. Administrators and supervisory personnel responsible for industrial arts programs are involved in developing the philosophical statement.

12345 c. Students are involved in developing the philosophical statement.

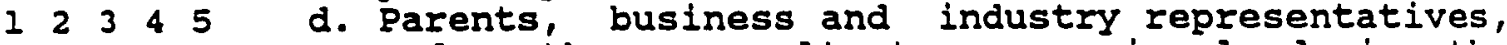
and other consultants are involved in the development of the philosophical statement.

$\begin{array}{llllll}1 & 2 & 3 & 4 & 2 & 2\end{array}$. The philosophical statement is consistent with Seventh-day Adventist philosophies of industrial arts, and local, state, and national philosophies when not in conflict.

$\begin{array}{llllll}1 & 2 & 3 & 4 & 5 & 3\end{array}$. The philosophy identifies the Christian virtues that the industrial arts program encourages students to exhibit.

4. The philosophical statement supports the existence of the program.

12345 a. The philosophy describes the industrial and technological nature of society in the past, present, and future.

1223045

b. The philosophy identifies the needs, abilities, and interests of all learners, regardless of race, sex, creed, national origin, or handicapping conditions. 
5 -- very important

1 -- very unimportant

$\begin{array}{llllll}1 & 2 & 3 & 4 & 5 & c \text {. The philosophy addresses the value of industrial }\end{array}$ arts including industrial and technological literacy; career orientation, exploration, and preparation; avocational activities; economic concepts; consumer skills; and manipulative skills; physical, mental, spiritual and social growth; and problem solving skills.

$\begin{array}{llllll}2 & 3 & 4 & 5 & d\end{array}$. The philosophy encourages development of personal and leadership skills.

$\begin{array}{llllll}2 & 2 & 4 & 5 & \text { e. The philosophy focuses upon the broad categories }\end{array}$ of communication, construction, manufacturing, and transportation.

$\begin{array}{llllll}1 & 2 & 3 & 4 & 5 & 5\end{array}$. The philosophical statement is written and on file.

$\begin{array}{llllll}1 & 2 & 3 & 4 & 5 & 6\end{array}$. The philosophy is based on the Bible as the revelation of the truth about God.

\subsection{UTILIZATION}

12345 1. The philosophical statement is a basis for program planning.

12345

2. The philosophical statement is a basis for program development.

$\begin{array}{llllll}1 & 2 & 4 & 5 & 3 & 3\end{array}$. The philosophical statement is a basis for program implementation.

12345 4. The philosophical statement is a basis for program research and evaluation.

\subsection{REVIEW AND REVISE}

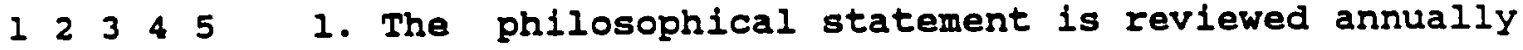
and revised on the basis of the annual review. 
5 -- very important

1 -- very unimportant

\section{STANDARD 2 INSTRUCTIONAL PROGRAM}

The statements contained within this standard topic concern the instructional program. This program, which reflects the stated philosophy, provides a wide variety of organized experiences for all students. These experiences assist learners in reaching predetermined goals.

\subsection{GOALS}

Program goals are established from the stated philosophy to provide direction for program development, implementation, and evaluation.

1. The program goals encompass the major purposes of industrial arts.

12345 a. Emphasis is placed upon assisting students in developing insight and understanding of our industrial and technological society.

12345 b. Emphasis is placed upon improving student ability to make informed and meaningful occupational choices.

12345

c. Emphasis is placed upon developing student character and integrity by encouraging the internalization of a set of personal Christian values.

$\begin{array}{lllll}1 & 2 & 3 & 4 & 5\end{array}$

d. Emphasis is placed upon developing individual student talents, creative abilities, positive self- concepts and potentials generaliy and in relation to industrial-technical areas.

12345

e. Emphasis is placed upon developing abilities in the safe and proper use of tools, materials, machines, and processes.

12345

f. Emphasis is placed upon developing student problem-solving and decision-making abilities invol ving industrial materials, processes, and products.

$\begin{array}{lllll}1 & 2 & 3 & 4 & 5\end{array}$

g. Emphasis is placed upon reinforcing the basic skills and interrelating the content of industrial arts with other school subjects.

$\begin{array}{lllll}1 & 2 & 3 & 4 & 5\end{array}$

h. Emphasis is placed upon developing leadership ability, encouraging and promoting positive social interaction and a sense of social and Christian responsibility. 
5 -- very important

1 -- very unimportant

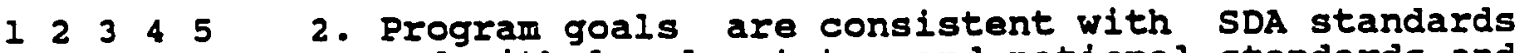
and with local, state, and national standards and emerging developments in the field when not in confilct.

123345

3. Program goals are developed with input from teachers, administrators, students, representatives from business and industry, constituents, and other consultants.

$\begin{array}{llllll}1 & 2 & 3 & 4 & 5 & 4\end{array}$. Program goals are developed from research, evaluation and follow-up studies.

1223045

5. Program goals are written and are on file.

$123 \quad 3 \quad 45$

6. Program goals are utilized by teachers and administrators for planning, implementing, and evaluating courses.

$\begin{array}{lllll}1 & 2 & 3 & 4 & 5\end{array}$

7. Program goals are reviewed annually and revised when necessary.

\subsection{OBJECTIVES}

Objectives which reflect program goals are utilized in each course.

1. Course objectives, written in measurable terms, are presented to students and are kept on file.

12345

1223045

a. Course objectives are utilized by teachers and administrators for planning, implementing, and evaluating course content and instructional methods.

b. Course objectives are known and understood by students prior to entry to the instructional program.

12345 2. Course objectives are reviewed annually and revised when necessary.

\subsection{CONTENT}

course content reflects the intent of the course objectives.

$12345 \quad 1$. Course content is offered in the broad categories 
5 -- very important

1 -- very unimportant

$\begin{array}{llllll}1 & 2 & 3 & 4 & 5 & 2\end{array}$. Course content is developed from course objectives and utilizes approved curriculum guides, courses of study and other professional resources.

12345 3. Course content is selected which provides instruction for all students based on the goals and objectives of the program.

I 23445 4. Course content includes the development of personal and leadership skills.

12345 5. Courses in the industrial arts program are sequential beginning with broad orientation and exploration of subject matter areas, followed by specialized experiences.

12345 6. Course content represents the state of the art in industry and technology.

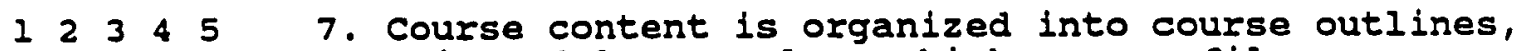
unit and lesson plans which are on file.

$\begin{array}{llllll}1 & 2 & 3 & 4 & 5 & 8\end{array}$. An accurate description for each course is available to all students prior to enrollment.

12345 9. Course content is reviewed annually and revised when necessary.

\subsection{SCHEDULING}

Industrial arts courses are of sufficient duration to achleve stated program objectives.

$\begin{array}{llllll}1 & 2 & 3 & 4 & 5 & 1\end{array}$. Industrial arts is offered for a minimum of 18 weeks, 255 minutes per week at each grade level of the junior high/high school.

$\begin{array}{llllll}1 & 2 & 3 & 4 & 2 & 2\end{array}$. Students are encouraged to enroll in courses from more than one content category during their total industrial arts experience. 
5 -- very important

1 -- very unimportant

\section{STANDARD 3 - STUDENT POPUIATIONS SERVED}

The statements contained within this standard topic concern the student populations served. The industrial arts program may serve all persons, pre-school through adult. Accomodations in the program are made for students with special needs.

\subsection{INDIVIDUAL DIFFERENCES}

All students, regardless of their abilities and needs, are served by the industrial arts program.

$\begin{array}{llllll}1 & 2 & 3 & 4 & 5 & 1\end{array}$. All students are provided a variety of effective and meaningful learning experiences commensurate with industrial arts program goals and course objectives.

$\begin{array}{lllll}1 & 2 & 3 & 4 & 5\end{array}$

2. Students who are academically and/or economically disadvantaged are provided special services, and assistance as required, to enable them to succeed in the industrial arts program.

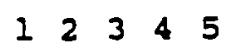

3. Students who have physical, mental, and/or emotional impairments are provided special services and assistance as required, to enable them to succeed in the industrial arts program.

1223445

4. Students identified as gifted and/or talented are provided learning activities consistent with their abilities.

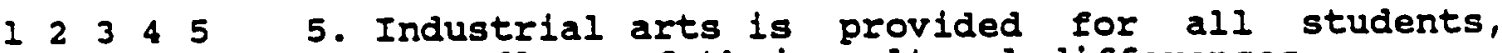
regardless of their cultural differences.

$123 \quad 3 \quad 4 \quad 5$

6. Industrial arts activities are provided for all students appropriate to their maturity and/or educational level.

\subsection{SEX EQUITY}

Industrial arts is provided equitably for females as well as males.

$\begin{array}{llllll}1 & 2 & 3 & 4 & 5 & 1\end{array}$. Both sexes are encouraged to enroll in industrial arts courses. 
5 -- very important

1 -- very unimportant

$\begin{array}{lllll}1 & 2 & 3 & 4 & 2\end{array}$. Industrial arts activities are provided on an impartial basis to all students.

11

Reproduced with permission of the copyright owner. Further reproduction prohibited without permission. 
5 -- very important

1 -- very unimportant

\section{STANDARD 4 - INSTRUCTIONAL STAFE}

The statements contained within this standard topic concern the instructional staff of an industrial arts program. The instructional staff responsible for teaching industrial arts provides the essential component for a quality program. staff members should meet the highest standards of professional and technical competence.

\subsection{LEGAL REGULATORY QUALIFICATIONS}

The instructional staff meets established state and local degree, certification, and competency requirements.

$\begin{array}{llllll}1 & 2 & 3 & 4 & 5 & 1\end{array}$. The industrial arts teacher posseses a minimum of a baccalaureate degree with a major in industrial arts education from an accredited teacher education program.

$\begin{array}{llllll}1 & 2 & 3 & 4 & 2 & 2\end{array}$. The industrial arts teacher is competent in planning, organizing directing, and evaluating activities in the industrial arts program.

12345 3. The industrial arts teacher is technically competent in the assigned teaching area(s).

123345

4. The industrial arts teacher is prepared, through preservice/inservice education, to provide experiences for students with special needs.

12345

5. The industrial arts teacher is prepared, through preservice/inservice education to utilize denominationally prepared and adopted curriculum guiles.

123445

6. The industrial arts teacher, through preservice/ inservice education, has knowledge of the iegal and liability requirements of classroom/ laboratory operation.

\subsection{PROFESSIONAL RESPONSIBIIITIES}

The industrial arts teacher fulfills the roles and responsibilities of a professional educator.

12345 1. The industrial arts teacher is a member of and 
5 -- very important

1 -- very unimportant

\begin{abstract}
$123 \quad 3 \quad 4 \quad 5$
2. The industrial arts teacher has a professional development plan for maintaining and expanding professional and technical teaching competencies.

$\begin{array}{llllll}1 & 2 & 3 & 4 & 5 & 3\end{array}$. The industrial arts teacher participates in a minimum of one industrial arts related inservice activity annually.

$\begin{array}{lllll}1 & 2 & 3 & 4 & 5\end{array}$

4. The industrial arts teacher maintains current knowledge in the industrial arts field through activities such as reading professional and technical publications.

$\begin{array}{llllll}1 & 2 & 3 & 4 & 5 & 5\end{array}$. The industrial arts teacher serves as an active member of the school instructional staff, sharing in decision-making processes and participating in program promotion and staff development.

1223345

5. The industrial arts teacher plans and implements instruction in cooperation with counselors and other appropriate support personnel.

12345

7. The industrial arts teacher has a positive attitude toward the teaching profession and demonstrates a concern for the advancement of industrial arts education.
\end{abstract}

\title{
4.3 PERSONAL QUALITIES
}

The industrial arts teacher exhibits personal qualities that contribute to the fulfiliment of his professional responsibilities.

$\begin{array}{llllll}1 & 2 & 3 & 4 & 5 & 1 \text {. The industrial arts teacher adheres to a written }\end{array}$ Christian code of ethics related to personal conduct and to the performance of professional teaching responsibilities.

$\begin{array}{llllll}1 & 2 & 3 & 4 & 5 & 2\end{array}$. The industrial arts teacher demonstrates adequate and appropriate written and oral language skills. $\begin{array}{llllll}1 & 2 & 3 & 4 & 5 & 3 \\ \text {. The industrial arts teacher provides positive } \\ \text { Christian leadership in the classroom, the }\end{array}$ school, and the profession. 
5 -- very important

1 -- very unimportant

$\begin{array}{llllll}1 & 2 & 3 & 4 & 5 & 4\end{array}$. The industrial arts teacher adheres to acceptable school practices regarding personal appearance.

$\begin{array}{llllll}1 & 2 & 3 & 4 & 5 & 5\end{array}$. The industrial arts teacher exhibits good work habits such as safe practices, punctuality, neatness, and attendance that have a positive effect on the educational environment.

12345 6. The industrial arts teacher is sensitive to student needs, recognizes individual student abilities, and practices appropriate teaching methods that motivate students to maximum performance. 
5 -- very important

1 -- very unimportant

\section{STANDARD 5 - ADMINISTRATION AND SUPERVISION}

The statements contained within this standard topic concern the administration and supervision of an industrial arts program. Administrators and supervisors provide management of and direction for the program. These personnel perform leadership functions that help to ensure attainment of all current program goals.

\subsection{STAFFING}

An adequate number of certified and qualified administrators, supervisors, and faculty is provided to ensure attainment of program goals and objectives.

$\begin{array}{llllll}1 & 2 & 3 & 4 & 5 & 1\end{array}$. An adequate number of qualified and certified industrial arts teachers is provided to meet enrollment demands.

125345 a. The number of students enrolled in an industrial arts class does not exceed the capacity and safety of the facilities and equipment at a 125 square foot per-pupil criterion level.

12345 b. A minimum of one non-teaching period for preparation is provided each day.

$\begin{array}{lllll}1 & 2 & 3 & 4 & 5\end{array}$

2. Teacher aides or paraprofessionals are provided in classes where enroliment of students with special needs necessitates their assistance.

\subsection{PLANNING AND ORGANIZING}

A system is provided which ensures program direction, short and long range planning, organization and administration for program operation and improvement.

$\begin{array}{llllll}1 & 2 & 3 & 4 & 5 & 1\end{array}$. Supervisors and teachers utilize predetermined standa:eds to plan and organize the industrial arts program.

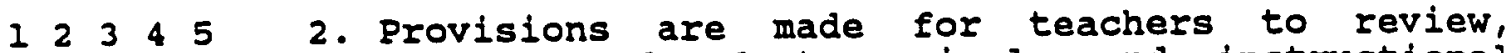
develop, and adapt curriculum and instructional materials which are compatible with local, Union and General Conference industrial arts guidelines.

$12345 \quad 3$. Supervisors and teachers cooperatively develop 
5 -- very important

1 -- very unimportant

12345

specifications for industrial arts equipment and resource materials.

4. Supervisors involve teachers in developing specifications for industrial arts facility design, development, and renovation.

\subsection{BUDGETING}

A budgeting system is utilized to ensure the identification and procurement of all resources essential for the accomplishment of program goals and course objectives, consistent with student enrollment and unique student needs.

$\begin{array}{llllll}1 & 2 & 3 & 4 & 5 & 1\end{array}$. Funds are budgeted for purchase of equipment to accomplish course objectives.

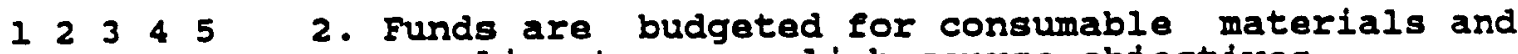
supplies to accomplish course objectives.

12345

3. Funds are budgeted for equipment maintenance and facility improvements to accomplish course objectives.

122345

4. Funds are budgeted for instructional materials to accomplish course objectives.

5. Funds are budgeted for staff development.

1223345

$\begin{array}{lllll}1 & 2 & 3 & 4 & 5\end{array}$

a. Funds are budgeted for travel, release time, and substitutes for personnel to participate in inservice professional activities.

b. Funds are budgeted for travel, release time, and substitutes for personnel to participate in iocal and regional professional organization activities.

\subsection{DIRECTING AND MONITORING}

Appropriate policy statements, written directives, and supervisory visits are utilized to ensure full program implementation.

$123^{\circ} 5$ 1. Written administrative policies and directives, specifically addressing the operation of the indus- trial arts program and cooperatively developed by administration and staff, are 
5 -- very important

1 -- very unimportant

available.

12345

2. Teachers are visited on a regularly scheduled basis by supervisory personnel.

\subsection{DATA COLLECTING AND REPORTING}

An information system is utilized to collect, analyze, transmit, and maintain data on programs, teachers anci students.

12345 1. Reports required by local, state, and church agencies are prepared and submitted on schedule.

$\begin{array}{lllll}1 & 2 & 3 & 4 & 5\end{array}$

2. Accurate financial reports are prepared and submitted on schedule.

$123 \quad 3 \quad 45$

3. Safety reports are prepared and submitted on schedule.

4. Student records are prepared, maintained, and utilized by appropriate school officials according to regulations.

12345 a. A biographic, academic, and medical profile is maintained on each student enrolled in industrial arts.

12345

b. Demographlc data about all industrial arts students are available by grade level and by course, including but not limited to course enrollment.

12345 5. Records and related information on all advisory committee activities are prepared and distributed to appropriate staff, administrators, and other personnel.

123456 6. Records and related information on equipment, tools, textbooks, and supplies are prepared and made available to appropriate personnel. 
5 -- very important

1 -- very unimportant

\subsection{COMMUNICATING}

Communication is maintained among faculty,
administrative personnel, students, and the commuity.

$\begin{array}{llllll}1 & 2 & 3 & 4 & 5 & 1\end{array}$. Effective, open communication pertaining to all elements in the instructional program is established and utilized consistently among industrial arts faculty and school staff.

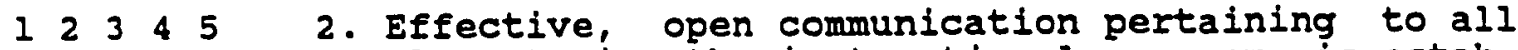
elements in the instructional program is established and utilized consistently among administrators, school board members, supervisors, advisory committees, and faculty.

12345 3. Effective, open communication pertaining to all elements in the instructional program is established estabilishedand utilized consistently among and parents. 
5 -- very important

1 -- very unimportant

\author{
STANDARD 6 - SUPPORT SYSTEMS
}

The statements contained within this standard topic concern support systems. These support systems include human, physical, and financial resources that are necessary to implement the instructional program. These resources are required to provide a comprehensive, quality industrial arts program.

\title{
6.1 HUMAN RESOURCES
}

Personnel services are provided and utilized to support and supplement the industrial arts program.

1. School support staff services are provided to support the industrial arts program.

12345

12345

12345

12345

12345

12345

12345

12345

12345 a. Media/instructional resources are available to support the industrial arts program.

b. Personnel are available to assist the industrial arts teacher in serving students with special needs.

c. Guidance services are provided to assist all students in determining their interests, aptitudes, and abilities in selecting the program that meets their career/avocational goals: and expanding their individual options.

d. Industrial arts teachers obtain interdisciplinary support to assist in achieving program objectives.

e. Secretarial and clerical services are provided for industrial arts personnel.

f Custodial services are provided to assure safe and anitary industrial arts facilities.

9. Maintenance services are provided to assure safe and functional industrial arts facilities and equipment.

h. Hedical personnel are available to provide instruction and ensure the safety and welfare of students and faculty.

2. The industrial arts teacher identifies and utilizes people in the community to assist in achieving program goals and course objectives.

a. Parents are utilized in achieving program goals and course objectives. 
5 -- very important

1 -- very unimportant

12345 b. The teacher involves representatives from business and industry to assist in achieving program goals and course objectives.

12345 c. Members of service/civic organizations are identified and utilized in achieving the program goals and course objectives.

3. An industrial arts advisory committee is established and utilized to support the program goals and course objectives.

$\begin{array}{llllll}1 & 2 & 3 & 4 & 5 & \text { a. The industrial arts advisory committee includes }\end{array}$ appropriate representation from business and industry.

$1223 \quad 4 \quad 5$

b. The industrial arts advisory committee is utilized to advise teachers and administrators in planning, developing, implementing, and evaluating the industrial arts program.

$\begin{array}{llllll}1 & 2 & 3 & 4 & 5 & c\end{array}$. The industrial arts advisory committee meets at least twice a year.

\subsection{PHYSICAL RESOURCES}

Physical resources such as the facility, equipment, ar 1 instructional materials are provided to assist in achieving the program goals and course objectives.

$123 \quad 3 \quad 4 \quad 5$

1. Industrial arts laboratories average 2500 square feet or 125 square feet per student, exclusive of ancillary space.

12345

2. Industrial arts ancillary space, at an average of 500 square feet for each laboratory, is provided for storage of materials, projects/products, and tools.

12345 3. Facilitles meet existing local, state, and federal health and safety standards.

12345 4. Facilities are logically arranged and maintained with consideration given to effective teaching, safety, class management, and economy.

123345 5. At least 100 square feet of office space per teacher, within or adjacent to the industrial arts facility is provided. 
5 -- very important

1 -- very unimportant

12345 6. Adequate visual control and supervision of all instructional areas is possible.

12345

7. Facilities are reviewed annually and modified, as needed, to accommodate changes in the course objectives and changes in technology.

12345

8. Accessibility for the handicapped is ensured through the elimination of architectural barriers.

$\begin{array}{lllll}1 & 2 & 3 & 4 & 5\end{array}$

9. Students are informed prior to enrollment of all supplies they are required to purchase, where they are obtained, and how much they cost.

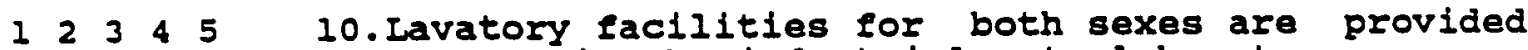
near or in the industrial arts laboratory.

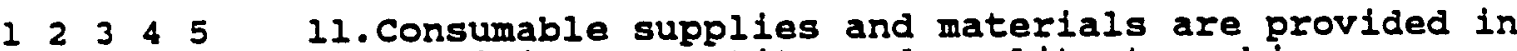
sufficlent quantity and quality to achieve course objectives.

1223045

12. Properly maintained tools, machines, and equipment are available on the basis of their instructional value in fulfilling program goals and course objectives.

12345 13.Specially designed or modified tools, machines, and equipment are provided for students with special needs.

12345 14. Equipment meets or exceeds 1ocal, state, ard federal safety standards.

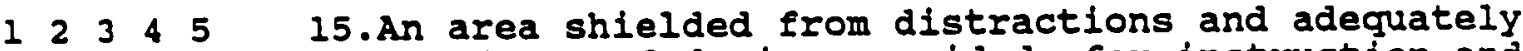
sound proofed is provided for instruction and individual research.

12345 16.Books and other instructional materials contain sex-fair language and images and provide a wide range of role options.

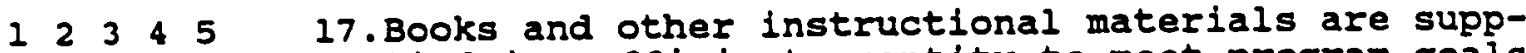
lied in sufficient quantity to meet program goals and course objectives.

$12345 \quad 18$.Books and other instructional materials are 
5 -- very important

1 -- very unimportant

123345

provided to meet the unique requirements of students with special needs.

12345

19. Books and other resource materials are available for student research purposes.

\subsection{FINANCIAL RESOURCES}

Sufficient funds are budgeted and expended to operate and maintain the industrial arts program.

$\begin{array}{llllll}1 & 2 & 3 & 4 & 5 & 1\end{array}$. The program is supported by an annual written budget based upon the program needs and student enrollment.

$\begin{array}{llllll}1 & 2 & 3 & 4 & 5 & 2\end{array}$. Budgeted funds for supplies, equipment, student labor and resource materials are expended to fully achieve program goals and objectives.

$\begin{array}{llllll}1 & 2 & 3 & 4 & 5 & 3\end{array}$. Budgeted funds are expended for staff development activities.

$\begin{array}{llllll}1 & 2 & 3 & 4 & 5 & 4\end{array}$. The budget is prepared and approved before the iscal year begins.

12345 5. The budget is prepared with input from the industrial arts faculty. 
5 -- very important

1 -- very unimportant

\section{STANDARD 7 - INSTRUCTIONAL STRATEGIES}

The statements contained within this standard topic concern instructional strategies. These strategies are the methods utilized to deliver instruction and promote student achievement of goals and objectives. The industrial arts instructor plans, implements, and evaluates these strategles.

\subsection{PIANNING}

Written instructional plans which meet individual needs are developed and utilized to achieve stated course objectives.

$\begin{array}{lllll}1 & 2 & 3 & 4 & 5\end{array}$

1. Teachers plan and prepare written courses of study designed to develop student competencies consistant with program goals and course objectives.

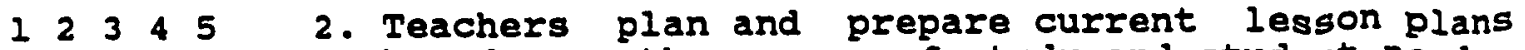
based upon the course of study and student needs.

$\begin{array}{llllll}1 & 2 & 3 & 4 & 5 & 3\end{array}$. Teachers consider alternatives and select appropriate methods to assist students in meeting course obfectives.

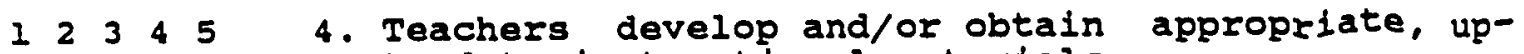
to-date instructional materials.

12345 5. Teachers plan and provide for evaluating the effectiveness of their instruction.

12345

6. Any outside work accepted by the instructor is on the basis of its instructional value in accordance with school policies.

\subsection{IMPLEMENTING}

Instructional and leadership development methods are utilized to accomplish course objectives and meet the unique needs of individual stucients.

1. The industrial arts teacher utilizes a variety of teaching methods in conducting classroom and laboratory activities. 
5 -- very important

1 -- very unimportant

12345 a. Both teacher-centered and student-centered instructional methods are utliized.

$\begin{array}{lllll}1 & 2 & 3 & 4 & 5\end{array}$

b. Instructional methods include both group and individual student learning activities.

12345 c. Instructional methods utilized are based upon individual student needs rather than upon the sex of the students.

$\begin{array}{lllll}1 & 2 & 3 & 4 & 5\end{array}$

d. Instructional strategies appropriate for serving students with special needs have been identified and incorporated into the industrial arts program.

123445

e. The teacher utilizes facilities and resources avallable in the environment to enrich learning.

$\begin{array}{lllll}1 & 2 & 3 & 4 & 5\end{array}$

2. Student achievement is measured through a variety of testing techniques and other evaluation methods.

$\begin{array}{lllll}1 & 2 & 3 & 4 & 5\end{array}$

3. Student leadership skills are developed through a variety of curricular and extracurricular activities.

\subsection{REVIEWING AND REVISING}

Instructional strategies are evaluated annually and revised when necessary.

123345

1. Measures of student achiavement are utilized to make systematic decisions regarding the effectivenes of instructional materials and teaching strategies.

$\begin{array}{llllll}1 & 2 & 3 & 4 & 5 & 2\end{array}$. Provisions are made for student input into the evaluation of instructional strategies. 
5 -- very important

1 -- very unimportant

\section{STANDARD 8 - PUBLIC RELATIONS}

The statements contained within this standard topic concern public relations. An informed and involved public is essential to the promotion of an industrial arts program. vartous media are utilized to inform target populations

\subsection{TARGET POPULATIONS}

The educational community, the lay public, the constituents, business and industry are informed of and given the opportunity to participate in industrial arts programs and activities.

1. Parents, faculty and staff, school administrators, and members of professional teacher organizations are informed of and given the opportunity to participate in industrial arts programs and activities.

$\begin{array}{llllll}1 & 2 & 3 & 4 & 5 & \text { a. Parents support and participate in the industrial }\end{array}$ arts program by functioning as paraprofessionals, advisors, or resource people.

$\begin{array}{llllll}1 & 2 & 3 & 4 & 5 & \mathrm{~b} \text {. Non industrial arts faculty and staff are }\end{array}$ informed about the industrial arts program for the purpose of generating support, guidance, and interdisciplinary educational opportunities.

12345

c. Administrators are informed about and participate in the industrial arts program.

12345 d. Local, state, and national professional associations are informed about and participate in the industrial arts program.

2. The industrial arts faculty actively encourages community involvement and promotes a greater understanding of the program's needs and accomplishments.

$\begin{array}{llllll}1 & 2 & 3 & 4 & 5 & \text { a. Community service organizations are informed of }\end{array}$ and encouraged to support the industrial arts program.

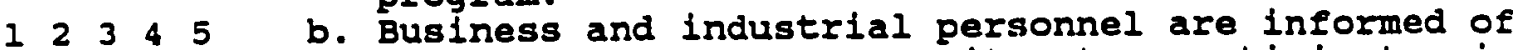
and given the opportunity to participate in industrial arts programs and activities.

12345 c. Technical and professtonal industry organizations are informed of and encouraged to 
5 -- very important

1 -- very unimportant

support and participate in the industrial arts
program. 8.2 MEDIA

Varlous media are utilized to communicate the goals, objectives and accomplishments of the incustrial arts program.

$\begin{array}{llllll}1 & 2 & 3 & 4 & 5 & 1 .\end{array}$ plishments of the industrial arts program are prepared and published in the local news media on a regular basis.

$\begin{array}{llllll}1 & 2 & 3 & 4 & 5 & 2\end{array}$. Handbooks and brochures describing the industrial arts program, goals, objectives, and policies are prepared and utilized.

$\begin{array}{llllll}1 & 2 & 3 & 4 & 5 & 3\end{array}$. Media events, including open houses, exhibits, displays, presentations, demonstrations, and industrial arts education week activities are utilized to promote the program. 
5 -- very important

1 -- very unimportant

\section{STANDARD 9 - SAFETY AND HEALTH}

The statements contained within this standard topic concern safety and health. A comprehensive safety and health program is essential to the success of a quality industrial arts program. the program provides for a safe environment and promotes lifelong attitudes and practices regarding safety and health.

\subsection{EROGRAM}

Learning experiences and activities are designed for the development of knowledge, skills, and attitudes concerning the safe use of tools, machines, materials, and processes.

1. An instructional plan for safety and heelth is prepared utilizing community resources, administrative personnel, instructors, and safety literature.

12345 a. Teachers prepare a written plan for a comprehensive safety and health program.

$123 \quad 3 \quad 45$

$\begin{array}{lllll}1 & 2 & 3 & 4 & 5\end{array}$

b. Administrative personnel provide input for and approval of the safety and health program.

c. Community resources, including the industrial arts advisory committee, provide input to the safety and health program.

12345 d. SDA, local, state, and national safety and health literature and regulations are utilized in planning the safety and health program.

2. Safety and health instruction is documented and included in classroom and laboratory activities.

12345 a. Safety and health information is included in instruction for all laboratory activities.

$\begin{array}{llllll}2 & 3 & 4 & 5 & \text { b. Teacher and student activities reinforce safety }\end{array}$ and health instruction.

123445

c. Safety and health instruction is adapted to individual student needs.

3. Techniques are utilized to assess the effectiveness of he safety and health program.

12345 a. Safety and health practices are monitored continuously and reviewed annually by the teacher. 
5 -- very important

I -- very unimportant

1 i 345 b. Proper authorities, external to the school, inspect periodicaliy and report on the safety and health program.

12345

c. Students demonstrate acceptable knowledge, skilis, and attitudes of safety and health practices and rules through written and performance tests, and in-class behavior.

1223445

d. Teachers and administrators review each recorded accident and all unsafe practices to correct deficiencies.

\subsection{PHYSICAL ENVIRONMENT}

The physical facilities and equipment are designed, constructed, and maintained to ensure a safe and healthful learning environment.

125345 1. Laboratory facilities meet safety and health laws and regulations.

2. Laboratory facilities conform to acceptable industrial arts safety and health practices.

$\begin{array}{lllll}1 & 2 & 3 & 4 & 5\end{array}$

$\begin{array}{lllll}1 & 2 & 3 & 4 & 5\end{array}$

12345

12345

12345

12345

12345

12345

12345

12345

12345 a. Safety zones and aisles are properly marked.

b. Lighting is appropriate for the activities performed within the facility.

c. Proper exhaust system equipment which removes fumes, chips, and dust from the building is provided.

d. Proper equipment is provided to heat, cool, and ventilate all instructional and anciliary areas.

e. Approved safe cabinets, containers, or rooms are provided to store flammable and corrosive materials.

f. Special safety and health accommodations are provided for students with special needs.

9. Floors and all other surfaces are kept free of waste material, grease, and obstructions.

h. Floors have non-skid surfaces, with special application on machine-operator work areas.

i. Each laboratory with powered equipment has the equivalent of one easily accessible emergency disconnect switch (pantc button) per perimeter wa11.

j. Fire extinguishers of the correct class are provided in appropriate locations.

k. A flrst-aid kit and related emergency supplies 
5 -- very important

1 -- very unimportant

$\begin{array}{lllll}1 & 2 & 3 & 4 & 5\end{array}$

are provided in accordance with local regulations.
1. Facilities are available (sink unit, paper towel and soap dispensers) for students to wash before leaving the laboratory.

3. Machines and tools are selected, organized, guarded, color coded, controlled, and ventilated in accordance with regulations and codes.
$123 \quad 345$
a. Equipment which satisfies state and federal regulations is selected on the basis of the ability to meeet program objectives safely.
$\begin{array}{lllll}1 & 2 & 3 & 4 & 5 \\ 1 & 2 & 3 & 4 & 5 \\ 1 & 2 & 3 & 4 & 5 \\ 1 & 2 & 3 & 4 & 5 \\ 1 & 2 & 3 & 4 & 5 \\ 1 & 2 & 3 & 4 & 5 \\ 1 & 2 & 3 & 4 & 5 \\ 1 & 2 & 3 & 4 & 5\end{array}$
b. Machines and tools are placed, mounted if necessary, and arranged in a safe and functional manner.
c. All machines and power tools are provided with
d. Safety guards remain in place, except when the machine is disconnected for cleaning, repair, or adjustment.
e. Any machine or tool found to be unsafe is removed from service and marked accordingly.
f. Color-coding schemes for safety purposes are used throughout the industrial arts laboratory.
g. Conveniently located magnetic control switches and/or control boxes and braking devices are provided for appropriate machines.
h. Lockable master switch boxes are located in each industrial arts laboratory.
i. Machines and work stations where dust or fumes are produced beyond accepted health limits are connected to an exhaust system.

4. Personal protection devices are used by teachers, students, and visitors to maximize safety, and such devices are sanitized to maximize health in the laboratory.

12345 a. State or federally approved eye protection devices are required of all persons exposed to conditions which may cause eye injury.

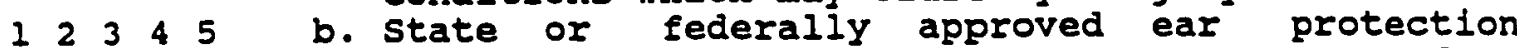
devices are required of all persons exposed to conditions which may cause ear damage.

12345 c. State or federally approved respiratory protection devices are required of all persons 
5 -- very important

1 -- very unimportant

$\begin{array}{lllll}1 & 2 & 3 & 4 & 5\end{array}$

exposed to conditions which may cause respiratory problems.

$\begin{array}{lllll}1 & 2 & 3 & 4 & 5 \\ 1 & 2 & 3 & 4 & 5 \\ 1 & 2 & 3 & 4 & 5 \\ 1 & 2 & 3 & 4 & 5 \\ 1 & 2 & 3 & 4 & 5 \\ 1 & 2 & 3 & 4 & 5\end{array}$

d. State or federally approved head protection devices are required of all persons exposed to conditions which may cause head injury.

e. Specially adapted personal protection devices are available for and used by students with special needs.

f. Teachers and students wear appropriate clothing when exposed to conditions which warrant such protection.

g. Personal protection devices requiring sanitation are sanitized after each use.

5. Corrective and preventive maintenance is performed with in a reasonable time following written notification to the appropriate administrator.

\subsection{RECORDS}

Records are on file to document the existence of an effective safety and health program.

1. Safety and health instructional records are on file.

a. Lesson plans documenting provision for safety and health instruction are on file.

b. Results of written and performance tests and obsesvations documenting student safety and health knowledge, attitudes, and skills are on flle.

2. Records detalling current safety and health conditions in the facility are on flle.

12345

a. Inspection maintenance, repair, and replacement

b. Records of each accident and the follow-up

123345

$\begin{array}{lllll}1 & 2 & 3 & 4 & 5\end{array}$ procedures taken are on file.

c. Emergency procedures for responding to accidents are posted and on file. 
5 -- very important

1 -- very unimportant

\section{STANDARD 20 - EVALUATION}

The statements contained within this stindard topic concern the evaluation process. All elements of the program are systematicaliy and continuously assessed and compared to desired standards. The standards in this document serve as bases for the evaluation of industrial arts programs.

\subsection{ESTABLISHING A DATA COLLECTION AND ANALYSIS SYSTEM}

Appropriate procedures are established and utilized to obtain valid and reliable information for program assessment.

$\begin{array}{llllll}1 & 2 & 3 & 4 & 5 & 1 \text {. Teachers and administrators determine what }\end{array}$ aspects of the industrial arts program are to be included in the data collection and analysis system.

123345

2. Instruments, based upon the standards contained in this document, are designed and/or selected to obtain valid and reliable information.

1223345

3. A range of evaluative techniques is utilized, sufficient to encompass the range of outcomes and elements to be evaluated.

\subsection{COLLECTING AND ANALYZING DATA}

Data on selected aspects of the industrial arts program are collected on a prescribed schedule.

$\begin{array}{llllll}1 & 2 & 3 & 4 & 5 & 1\end{array}$. Instruments are administered annually to collect valid and reliable data on selected aspects of the industrial arts program.

$\begin{array}{lllll}1 & 2 & 3 & 4 & 2\end{array}$. Data on the total industrial arts program are collected at least once every seven years.

12345

3. Data are collected in compliance with accrediting agencies and church, state, and federal mandates.

$\begin{array}{lllll}1 & 2 & 3 & 4 & 5\end{array}$

4. Valid procedures are utilized to analyze data and identify discrepancies between the current program and the standards in this document. 
5 -- very important

1 - very unimportant

\subsection{REPORTING}

An assessment report containing data, notations of discrepancies, and recommendations is made annually.

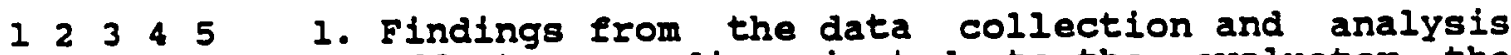
efforts are disseminated to the evaluator, the evaluatee and to appropriate decision makers.

$\begin{array}{llllll}1 & 2 & 3 & 4 & 5 & 2\end{array}$. Discrepancies between program status and standards are reported to appropriate decision makers.

$\begin{array}{llllll}1 & 2 & 3 & 4 & 5 & 3\end{array}$. Recommendations for correcting deficiencies are reported to appropriate decision makers.

\subsection{DECISION MAKING}

Decisions for program improvement are based upon the assessment report.

$123 \quad 355$ 1. A written course of action is developed for overcoming each deficiency.

$\begin{array}{llllll}1 & 2 & 3 & 4 & 5 & 2\end{array}$. Priorities are determined and actions are implemented to correct deficiencies.

$\begin{array}{llllll}1 & 2 & 3 & 4 & 5 & 3\end{array}$. The effectiveness of the courses of action taken is assessed. 
APPENDIX I

GENERAL COVER LETTER FOR STANDARDS

Reproduced with permission of the copyright owner. Further reproduction prohibited without permission. 


\section{SDA Industrial Arts Standards Project}

Standards Project, 100 Smith Hall, Andrews University,

Berrten Springs, MI 49104

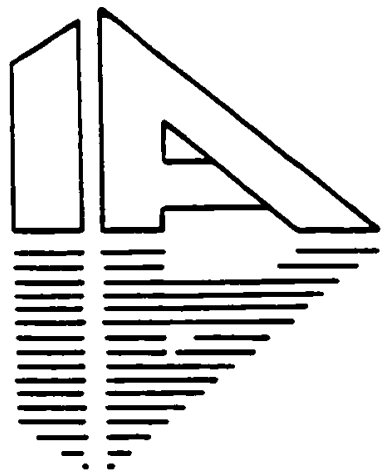

JulY 14, 1984

Lear Sir,

This document is the end product of a project begun about 10 months ago to develop standards for industrial arts programs in SDA schools. The project began with a survey of all the SDA secondary schools in the us that conduct industrial arts programs. The survey results, together with an extensive review of literature relating to standards, resulted in this pilot tested document. The final task remaining is to validate each of the standards, and that is where I would like your help.

Each standard must be validated by rating it on a scale of 1 - 5. The ratings will then be statistically evaluated to determine which of the standards are acceptable or valid as industrial arts program standards for SDA schools.

The relatively small validation panel, of which you have been selected a member, has been chosen carefully according to specific criteria. This renders each member's response critically important to the valid selection of the final standards.

In anticipation of your assistance, I thank you for the time and effort involved in this worthwhile project. Soecific directions ars contained within the standards.

Thanks,

P. John Williams

Project Director 
APPENDIX J

FINAI STANDARDS DOCUMENT

(pp. 232-261, inclusive)

Reproduced with permission of the copyright owner. Further reproduction prohibited without permission. 
SDA INDUSTRIAL ARTS STANDARDS PROJECT

\author{
STANDARDS FOR INDUSTRIAL ARTS
}

P. JOHN WILIIAMS

Reproduced with permission of the copyright owner. Further reproduction prohibited without permission. 
STANDARD 1 PHILOSOPHY

CONTENTS

1.1 Development . . . . . . . . . . . . . 3

1.2 Utilization.................... . 4

1.3 Review and Revise... . . . . . . . . . . 4

STANDARD 2 INSTRUCTIONAL PROGRAM

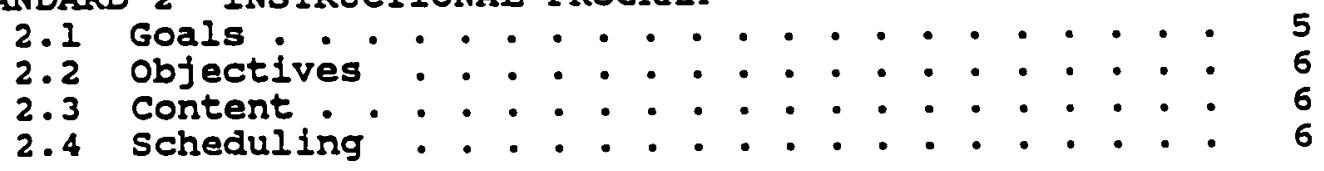

STANDARD 3 STUDENT POPULATIONS SERVED

3.1 Individual Differences . . . . . . . . . . . 7

3.2 Sex Equity .. . . . . . . . . . . . . . . . . 7

STANDARD 4 INSTRUCTIONAL STAFF

4.1 Legal/Regulatory Qualifications . . . . . . . . 8

4.2 Professional Responsibilities... . . . . . . . 8

4.3 Personal Qualities . . . . . . . . . . . . . . 9

STANDARD 5 ADMINISTRATION AND SUPERVISION

5.1 Staffing . . . . . . . . . . . . . . . 10

5.2 Planning and organizing . . . . . . . . . . 10

5.3 Budgeting . . . . . . . . . . . . . . . 10

5.4 Directing and Monitoring . . . . . . . . . . 11

5.5 Data Collecting and Reporting... . . . . . . 11

5.6 Communicating .. . . . . . . . . . . . . 12

STANDARD 6 SUPPORT SYSTEMS

6.1 Human Resources... . . . . . . . . . . . . 13

6.2 Physical Resources :. . . . . . . . . . . . . 14

6.3 Financial Resources... . . . . . . . . . 15

STANDARD 7 INSTRUCTIONAL STRATEGIES

7.1 Planning .. . . . . . . . . . . . . . 16

7.2 Implementing . . . . . . . . . . . . . . . . 16

7.3 Reviewing and Revising . . . . . . . . . . . 17

STANDARD 8 PUBLIC REIATIONS

8.1 Target Populations . . . . . . . . . . . . 18

8.2 Media... . . . . . . . . . . . . . . 18

STANDARD 9 SAFETY AND HEALTH

9.1 Program . . . . . . . . . . . . . . 20

9.2 Physical Environment . . . . . . . . . . 20

9.3 Records... . . . . . . . . . . . . . 22 


\section{STANDARD 10 EVALUATION}

10.1 Establishing an Evaluation system . . . . . . . 23

10.2 Collecting and Analysing Data . . . . . . . . 23

10.3 Reporting.................... . 23

10.4 Decision Making .. . . . . . . . . . . . 23 
The statements contained within this standard topic concern the philosophy of an industrial arts program. A philosophy is a statement of fundamental beliefs which reflect a value system. It serves as a foundation and framework for elements of a program.

\subsection{DEVELOPMENT}

A philosophical statement for including industrial arts as an integral part of the school curriculum is developed.

1. The philosophical statement is developed as a joint effort of a number of contributors.

a. Industrial arts teachers are involved in developing the philosophical statement.

b. Administrators and supervisory personnel responsible for industrial arts programs are involved in developing the philosophical statement.

c. Parents, business and industry representatives, and other consultants are involved in the development of the philosophical statement.

2. The philosophical statement is consistent with seventhday Adventist philosophies of industrial arts, and local, state, and natioal philosophies when not in conflict.

3. The philosophy identifies the Christian virtues that the industrial arts program encourages students to exhibit.

4. The philosophlcal statement supports the existence of the program.

a. The ohilosophy describes the industrial and technological nature of society in the past, present, and future.

b. The philosophy identifies the needs, abllities, and interests of all learners, regardless of race, sex, creed, national origin, or handicapping conditions.

c. The philosophy addresses the value of industrial arts including industrial and technological 
literacy; career orientation, exploration, and preparation; avocational activities; economic concepts; consumer skills; and manipulative skills; physical, mental, spiritual and social growth; and problem solving skills.

d. The philosophy encourages development of personal and leadership skills.

5. The philosophical statement is written and on file.

6. The philosophy is based on the bible as the revelation of the truth about God.

\subsection{UTILIZATION}

1. The philosophical statement is the basis for program planning.

2. The philosophical statement is a basis for program development.

3. The philosophical statement is a basis for program implementation.

4. The philosophical statement is a basis for program research and evaluation.

\subsection{REVIEW AND REVISE}

1. The phllosophical statement is reviewed annually and revised on the basis of the annual review. 


\section{STANDARD 2 INSTRUCTIONAL PROGRAM}

The statements contained within this standard topic concern the instructional program. This program, which reflects the stated philosophy, provides a wide variety of organized experiences for all students. These experiences assist learners in reaching predetermined goals.

\subsection{GOALS}

Program goals are established from the stated philosophy to provide direction for program development, implementation, and evaluation.

1. The program goals encompass the major purposes of industrial arts.

a. Emphasis is placed upon assisting students in developing insight and understanding of our industrial and technological society.

b. Emphasis is placed upon improving student ability to make informed and meaningful occupational choices.

c. Emphasis is placed on developing student character and integrity by encouraging the internalization of a set of personal Christian values.

d. Emphasis is placed upon developing individual student talents, creative abilities, positive selfconcepts and potentials generaliy and in relation to industrial-technical areas.

e. Emphasis is placed upon developing student abilities in the safe and proper use of tools, materials, machines, and processes.

f. Emphasis is placed upon developing student problemsolving and decision-making abilities involving industrial materials, processes, and products.

g. Emphasis is placed upon reinforcing the basic skilis and interrelating the content of industrial arts with other school subjects.

h. Emphasis is placed upon developing leadership ability, encouraging and promoting positive social 
interaction and $a$ sense of social and Christian responsibility.

2. Program goals are consistent with SDA standards and with local, state, and national standards, and emerging developments in the field.

3. Program goals are developed with input from teachers, administrators, students, representatives from business and industry, constituents, and other consultants.

4. Program goals are developed from research, evaluation, and follow up studies.

5. Program goals are written and are on file.

6. Program goals are utilized by teachers and administrators for planning, implementing, and evaluating courses.

7. Program goals are reviewed annually and revised when necessary.

\subsection{OBJECTIVES}

objectives which reflect program goals are utilized for each course.

1. Course objectives, written in measurable terms, are presented to students and are kept on file.

a. Course objectives are utilized by teachers and administrators for planning, implementing, and evaluating course content and instructional methods.

b. Course objectives are known and understood by students prior to entry to the instructional program.

2. Course objectives are reviewed annually and revised when necessary.

\subsection{CONTENT}

course content reflects the intent of the course objectives. 
1. Course content is offered in the broad categories of communication, construction, manufacturing, and transportation.

2. Course content is developed from course objectives and utilizes approved curriculum guides, courses of study, and other professional resources.

3. Course content is selected which provides instruction for all students based on the goals and objectives of the program.

4. Course content includes the development of personal and leadership skills.

5. Courses in the industrial arts program are sequential, beginning with broad orientation and exploration of subject matter areas, followed by specialized experiences.

6. Course content represents the state of the art in industry and technology.

7. Course content is organized into course outlines and unit and lesson plans which are on file.

8. An accurate description for each course is avallable to all students prior to enrollment.

9. Course content is reviewed annually and revised when necessary.

\subsection{SCHEDULING}

Industrial arts courses are of sufficient duration to achieve stated program objectives.

1. Industrial arts is offered for a minimum of 18 weeks, 255 minutes per week at each grade level of the funior high/high school.

2. Students are encouraged to enroll in courses from more than one content category during their total industrial arts experience. 


\section{STANDARD 3 - STUDENT POPULATIONS SERVED}

The statements contained within this standard topic concern the student populations served. The industrial arts program may serve all persons, pre-school through adult. Accomodations in the program are made for students with special needs.

\subsection{INDIVIDUAL DIFFERENCES}

All students, regardless of their abilities and needs, are served by the industrial arts program.

1. All students are provided a variety of effective and meaningful learning experiences commensurate with industrial arts program goals and course objectives.

2. Students who are academically and/or economically disadvantaged are provided special services, and assistance as required, to enable them to succeed in the industrial arts program.

3. Students who have physical, mental, and/or emotional impairments are provided special services and assistance as required, to enable them to succeed in the industrial arts program.

4. Students identified as gifted and/or talented are provided learning activities consistent with their abilities.

5. Industrial arts is provided for all students, regardless of their cultural differences.

6. Industrial arts activities are provided for all students appropriate to their maturity and/or educational level.

\subsection{SEX EQUITY}

Industrial arts is provided equitably for females as well as males.

1. Both sexes are encouraged to enroll in industrial arts courses.

2. Industrial arts activities are provided on an impartial basis to all students. 


\section{STANDARD 4 - INSTRUCTIONAL STAFF}

The statements contained within this standard topic concern the instructional stafe of an industrial arts program. The instructional staff responsible for teaching industrial arts provides the essential component for a quality program. Staff members should meet the highest standards of professional and technical competence.

\subsection{IEGAL REGULATORY QUALIFICATIONS}

The instructional stafe meets established state and local degree, certification, and competency requirements.

1. The industrial arts teacher posseses a minimum of a baccalaureate degree with a major in industrial arts education from an accredited teacher education program.

2. The industrial arts teacher is competent in planning, organizing, directing, and evaluating activities in the industrial arts program.

3. The industrial arts teacher is technically competent in the assigned teaching area(s).

4. The industrial arts teacher is prepared, through preservice/inservice education, to provide experiences for students with special needs.

5. The industrial arts teacher, through preservice/ inservice education, has knowledge of the legal and liability requirements of classroom/ laboratory operation.

\subsection{PROFESSIONAL RESPONSIBIIITIES}

The industrial arts teacher fulfills the roles and responsibilities of a professional educator.

1. The industrial arts teacher is a member of and actively participates in professional and technical organizations related to industrial arts.

2. The industrial arts teacher has a professional development plan for maintaining and expanding professional and technical teaching competencles. 
3. The industrial arts teacher participates in a minimum of one industrial arts related inservice activity annually.

4. The industrial arts teacher maintains current knowledge in the industrial arts fleld through activities such as reading professional and technical publications.

5. The industrial arts teacher serves as an active member of the school instructional staff, sharing in decisionmaking processes and participating in program promotion and staff development.

6. The industrial arts teacher plans and implements instruction in cooperation with counselors and other appropriate support personnel.

7. The industrial arts teacher has a positive attitude toward the teaching profession and demonstrates a concern for the advancement of industrial arts education.

\subsection{PERSONAL QUALITIES}

The industrial arts teacher exhibits personal qualities that contribute to the fulfillment of professional responsibilities.

1. The industrial arts teacher adheres to a written Christian code of ethics related to personal conduct and to the performance of professional teaching responsibilities.

2. The industrial arts teacher demonstrates adequate and appropriate written and oral language skills.

3. The industrial arts teacher provides positive Christian leadership in the classroom, the school, and the profession.

4. The industrial arts teacher adheres to acceptable school practices regarding personal appearance.

5. The industrial arts teacher exhibits good work habits such as safe practices, punctuality, neatness, and attendance that have a positive effect on the educational environment.

6. The industrial arts teacher is sensitive to student 
needs, recognizes individual student abilities, and practices appropriate teaching methods that motivate students to maximum performance. 


\section{STANDARD 5 - ADMINISTRATION AND SUPERVISION}

The statements contained within this standard topic concern the administration and supervision of an industrial arts program. Administrators and supervisors provide management of and direction for the program. These personnel perform leadership functions that ensure attainment of ali program goaks.

\subsection{STAFFING}

An adequate number of certifled and qualified administrators, supervisors, and faculty is provided to ensure attainment of program goals and objectives.

1. An adequate number of qualified and certified industrial arts teachers is provided to meet enrollment demands.

a. The number of students enrolled in an industrial arts class does not exceed the capacity and safety of the facilities and equipment at a 125 square foot per-pupil criterion level.

b. A minimum of one non-teaching period for preparation is provided each day.

2. Teacher aldes or paraprofessionals are provided in classes where enroliment of students with special needs necessitates their assistance.

\subsection{PLANNING AND ORGANIZING}

A system is provided which ensures program direction, short and long range planning, organization and administration for program operation and improvement.

1. Supervisors and teachers utilize predetermined standards to plan and organize the industrial arts program.

2. Provisions are made for teachers to review, develop, and adapt curriculum and instructional materials which are compatible with local, Union and General Conference industrial arts guidelines.

3. Supervisors and teachers cooperatively develop specifications for industrial arts equipment and resource materials. 
4. Supervisors involve teachers in developing specifications for industrial arts facility design, development, and renovation.

\subsection{BUDGETING}

A budgeting system is utilized to ensure the identification and procurement of all resources essential for the accomplishment of program goals and course objectives, consistent with student enrollment and unique student needs.

1. Funds are budgeted for purchase of equipment to accomplish course objectives.

2. Funds are budgeted for consumable materials and supplies to accomplish course objectives.

3. Funds are budgeted for equipment maintenance and facility improvements to accomplish course objectives.

4. Funds are budgeted for instructional materials to accomplish course objectives.

5. Funds are budgeted for staff development.

a. Funds are budgeted for travel, release time, and substitutes for personnel to participate in inservice professional activities.

b. Funds are budgeted for travel, release time, and substitutes for personnei to participate in local and regional professional organization activities.

\subsection{DIRECTING AND MONITORING}

Appropriate policy statements, written directives, and supervisory visits are utllized to ensure full program

1. Teachers are visited on a regularly scheduled basis by supervisory personnel.

\subsection{DATA COLLECTING AND REPORTING}

An information system is utilized to collect, analyze, transmit, and maintain data on programs, teachers and students. 
1. Reports required by local, state, and church agencies are prepared and submitted on schedule.

2. Accurate financial reports are prepared and submitted on schedule.

3. Safety reports are prepared and submitted on schedule.

4. Student records are prepared, maintained, and utilized by appropriate school officials according to regulations.

a. A blographic, academlc, and medical profile is maintained on each student enrolled in industrial arts.

b. Demographic data about all industrial arts students are available by grade level and by course, including but not limited to course enrollment.

5. Records and related information on all advisory committee activities are prepared and distributed to appropriate staff, administrators, and other personnel.

6. Records and related information on equipment, tools, textbooks, and supplies are prepared and made available to appropriate personnel.

\subsection{COMMUNICATING}

Communication is maintained among faculty, administrative personnel, students, and the community.

1. Effective, open communication pertaining to all elements in the instructional program is established and utilized consistently among industrial arts faculty and school staff.

2. Effective, open communication pertaining to all elements in the instructional program is estab lished and utilized consistently among administrators, school board members, supervisors, advisory committees, and faculty.

3. Effective, open communication pertaining to all elements in the instructional program is established and utilized consistently among students and parents. 


\section{STANDARD 6 - SUPPORT SYSTEMS}

The statements contained within this standard topic concern support systems. These support systems include human, physical, and financial resources that are necessary to implement the instructional program. These resources are required to provide a comprehensive, quality, industrial arts program.

\subsection{HUMAN RESOURCES}

Personnel services are provided and utilized to support and supplement the industrial arts program.

I. School support staff services are provided to support the industrial arts program.

a. Media/instructional resources are available to support the industrial arts program.

b. Personnel are available to assist the industrial arts teacher in serving students with special needs.

c. Guidance services are provided to assist all students in determining their interests, aptitudes, and abilities in selecting the program that meets their career/avocational goals; and expanding their individual options.

d. Industrial arts teachers obtain interdisciplinary support to assist in achieving program objectives.

e. Secretarial and clerical services are provided for industrial arts personnel.

e. Custodial services are provided to assure safe and sanitary industrial arts facilities.

g. Maintenance services are provided to assure safe and functional industrial arts facilities and equipment.

h. Medical personnel are available to provide instruction and ensure the safety and welfare of students and faculty.

2. The industrial arts teacher identifies and utilizes people in the community to assist in achleving program goals and course objectives. 
a. Parents are utilized in achieving program goals and course objectives.

b. The teacher involves representatives from business and industry to assist in achieving program goals and course objectives.

c. Members of service/civic organizations are ldentified and utilized in achieving the program goals and course objectives.

3. An industrial arts advisory committee is established and utilized to support the program goals and course objectives.

a. The industrial arts advisory committee includes appropriate representation from business and industry.

b. The industrial arts advisory committee is utilized to advise teachers and administrators in planning, developing, implementing, and evaluating the industrial arts program.

c. The industrial arts advisory committee meets at least twice a year.

\subsection{PHYSICAI RESOURCES}

Physical resources such as the facility, equipment, and instructional materials are provided to assist in achieving the program goals and course objectives.

1. Industrial arts laboratories average 2500 square feet or 125 square feet per student, exclusive of ancillary space.

2. Industrial arts ancillary space, at an average of 500 square feet for each laboratory, is provided for storage of materials, projects/products, and tools.

3. Facilities meet existing local, state, and federal health and safety standards.

4. Facilities are logically arranged and malntajned with consideration given to effective teaching, safety, class management, and economy.

5. At least 100 square feet of office space per teacher, 
within or adjacent to the industrial arts facility is provided.

6. Adequate visual control and supervision of all instructional areas is possible.

7. Facilities are reviewed annually and modifled, as needed, to accommodate changes in the course objectives and changes in technology.

8. Accessibility for the handicapped is ensured through the elimination of architectural barriers.

9. Students are informed prior to enrollment of all supplies they are required to purchase, where they are obtained, and how much they cost.

10. Lavatory facilities for both sexes are provided near or in the industrial arts laboratory.

11. Consumable supplies and materials are provided in sufficient quantity and quality to achieve course objectives.

12. Properly maintained tools, machines, and equipment are available on the basis of their instructional value in fulfilling program goals and course objectives.

13. Specially designed or modified tools, machines, and equipment are provided for students with special needs.

14.Equipment meets or exceeds local, state, and federal safety standards.

15. An area shielded from distractions and adequately sound proofed is provided for instruction and individual research.

16. Books and other instructional materials are supplied in sufficient quantity to meet program goals and course objectives.

17. Books and other instructional materials are provided to meet the unique requirements of students with special needs.

18. Books and other resource materials are available for student research purposes. 


\subsection{FINANCIAL RESOURCES}

Sufficient funds are budgeted and expended to operate and maintain the industrial arts program.

1. The program is supported by an annual written budget based upon the program needs and student enrollment.

2. Budgeting funds for supplies, equipment, and resource materials are expended to fully achieve program goals and objectives.

3. Budgeted funds are expended for staff development activities.

4. The budget is prepared and approved before the fiscal year begins.

5. The budget is prepared with input from the industrial arts faculty. 
The statements contained within this standard topic concern instructional strategies. These strategies are the methods utilized to deliver instruction and promote student achievement of gcals and objectives. The industrial arts instructor plans, implements, and evaluates these strategies.

\subsection{PLANNING}

Written instructional plans which meet individual needs are developed and utilized to achieve stated course objectives.

1. Teachers plan and prepare written courses of study designed to develop student competencles consistant with program goals and course objectives.

2. Teachers plan and prepare current lesson plans based upon the course of study and student needs.

3. Teachers consider alternatives and select appropriate methods to assist students in meeting course objectives.

4. Teachers develop and/or obtain appropriate, up-to-date instructional materials.

5. Teachers plan and provide for evaluating the effectiveness of their instruction.

6. Any outside work accepted by the instructor is on the basis of its instructional value in accordance with sshool policies.

\subsection{IMPLEMENTING}

Instructional and leadership development methods are utilized to accomplish course objectives and meet the unique reeds of individual students.

1. The industrial arts teacher utilizes a variety of teaching methods in conducting classroom and laboratory activities.

a. Both teacher-centered and student-centered instructional methods are utilized. 
b. Instructional methods include both group and individual student learning activities.

c. Instructional methods utilized are based upon individual student needs rather than upon the sex of the students.

d. Instructional strategies appropriate for serving students with special needs have been identified and incorporated into the industrial arts program.

e. The teacher utilizes facilities and resources available in the environment to enrich learning.

2. Student achlevement is measured through a variety of testing techniques and other evaluation methods.

3. Student leadership skills are developed through a variety of curricular and extracurricular activities.

\subsection{REVIEWING AND REVISING}

Instructional strategies are evaluated annually and revised when necessary.

1. Measures of student achievement are utllized to make systematic decisions regarding the effectivenes of instructional materials and teaching strategies.

2. Provisions are made for student input into the evaluation of instructional strategies. 
STANDARD 8 - PUBLIC REIATIONS

The statements contained within this standard topic concern public relations. An informed and involved public is essential to the promotion of an industrial arts program. Various media are utilized to inform target populations

\subsection{TARGET POPULATIONS}

The educational community, the lay public, the constituents, business and industry are informed of and given the opportunity to participate in industrial arts programs and activities.

1. Students, parents, faculty and staff, school administrators, and members of professional teacher organizations are informed of and given the opportunity to participate in industrial arts programs and activities.

a. Non industrial arts faculty and staff are informed about the industrial arts program for the purpose of generating support, guidance, and interdisciplinary educational opportunities.

b. Administrators are informed about and participate in the industrial arts program:

2. The industrlal arts faculty actively encourages community involvement and promotes a greater understanding of the program's needs and accomplishments.

a. Community service organizations are informed of and encouraged to support the industrial arts program.

b. Business and industrial personnel are informed of and given the opportunity to participate in industrial arts programs and activities.

c. Technical and professional labor organizations are informed of and encourajed to support and participate in the industrial arts program.

\subsection{MEDIA}

Various media are utilized to communicate the goals, objectives and accomplishments of the industrial arts program. 
1. Articles describing unique activities and accomplishments of the industrial arts program are prepared and published in the local news media on a regular basis.

2. Media events, including open houses, exhibits, displays, presentations, demonstrations, and industrial arts education week activities are utilized to promote the program. 


\section{ITANDARD 9 - SAFETY AND HEALTH}

The statements contained within this standard topic concurn safety and health. A comprehensive safety and health program is essential to the success of a quality industrial arts program. the program provides for a safe environment and promotes life-long attitudes and practices regarding safety and health.

\subsection{PROGRAM}

Learning experiences and activities are designed for the development of knowledge, skilis, and attitudes concerning the safe use of tools, machines, materials, and processes.

1. An instructional plan for safety and health is prepared utilizing community resources, administrative personnel, instructors, and safety literature.

a. Teachers prepare a written plan for a comprehensive safety and health program.

b. Administrative personnel provide input for and approval of the safety and health program.

c. Community resources, including the industrial arts advisory committee, provide input to the safety and health program.

d. SDA, local, state, and national safety and health literature and regulations are utilized in planning the safety and health program.

2. Safety and health instruction is documented and included in classroom and laboratory activities.

a. Safety and realth information is included in instruction for all laboratory activities.

b. Teacher and student activities reinforce safety and health instruction.

c. Safety and health instruction is adapted to individual student needs.

3. Techniques are utilized to assess the effectiveness of the safety and health program. 
a. Safety and health practices are monitored continuously and reviewed annualiy by the teacher.

b. Proper authorities, external to the school, inspect periodically and report on the safety and health program.

c. Students demonstrate acceptable knowledge, skills, and attitudes of safety and health practices and rules through written and performance tests, and inclass behavior.

d. Teachers and administrators review each recorded accident and all unsafe practices to correct deficiencies.

\subsection{PHYSICAL ENVIRONMENT}

The physical facilities and equipment are designed, constructed, and maintained to ensure a safe and healthful learning environment.

1. Laboratory facilities meet safety and health laws and regulations.

2. Laboratory facilities conform to acceptable industrial arts safety and health practices.

a. Safety zones and aisles are properly marked.

b. Lighting is appropriate for the activities performed within the facility.

c. Proper exhaust system equipment which removes fumes, chips, and dust from the building is provided.

d. Proper equipment is provided to heat, cool, and ventilate all instructional and ancillary areas.

e. Approved safe cabinets, containers, or rooms are provided to store flammable and corrosive materials.

f. Special safety and health accommodations are provided for students with special needs.

g. Floors and all other surfaces are kept free of waste material, grease, and obstructions. 
h. Floors have non-skid surfaces, with special application on machine-operator work areas.

i. Each laboratory with powered equipment has the equivalent of one easily accessible emergency disconnect switch (panic button) per perimeter wall.

j. Fire extinguishers of the correct class are provided in appropriate locations.

k. A first-aid kit and related emergency supplies are provided in accordance with local regulations.

1. Facilities are available (sink unit, paper towel and soap dispenses) for students to wash before leaving the laboratory.

3. Machines and tools are selected, organized, guarded, color coded, controlled, and ventilated in accordance with regulations and codes.

a. Equipment which satisfles state and federal regulations is selected on the basis of the ability to meet program objectives safely.

b. Machines and tools are placed, mounted if necessary, and arranged in $a$ safe and functional manner.

c. All machines and power tools are provided with approved commercial guards and safety devices.

d. Safety guards remain in place, except when the machine is disconnected for cleaning, repair, or adjustment.

e. Any machine or tool found to be unsafe is removed from service and marked accordingly.

f. Color-coding schemes for safety purposes are used throughout the industrial arts laboratory.

g. Conveniently located magnetic control switches and/or control boxes and braking devices are provided for appropriate machines.

h. Lockable master switch boxes are located in each industrial arts laboratory.

1. Machines and work stations where dust or fumes are 
produced beyond accepted health limits are connected to an exhaust system.

4. Personal protection devices are used by teachers, students, and visitors to maximize safety, and such devices are sanitized to maximize health in the laboratory.

a. State or federally approved eye protection devices are required of all persons exposed to conditions wht.ch may cause eye injury.

b. State or federally approved ear protction devices are required of all persons exposed to conditions which may cause ear damage.

c. State or federally approved respiratory protection devices are required of all persons exposed to conditions which may cause respiratory problems.

d. State or federally approved head protection devices are required of all persons exposed to conditions which may cause head injury.

e. Specially adapted personal protection devices are avallable for and used by students with special needs.

f. Teachers and students wear approprlate clothing when exposed to conditions which warrant such protection.

g. Personal protection devices requiring sanitation are sanitized after each use.

5. Corrective and preventive maintenance is performed with in a reasonable time following written notification to the appropriate administrator.

\subsection{RECORDS}

Records are on file to document the existence of an effective safety and health program.

1. Safety and health instructional records are on file.

a. Lesson plans documenting provision for safety and health instruction are on file.

b. Results of written and performance tests and 
observations documenting student safety and health knowledge, attitudes, and skills are on file.

2. Records detalling current safety and health conditions in the facility are on file.

a. Inspection maintenance, repair, and replacement records are current and on file.

b. Records of each accident and the follow-up procedures taken are on file.

c. Emergency procedures for responding to accidents are posted and on file. 
STANDARD 10 - EVALUATION

The statements contained within this standard topic concern the evaluation process. All elements of the program are systematically and continuously assessed and compared to desired standards. The standards in this document serve as bases for the evaluation of industrial arts programs.

\subsection{ESTABLISHING A DATA COLIECTION AND ANALYSIS SYSTEM}

Appropriate procedures are established and utilized to obtain valid and reliable information for program assessment.

1. Teachers and administrators determine what aspects of the industrial arts program are to be included in the data collection and analysis system.

2. Instruments, based upon the standards contained in this document, are designed and/or selected to obtain valid and rellable information.

3. A range of evaluative techniques is utilized, sufficient to encompass the range of outcomes and elements to be evaluated.

\subsection{COILECTING AND ANALYZING DATA}

Data on selected aspects of the industrial arts program are collected on a prescribed schedule.

1. Instruments are administered annually to collect valid and reliable data on selected aspects of the industrial arts program.

2. Data on the total industrial arts program are collected at least once every seven years.

3. Data are collected in compliance with accrediting agencies and church, state, and federal mandates.

4. Valid procedures are utilized to analyze data and identify discrepancies between the current program and the standards in this document. 


\subsection{REPORTING}

An assessment report containing data, notations of discrepancies, and recommendations is made annually.

1. Findings from the data collection and analysis efforts are disseminated to the evaluator, the evaluatee, and to appropriate decision makers.

2. Discrepancles between program status and standards are reported to appropriate decision makers.

3. Recommendations for correcting deficiencies are reported to appropriate decision makers.

\subsection{DECISION MAKING}

Decisions for program improvement are based upon the assessment report.

1. A written course of action is developed for overcoming each deficiency.

2. Priorities are determined and actions are implemented to correct deficiencies.

3. The effectiveness of the courses of action taken is assessed. 
APPENDIX K

\section{DELETED STANDARDS}

Reproduced with permission of the copyright owner. Further reproduction prohibited without permission. 


\section{Standards Deleted}

The following standards are those which did not meet the criteria set for validity, and so are not included in the standards document.

1. Students are involved in developing the philosophical statement.

2. The philosophy focuses upon the broad categories of communication, construction, manufacturing, and transportation.

3. The Industrial arts teacher is prepared, through preservice/inservice education to utilize denominationaliy prepared and adopted curriculum guides.

4. Written administrative policies and directives, specifically addressing the operation of the indus trial arts program and cooperatively developed by administration and staff, are available.

5. Books and other instructional materials contain sexfair language and images and provide a wide range of role options.

6. Parents support and participate in the industrial arts program by functioning as paraprofessionals, advisors, or resource people.

7. Local, state, and national professional assoclations are informed about and participate in the industrial arts program.

8. Handbooks and brochures describing the industrial arts program, goals, objectives, and policies are prepared and utilized. 


\section{SELECTED BIBLIOGRAPHY}

Adams, I. La Mar, and Gale, Darwin. "Sclving the Quandry between Questionnaire Length and Response Rate in Educational Research." Research in Higher Education 17 (1982): 231-140.

Adler, Felix. "Technical and Art Education in Public Schools." Proceedings and Addresses of the National Education Association. Madison, WI: NEA, 1884.

Alexander, Bill. "Putting It All Together." Man/Society/ Technology 33 (November 1973):43-48.

Alwin, Duane F., ed. Survey Design and Analysis, Current Issues. Beverly Hills, CA: Sage Publications, 1978.

American council of Industrial Arts supervisors. Industrial Arts Education. Washington, DC: American Industrial Arts Association, 1969.

American Psychological Association. Standards for Evaluation of Educational Programs, Projects and Materials. New York: McGraw-Hill, 1981.

American Vocational Association. A Guide to Improving Instruction in Industrial Arts. Washington, DC: American Vocational Association, 1952.

- Instruments and Procedures for the Evaluation of Vocational/Technical Education. Washington, DC: American Vocational Association, 1971.

"An Interview with Three Curriculum Experts." Man/ Society/Technology 40 (December 1980):9-12.

Andreason, Alan R. "Personalizing Mail Questionnaire Correspondence." Public Opinion Quarterly 34 (1970): 273-277.

Anderson, John F., and Berdie, Douglass R. "Effects on Response Rates of Formal and Informal Questionnaire Follow-up Techniques." Journal of Applied Psychology $60(1975): 255-257$. 
Armstrong, J. Scott, and overton, Terry S. "Estimating Nonresponse Bias in Mail Surveys." Journal of Marketing Research 14 (August 1977) :396-402.

Babbie, Earl R. The Practice of Social Research. 2nd ed. Belmont, CA: Wadsworth Publishing Co., 1979.

- Survey Research Methods. Belmont, CA: Wadsworth Publishing Company, 1973.

Babcock, G. "Work-study Programs in SDA Schools." The Journal of Adventist Education 42,2 (April-May 1980):33-34, 39-40.

Backus, Rerby D. "A Study of Perceived Objectives of Industrial Arts among superintendants, Industrial Arts Coordinators and Industrial Arts Teachers of six Public School Districts of Texas." (Ed.D. dissertation, Colorado State University, 1968). Dissertation Abstracts International/A 2908 (1969):2583.

Barlch, Dewey F. "Observations of a Former Industrial Arts Educator." Man/Society/Technology 36 (February 1977): $143-145$.

Barlow, Melvin I. History of Industrial Education in the United States. Peoria, IL: Chas. A. Bennett Co., 1967 .

Barnett, Jim. "A Time to Return to the Fundamentals in Industrial Arts Education." Man/Society/Technology 41 (January 1982):17-18.

Barrier, Lyn P., ed. Contemporary Approaches for Teaching Technology. Richmond, VA: American Council of Industrial Arts supervisors, 1983.

Bateson, Willard M. "The Determination of Standards for Industrial Arts Iaboratories." Ph.D. dissertation, University of Michigan, 1952.

Bauer, E. Jackson. "Response Bias in a Mail Survey." Public Opinion Quarterly il (1947):594-600.

Bell, Daniel. The Coming of Post Industrial society. New York: Basic Books, 1973.

Bennett, C. A. History of Manual And Industrial Education 1870 to 1917 . Peoria, IL: C. A. Bennett, 1937.

- "Industrial Arts in Senior High Schools." Industrial Education Magazine 26 (February 1925): 226 . 
Bensen, M. J. "Summary--A Parting Perspective." In Technology and Society: Interfaces with Industrial Arts, pp. 334-340. Edited by $\mathrm{H}$. A. Anderson and M. J. Bensen. American Council on Industrial Arts Teacher Education 29th Yearbook. Bloomington, IL: McKnlght, 1979 .

Berdie, D. R. "Questionnaire Length and Response Rate." Journal of Applied Psychology 58 (1973):278-280.

Berdie, D. R., and Anderson, J. F. Questionnaires: Design and Use. Metuchen, NJ: Scarecrow Press, 1974.

Black, J. A., and Champion, D. J. Methods and Issues in Social Research. New York: John Wiley \& Sons, 1976.

Blalock, H. M., Jr. Social Statistics. 2nd ed. New York: MCGraw-Hili, 1972 .

Blumberg, Herbert $H$. "Response Rates in Postal Surveys." Public opinion Quarterly 38 (1974): 113-123.

Bock, Walter E., and Iade, James H. "A Test of the Usefulness of the Post-card Technique in a Mail Questionnaire study." public opinion Quarterly 27 $(1963): 304-306$.

Bode, B. H. Industrial Arts and the American Tradition. Columbus, OH: Epsilon P1 Tau, 1942.

Bonser, Fredrick G., and Mossman, Lois C. Industrial Arts for Elementary Schools. New York: Macmillan Co., 1938 .

Bonser, Fredrick G., and Russell, James E. Industrial Education. New York: Teachers College, Columbia University, 1914.

Boyd, H. W., and Westfall, R. Marketing Research. 3 rd ed. Homewood, IL: Richard Irwin, 1972.

Bracht, G., and Glass, G. "The External Validity of Experiments." American Educational Research Journal $5(1968): 437-7 \overline{4}$.

Brown, R. Model of a Theoretical Base for Industrial Arts Education. Washington, DC: American Industrial Arts Association, 1977.

Brown, Morton L. "Use of a Postcard Query in Mail surveys." Public opinion Quarterly 29 (1965):635-637. 
Brunner, Allen G., and Carroll, stephen J. "The Effect of Prior Telephone Appointments on Completion Rates and Response content." Public opinion quarterly 31 $(1967-8): 652-654$.

Bucher, Mary Ann et al. Learring Resource Center Standards for Vocational Programs. Columbus, OH: Ohio Educational Iibrary, 1979. (ERIC Document Reproduction Service No. Ed 179 215).

Campbell, D. T., and stanley, J. C. "Experimental and Quasi Experimental Designs for Research and Teaching." In Ha:hdbook of Research on Teaching, pp. 171-246. Edited by N. I. Gage. Chicago: Rand McNally, 1963.

Carithers, Polly. How to Conduct Low Cost Surveys. Arlington, VA: National School Public Relations Association, 1973.

Carpenter, Edwin H. "Personalizing Mail Surveys: A Replication and Reassessment." Public Opinion Quarterly 38 (1974):614-620.

Champion, Dean J., and Sear, Alan M. "Questionnaire Response Rilte: A Methodological Analysis." Social Forces 47 (1969):335-339.

Cooley, william W., and Lohnes, Paul R. Evaluation Research in Education. New York: Irvington Publishers, 1976.

Cooper, Sarah, B. "The Kindergarten as a Child Saving Work." Proceedings of the National Conference of Charities and Correction. St. Paul, MN: n.p., 1886.

Copeland, Ieon I. "Industrial Arts: A Call for Change." Man/Society/Technology (April 1982):10-12.

Copeland, Leon I., and Bame, Allen E. "A National Study Using the Delphi Technique to Identify Teacher Competencies for Evaluating Industrial Arts student Teachers." Journal of Industrial Teacher Education 16 (1979): 39-49.

Corpus Christi Public schools. The Industrial Arts Teaching Guide, Introduction to General shop. Corpus christi, TX: Corpus Christi Public schools, 1973.

Council for Exceptional Children. Professional Standards for Personnel in the Education of Exceptional Children. Washington, DC: Council for Exceptional Children, 1966. (ERIC Document Reproduction Service No. Ed 071285 ). 
Cox, Ell P., III; Anderson, Thomas, Jr.; and Fulcher, David G. "Reappraising Mail Survey Response Rates." Journal of Marketing Research 11 (November 1974): 413-417.

Crawford, Harold $R_{.}$, and Carter, Richard I. Standards for Quality Vocational programs in Agriculture/ Agri-business Education. Ames: Iowa state University, 1977 .

Cremin, Lawrence A.; Shannon, David A.: and Townsend, Mary E. A History of Teachers College, Columbla University. New York: Columbia University Press, 1954 .

Daniel, Wayne พ. "Nonresponse in Soclologlcal Surveys: A Review of Some Methods of Handling the Problem." Sociological Methods and Research 3 (February 1975):291-307.

Davis, J. A. Elementary Survey Analysis. Englewood Cliffs, NJ: Prentice Hall, 1971.

Dean, Arthur D. Our Schools in War Time--and After. Boston: Ginn and Company, 1918.

Demaline, Randy E., and Quinn, william D. Hints for Planning and conducting a Survey and a Bibliography of Survey Methods. Kalamazoo, MI: Evaluation Center, Western Michigan University, 1979.

DeTombe, Robert F. "Essential Content for Motor Cycle operator Handbooks Published by the state Department of Motor vehicles." Ed.D. dissertation, West Virginia University, 1974 .

Devore, P. W. Structure and content Foundations for Curriculum Development. Washington, DC: American Industrial Arts Association, 1968.

Dewey, John. School and Society. Rev. ed. Chicago: University of Chicago Press, 1915.

Dillman, Don A. "Increasing Mail Questionnaire Response In Large Samples of the General Public." Public opinion Quarterly 36 (1972):254-257.

- Mall and Telephone Surveys. New York:

John wiley and Sons, 1978 .

Dillman, Don A., and Frey, James H. "Contribution of Personalization to Mail cuestionnaire Response as an Element of a Previously Tested Method." Journal of Applied Psychology 59 (1974):297-301. 
Dixon, พ. J., and Brown, M. B. Biomedical Computer Programs, $P$ series. Berkeley, CA: University of California Press, 1979.

Doll, R. C. Curriculum Improvement. 4th ed. Boston: Allyn and Bacon, 1978.

Drezek, S.; Holly, F. M.; Ligon, G; and Matuszek, P. "How to Get More Back: Increasing Questionnaire Return Rates". Paper presented at the American Educational Research Association, Toronto, March 1978.

Dugger, William E., Jr. "Report of Survey Data." In Standards for Industrial Arts Education Prograns Project. Blacksburg, VA: Virginia Polytechnic Institute and state University, 1980c.

- "The Standards for Industrial Arts Programs Project: An Overview." Journal of Industrial Teacher Education 18, 1 (Fall 1980a):5-13.

- "Update on the Standards for Industrial Arts Education Programs Project." Man/Society/Technology (September-October 1980b): 16-18.

Dugger, William E., Jr., ed. Standards for Industrial Arts Programs. Blacksburg, VA: Virginia Polytechnic Institute and state University, 1981.

Duvall, J. Barry. "The Year 2000 and Industrial Arts." Man/Society/Technology (May-June 1980):18,19,30.

Employment and Training Administration. National Apprentiship standards for Automotive Service Councils. Washington, DC: Department of Labor, 1977. (ERIC Document Reproductinn Service No. Ed 147 646).

Erdos, Paul L. "How to Get Higher Returns from Your Mail surveys." Printers Ink, February 1957a, pp. 30-31.

- Professional Mail surveys. New York:

McGraw-Hill, 1970 .

. "Successful Mall Surveys: High Returns." Printers Ink, March 1, 1957b, pp. 56-60.

Evans, Rupert N. "Possible Futures in Industrial Education and The Mississippi Valley Industrial Teacher Education Conference (MUITEC)." Journal of Epsilon Pi Tau 8 (Spring 1982):12-17.

Feirer, J. "Back to Basics." Industrial Education 68 $(1979): 2$. 
Feirer, John I., and Iindbeck, John R. Industrial Arts Education. Washington, DC: Center for Applied Research in Education, 1964.

Ferber, R., ed. Handbook of Marketing Research. New York: McGraw-Hill, 1974.

Ferber, R; Sheatsley, Paul; Turner, Anthony; and Wa'sburg, Joseph. What Is a Survey? Washington, DC: American Statistical Association, 1580.

Ferris, A. L. "A Note on Stimulating Fesponse to Questionnaires." American Sociologlcal Review 16 (1951):247-249.

Filion, F. L. "Estimating Bias Due to Nonresponse in Mail Surveys." Public opinion Quarterly 39 (1975): 482-492.

Ford, Neil M. "Questionnaire Appearance and Response Rates in Mail Surveys." Journal of Advertising Research 8 (1968):43-45.

Francis, J. B., and Bork, C. Design and Administration of Mall Questionnaires. Williamsville, New York: Action Research Associates Press, 1979.

Francis, J. Bruce; Frey, James H.; and Harty, Harold. "Advantages and Disadvantages of Different Survey Techniques." New Directions for Institutional Advancement 6 (1979):11-18.

Frary, Jill M.; Elson, Donald E; and Gerken, Shirley $H$. "Using Mail Questionnaires in Vocational Education Research: The Need for Follow-up." The Journal of Vocational Education Research 6 (Spring 1981): 41-54.

Fuglsby, Glen O. "A Widened Horizon." Man/Society/ Technology 37 (May-June 1978):22-24.

Fuller, Carol. "Effect of Anonymity on Return Rate and Response Bias in a Mail Survey." Journal of Applied Psychology 59 (1974):292-296.

Fuqua, Dale R. Survey Research in Higher Education. Grand Forks, ND: University of North Dakota, 1977. (ERIC Document Reproduction Service No. Ed 209 259).

Futrell, Charles M., and Lamb, Charles w. "Effect on Mail Survey Returns Rates of Including Questionnaires with Follow-up Letters." Perceptual and Motor Skills 52 (1981) : 11-15. 
Gannon, Martin J.; Nothern, Joseph C.; and Carroll, Stephen J. "Characteristics of Nonrespondents among Workers." Journal of Applied Psychology 55 (1971): 586-588.

Gebhart, R. H. "Developing American Industry Courses for the secondary school." In American Industry Project Bulletin. Menomonie, WI: University of Wisconsin-stout, March 1968.

Glock, C. Y., ed. Survey Research in the social sciences. New York: Russell Sage Foundation, 1967.

Goldstein, Larry, and Freidman, Hershey H. "A Case for Double Postcard in Surveys." Journal of Advertising Research 15 (April 1975):43-47.

Godstadt, Michael s. et al. "Mail Survey Response Rates: Their Manipulation and Impact." Journal of Marketing Research 14 (August 1977): 391-395.

Gray, Madeline. A Profect to Develop a Methodology to Establish standards of Job Performance and Continuing Education opportunities for Maintaining competency of Occupational Therapists. Rockvilie, MD: American Occupational Therapy Association, 1976. (ERIC Document Reproduction Service No. Ed 133453 ).

Griffin, wilma P., ed. Standards for Vocational Home Economics Education. Austin, TX: University of Texas at Austin, 1981.

Gullahorn, Jeanne E., and Gullahorn, John. "An Investigation of the Effects of Three Factors on Response to Mail Questionnaires." Public opinion Quarterly 27 (1963):294-96.

Hacker, Michael. "The syosset Plan." Industrlal Arts and vocational Education 58 (January 1969):24-25.

Hacker, Michael, and Barden, Robert. "A Systems Approach to Technology Education." Man/Society/Technology 42 (March 1983):9-14.

Hackler, James C., and Bourgette, Patricia. "Dollars Dissonance and survey Returns." Public opinion Ruarterly 37 (1973):276-281.

Hales, J. A., and snyder, J. F. "Jackson's Mill Industrial Arts Currriculum Theory: A Base for Curriculum Conceptualization." Man/Society/ Technology 41,5 (1982a): 6-10. 
- "Jackson's Mill Industrial Arts Curriculum Theory; A Base for Curriculum Conceptualization." Man/Society/Technology 41, 6 (1982b):6-8.

Harty, Harold. "Questionnaire Design and Administration." New Direction for Institutional Advancement 6 (1979): 45-57.

Healey, William C. Standards and Guidelines for Comprehensive Language Speech and Hearing Problems in the Schools. Washington, DC: American Speech and Hearing Association, 1974. (ERIC Document Reproduction Service No. Ed 089480 ).

Hemp, Paul E. Development and Validation of standards for Teacher Education in Agriculture. Normal, II: Department of Vocational and Technical Education, Illinois State University, 1979. (ERIC Document Reproduction Service No. Ed 173641 ).

Hemsley, Wayne E. "Increasing Response Rate by Choice of Postage Stamps." Public Opinion Quarterly 38

$(1974): 280-283$.

Herschbach, Dennis R. "The Roots of Industrial Arts: Late l9th Century Social Reform." Man/Society/Technology 39 (November 1979): 10-14.

Hildreth, Kenneth H. "Occupational Safety and Health standards Applicable to Industrial Arts operations in Schools." Ed.D. dissertation, Virginia university, 1976 .

Hochstim, Joseph R., and Athanasopolous, Demetrios A. "Personal Follow-up in a Mall Survey: Its Contribution and Its Cost." Public opinion Quarterly 34 (1970): 69-8I.

Hornbake, R. I. "What Is the Place of Industrial Arts in the American Culture?" Man/Society/Technology 40 $(1980): 25-29$.

House, James $s$. et al. "Increasing Mail Questionnaires Response: Controlled Replication and Extension." Public Opinion Quarterly 41 (1977):95-99.

Houston, Michael J., and Jefferson, Robert. "The Negative Effects of Personalization on Response Patterns in Mail Surveys." Journal of Marketing Research 11 (February 1975):114-117.

Hyman, H. Survey Design and Analysis. New York: Free Press, 1955. 
IIlinois State Board of Education. Illinols Plan For Industrial Education. Springfield, IL: Illinols State Board of Education, 1983.

Innes, Allison R. Blases: Threats to Validity in Evaluation Models. New York: Paper presented at the annual meeting of the American Educational Research Association, March 19-23, 1982. (ERIC Document Reproduction Service No. Ed 218352 ).

Iowa state University. Development of Standards for Textiles and Clothing Post Secondary Programs. Ames, IA: Iowa state University of Science and Technology, Department of Home Economics Education, 1979. (ERIC Document Reproduction Service No. Ed 174829 ).

Isaac, S., and Michael, W. B. Handbook in Research and Evaluation. San Diego, CA: Edits Publishers, 1980.

Israel, Everett. "Stagnation in Industrial Arts. Pt. 1." Man/Society/Technology 40 (January 198la):3-5.

- "Stagnation in Industrial Arts. Pt. 2." Man/ Soclety/Technology 40 (February 1981b):9-11.

Jaeger, Richard M., and Wolf, Marian B. An Experimental Comparison of Four Methods of Assessing Parents Preferences for School system Goals. Greensboro, NC: North Carolina University, 1980. (ERIC Document Reproduction Service No. Ed 193 317).

Jensen, George Henry. "Industrializing the Manual Arts." National Education Association Proceedings. n.p. 1917.

Johnson, M. "Definitions and Models in Curriculum Theory." In Contemporary Thought on public school curriculum, pp. 42-49. Edited by E. Short and G. Marconnit. Dubuque, IA: Wm. C. Brown, 1971.

Joint Committee on Standards for Educational Evaluation. Standards for Evaluation of Educational Programs, Projects, and Materials. New York: McGraw-Hill, 1981.

Jolson, Marvin A. "How to Double or Triple Mail-survey Response Rates." Journal of Marketing (October 1977): 78-81.

Jones, Ralph H. Methods and Techniques of Educational Research. Danvilie, IL: Interstate Printers and Publishers, 1973.

Kalton, Graham. Compensating for Missing Data. Ann Arbor, MI: University of Michigan, 1983. 
Kansas State University. Validation of Instrument and Procedures for Evaluating Local Vocational Education Practices. Manhattan, KS: Kansas State University, 1978. (ERIC Document Reproduction Service No. Ed 186 640).

Kanuk, Leslie, and Berenson, Conrad. "Mall Surveys and Response Rates." Journal of Marketing Research 22 (November 1975): 440-453.

Kerlinger, F. N. Foundations of Behavioral Research. New York: Holt Rinehart and Winston, 1973 .

Kimball, Andrew E. "Increasing the Rate of Return in Mail Surveys." Journal of Marketing (October 1961): 63-64.

Kish, I. Survey Sampling. New York: John Wiley, 1965.

Kozak, Michael R. et al. Identification and Validation of Professional and Technical Competencies for Industrial Arts Teacher Educators of Texas. Denton, TX: North Texas State University, 1982. (ERIC Document Reproduction Service No. Ed 218485 ).

Lake Union Conference. Curficulum Guide/Course Outline for Practical and Industrial Arts K-12. Berrien Springs, MI: Iake Union Conference, Office of Education, 1982 .

- Evaluative Criteria for Seventh-day Adventist Schools $\mathrm{k}-10$. Berrien Springs, MI: Lake Union Conference, office of Education, 1982.

- Philosophy for Practical and Industrial Arts Education. Berrien Springs, MI: Lake Union Conference, office of Education, n.d.

Lange, Robert R., and Hayes, B. D. "Industrial Sciences-Technology Education for the 80's and 90's." Man/ Society/Technology 41 (November 1981):8-10.

Lansing, John B., and Morgan, James N. Economic Survey Methods. Ann Arbor, MI: Survey Research Center, University of Michigan, 1971.

Lauda, Donald P. "A Response to a Critical View: Technology Education." Journal of Epsilon P1 Tau 8 (Spring 1982):9-11.

- "Technology Education: A Concept in

Transition." In Symposium 180 , Technology Education Proceedings. Charleston, IL: Eastern Illinois University student Publications, 1980. 
Laverman, Gerald. Industrial Arts in the Christian School. Chlcago: National Union of Christian Schools, 1970.

Leslie, Larry I. "Increasing Response Rates to Iong Questionnaires." The Journal of Educational Research 63 (Aprt1 1970):347-350.

Leutkemeyer, Joseph. "Curriculum Development in Industrial Arts Education: A Critical Analysis." Man/ Society/Technology 42 (March 1983):2-4.

Levine, Sol, and Gordon, Gerald. "Maximizing Return on Mail Questionnaires." Public Opinion Quarterly 22 $(1958): 568-575$.

Lindbeck, J. R. Practical Guide to Industrial Arts Education. New York: Center for Applied Research in Education, 1972 .

Iindvall, C. Mauritz, and Nitko, Anthony J. "Basic Considerations in Assessing the Validity of Evaluation Designs." Educational Evaluation and Policy Analysis 3 (July-August 1981):49-60.

Linsky, Arnold s. "Stimulating Responses to Malled Questionnaires: A Review." Public Opinion Quarterly 39 (1975): 82-101.

Long, Sandra M. "The 1980 Census: Implications for Education." Phl Delta Kappa 62 (May 1981):619.

Longworth, Donald S. "Use of a Mail Questionnaire." American Sociological Review 18 (1953):310-313.

Looney, Eva F., and Hoerner, James L. Formulating Goals and Objectives for Vocational Education Programs. Blacksburg, VA: Virginia Polytechnic Institute and State University, Division of Vocational Technical Education, 1977. (ERIC Document Reproduction Service No. Ed 145 125).

Los Angeles County Superintendant of schools, Career Education section. California Industrial Arts Education Program Guide. Los Angeles, CA: Los Angeles County superintèndant of Schools, 1975.

Lucas, stephen R., and Miles, Benton E. The Development: of Standards for Distributive Education Programs. Washington, DC: American Vocational Association, 1978. (ERIC Document Reproduction Service No. Ed 203 041). 
Luck, D. J.; Wales, H. G. ; and Taylor, D. A. Marketing Research. 3rd ed. Englewood Cliffs, NJ: prentice Hall, 1970.

Luftig, Jeffrey $T$. "The Future of Industrial Arts: What Will Shape It?" Man/Society/Technology 36 (February 1977): 139-142.

Lux, D., and Ray, W. "Industrial Arts Curriculum Project." American Vocational Journal 44 (March 1969):61-62.

MCGinnis, Michael A., and Hollon, Charles J. "Mail Survey Response Rate and Bias: The Effect of Home Versus Work Address." Journal of Marketing Research 14 (August 1977): 383-384.

Mchale, John. The Future of the Future. New York: George Braziller, 1969.

McPherson, william $\mathrm{H}$. "Industrial Arts Education Identity Crisis." Man/Society/Technology 35 (February 1976): $138-140$.

Maley, Donald. The Maryland Plan. New York: Bruce, 1973. - "Perspectives on the Future: Industrial Arts Plays a Key Role in Future Education." Man/Society/ Technology 39 (January 1980):10-15, 29-30.

- "The Role of Industrial Arts/Technology Education for Student Development in Mathematics, science and other school subjects." Paper presented at the AIAA National Convention, Columbus, OH, March 1984.

Mangano, Ronald M. "Industrial Arts, Technology and the Future." Man/Society/Technology 35 (February 1976): 141, 147-149, 158 .

Marshall, B. G., and Gee, Carol Ann. Mail Questionnaire Research: A Selected Bibliography. Exchange Bibliography \#994. Monticello, II: Council of Planning Librarians, March 1976.

Martin, Gordon E. "A Contemporary Basis for the Development of a More Relevant Industrial Arts Curriculum." Journal of Industrial Teacher Education 11,1 (1973): 67-73. - "Curriculum Implications for Technology Education--1990." Man/Society/Technology 42 (April 1983): $4-6$. 
Martorella, Peter H. Standards for Secondary Social studies Teacher Education Programs. Paper presented at the annual meeting of the National Council for the social studies, Cincinnati, OH, 1977. (ERIC Document Reproduction Service No. Ed 146 109).

Maryland State Department of Education. Standards for Successful Mathematics Programs. Baltimore, MD: Maryland State Department of Education, Division of Instruction, 1978. (ERIC Document Reproduction Service No. Ed 162864 ).

Mason, Ward S.; Dressel, Robert J.; and Bain, Robert K. "An Experimental Study of Factors Affecting Response to a Mall Survey of Beginning Teachers." Public opinion Quarterly 25 (1961):296-299.

Matteson, Michael T. "Type of Transmittal Letter and Questionnaire Color as Two Variables Influencing Response Rates in a Mail Survey." Journal of Applied Psychology 59 (1974):535-536.

Mayer, Charles S., and Pratt, Robert $W$. "A Note on Non-response in a Mall Survey." Public Opinton Quarterly 30 (1966):637-646.

Meleney, Clarence E. "The True Object of Early School Training." In Proceedings and Addresses of the National Education Assoclation. Topeka, KS, n.p., 1886.

Michigan Industrlal Arts standards. Lansing, MI: Michigan Industrial Education Society, 1982.

Mignon, Edmond, ed. Proposed Standards for Education in online Searching. Seattle, WA: Washington University, school of Iibrarianship, 1978. (ERIC Document Reproduction Service No. Ed 157 553).

Miller, D. C. Handbook of Research Design and Social Measurement. 2nd ed. New York: David McKay, 1970.

Miller, Rex. "An Examination of the Objectives of Industrial Arts with Respect to selected sociological Factors of Contemporary American Society." (Ed.D. dissertation, University of Buffalo, 1961). Dissertation Abstracts International 2206 (1961):1922. - "The Project Is Alive and Doing Well." Industrial Education 63 (September 1974):26-27. 
Mitchell, J. The Plan for Futuring of Occupational and Practical Arts Education. Albany, NY: Office of Occupational and Continuing Education, Education Department, 1981.

Moore, Gary ผ. Developing and Evaluating Educational Research. Boston: Little, Brown \& Co., 1983.

Moore, Martin H. "The Postman Rings Thrice." Case Currents (May-June 1982):44-47.

Moser, C. A., and Kalton, G. Survey Methods in Social Investigation. 2nd ed. New York: Basic Books, 1972.

Moss, Gwenna. "Factors Affecting Response Rate and Response speed in a Mail survey of part-time university Students." The Canadian Journal of Higher Education 11 (1981): 79-89.

NADOE. Framework for Applied Arts $\mathrm{K}-12$. Washington, DC: North American Division Office of Education, General Conference of Seventh-day Adventists, 1979.

- Implementation of the: Seventh-day Adventist Curriculum K-12. Washington, DC: North American Division Office of Education, General Conference of Seventh-day Adventists, 1981 .

National Association of Industrial Teacher Educators. summary of studies in Industrial Education. Dearborn, MI: Ford Motor Company, 1953.

National Council for the soclal studies. Standards for Social studies Teachers. Washington, DC: National Council for the social studies, 1971. (ERIC Document Reproduction Service No. Ed 055 065).

National Association of Social Workers. Standards for Social Work Services in schools. Washington, DC: National Association of Social Workers, 1978. (ERIC Document Reproduction Service No. Ed 163 3io).

Nevin, John R., and Ford, Neil M. "Effects of a Deadline and a Veiled Threat on Mail Survey Responses." Journal of Applied Psychology 61 (1976):116-118.

Newell, M. A. "The President's Address." In Proceedings and Addresses of the National Education Association. Louisville, KY, N.P., 1877. 
New York City, Human Resources Administration. Handbook of Standards for Pre-school Group Day Care Centers. New York: New York City Human Resources Administration, 1979. (ERIC Document Reproduction Service No. Ed 184687 ).

Nixon, John E. "The Mechanics of Questionnare Construction." Journal of Educational Research 47 (March 1952): $48 \overline{1-487}$.

Ohio State University. Standards for Vocational Education in Correctional Institutions. Columbus, OH: Ohio state University, 1977. (ERIC Document Reproduction Service No. Ed 185350 ).

olson, Delmar W. "Interpreting a Technological society: The Function of Industrial Arts." School Shop 33 (March 1974): 35-36.

oregon state Department of Education. Industrial Arts in oregon Schools. Salem, OR: Oregon State Department of Education, 1967.

orr, David B. "Considerations, Costs, and Returns in a Iarge scale Follow-up study." The Journal of Educational Research 58 (April 1965):373-378.

Osterndorf, Logan. Summary of Offerings and Enrollments in Public Secondary Schools, 1972-1973. Washington, DC: U.S. Office of Education, National Center for Educational statistics, 1973.

Parten, M. Surveys, Polls, and Samples: Practical Procedures. New York: Harper and Bros., 1950.

Pascarella, P. Technology: Fire in a Dark World. New York: Van Nostrand Reinhold, 1979.

Pearlin, Leonard I. "The Appeals of Anonymity in Questionnaire Response." Public Opinion Quarterly 25 (1961):640-647.

Peoria Public Schools. Secondary school Curriculum Guide for Industrial Arts. Peorla, IL: Peoria public Schools, 1977 .

Peter, Richard, and Peter, Virginia. "Values Clarification Skills: Helping Problem Solvers Become Decision Makers." Man/Society/Technology 38

(November 1978):28-31.

Peterson, Robert A. "An Experimental Investigation of Mail Survey Responses." Journal of Business Research 3 (July 1975):139-209. 


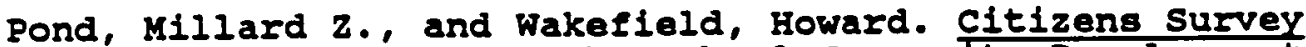
Their school Needs. The school Community Development Study Monograph Series, No. 1. Columbus, OR: Ohio state University, 1974.

Powers, Donald E., and Alderman, Donald I. "Feedback as an Incentive for Responding to a Mail Questionnaire." Research in Higher Education 17 (1982):207-210.

Prakken, Lawrence $w$. "Whither Industrial Arts?" Journel of Epsilon PI Tau 3 (Fall 1977):4-8.

President's Commission on School Finance. Schooling for the Future. Ios Angeles, CA: Educational Inquiry, 1970. Quoted in kendall starkweather, "The

Nature of Industrial Arts in a Post-industrial

Society." Man/Society/Technology 35 (April 1976): 196-200.

Pride, Cletis. "Building Response to a Mail survey." New Directions for Institutional Advancement 6 (1979): 59-69.

Raj, Des. The Design of Sample Survey. New York: MCGraw-Hill, 1972 .

Rationale for the Teaching of Practical Arts. n.p., n.d.

Ray, W. E. "Toward Consensus Regarding an Industrial Arts Curriculum Base." Journal of Epsilon P1 Tau 6, 2 $(1980): 8-12$.

Resnick, Harold s. Validation of the Competencles Needed by Vocational education Teachers, Middle Managers and Administrators. Boston: Boston University, School of Education, 1977. (ERIC Document Reproduction Service No. Ed 146408 ).

Ressler, Ralph. "The Project Method vs. Technology Education." Man/Soclety/Technology 36 (May-June 1977):232, 250 .

Review and Herald Publishing Association. Seventh-day Adventist Yearbook. Washington, DC: Review and Herald Publishing Association, 1983.

Richards, Charles R. "Industrial Arts." Manual Training Magazine $6(1904): 32-33$.

Richardson, E. S. Readers Digest, 1976. Quoted in Kendall N. Starkweather, "The society of the Future: Implication for Learning Through Industrial Arts." Journal of Epsilon P1 Tau 4 (Fall 1978):10-15. 
Ritz, John M. "Technology as the Content Base for Industrial Arts." Man/Society/Technology 41 (September-october 198I):2-4.

Roberts, william E. Standards of Attainment in Industrial Arts Teaching, Washington, DC: American vocational Association, 1934.

Robinson, R. A. "How to Boost Returns from Mail Surveys." Printers Ink, June 6, 1952, Pp. 35-37.

Robinson, R. A., and Agism, Phillip. "Making Mail Surveys More Reliable." The Journal of Marketing 15 (1951): 415-24.

Rocher, G. Allan. "Effective Techniques in Increasing Response to Malled Questionnaires." Public opinion Quarterly 27 (1963):299-302.

Roth, Robert A. How to Conduct Surveys, Follow-up studies, and Basic Data Collection in Evaluation Studies. Washington, DC: University Press of America, 1981.

Sackman, Harold. Delphi Critique. Lexington, MA: Lexington Books, 1975 .

Sax, Gilbert. Foundations of Educational Research. Englewood Cliffs, NJ: Prentice Hall, 1979.

Schmid, Calvin F., and Schmid, stanton E. Handbook of Graphic Presentation. 2nd ed. New York: John Wiley and Sons, 1979.

Schmitt, Marshall L. "Trends in Industrial Arts." School Shop 36 (September 1976):37-38.

Schmitt, Marshall I., and Pelley, Albert I. Industrial Arts Education. Washington, DC: U.S. Government Printing office, 1966.

Schroeder, Paul E. National study of Vocational Education in Correctional Facilities. Final Report. Columbus, OH: Ohio State University, National Center for Research in Vocational Education, 1977. (ERIC Document Reproduction service No. Ed 151 569).

scott, Christopher. "Research in Mail Surveys." Journal of Royal statistical society 124 (1961):143-205.

Scott, F. G. "The Use of Mail Questionnaires." Sociology and Social Research 41 (1957): 281-284. 
Selltiz, Claire; Jahoda, Marle; Deutsch, Morton; and Cook, Stuart $\mathrm{w}$. Research Methods in Social Relations. Rev. ed. New York: Holt, Rinehart and Winston, 1959.

Sheets, Norman I. "The Development and Application of Evaluative Criteria for Undergraduate Professional Preparation in physical Education in Institutions of Higher Learning in the state of West Virginia." Ed.D. dissertation, west virginia University, 1958.

Simon, J. I. Basic Research Methods in Social Sciences: The Art of Empirical Investigation. New York: Random House, 1978 .

Smith, Homer $\mathrm{H}$. Improving Instruction in Industrial Arts. Washington, DC: American Vocational Association, Industrial Arte Division, 1948.

Snelling, w. Rodman. "The Impact of a Personalized Mail Questionnaire." The Journal of Educational Research 63 (November 1969):126-129.

Southern Regional Education Board. Guldeline Standards for Prevention/Promotion Services in Mental Health. Atlanta, GA: Southern Regional Education Board, 1980. (ERIC Document Reproduction Service No. Ed 205 853).

starkweather, Rendall N. "Industrial Arts in a Post-Industrial Age." American Vocational Journal 51 (November 1976C) : 82-85.

- "The Nature of Industrial Arts in a Post-Industrial Society." Man/Society/Technology 35 (April 1976a):196-200.

- "The Society of the Future: Implications for Learning through Industrial Arts." Journal of Epsilon P1 Tau 4 (Fal1 1978): 10-15.

- "A Study of Potential Directions for Industrial Arts toward the Year 2000 A.D." Journal of Industrial Teacher Edication 31, 2 (1976b): 64-70.

Stitt, Thomas R. Standards for Quality Agricultural Occupations programs as Validated by the Agricultural occupations Teachers in the Secondary and Area Vocational Centers. Carbondale, IL: Southern Illinois University, 1978. (ERIC Document Reproduction Service No. Ed 163174 ). 
Stitt, Thomas R. et al. Standards for Quality Programs in Agricultural occupations in the secondary schools and Area vocational Centers of Illinols. Carbondale, IL: Southern IIIInois University, 1979. (ERIC Document Reproduction Service, No. Ed 173 600).

Stombaugh, Ray, A Survey of the Movements Culminating in Industrial Arts Education in Secondary Schools. New York: College Press, 1936.

strong, Merle E., and schaefer, Carl J. Introduction to Trade, Industrial and Technical Education. Columbus, OH: Charles E. Merrill Publishing Company, 1975.

Sudman, Seymour. Applied Sampling. New York: Academic Press, 1976.

- Reducing the cost of Surveys. Chicago: Aldine Publishing Company, 1967.

Sudman, S., and Bradburn, N. M. Response Effects in Surveys: A Review and Synthesis. Chicago: Aldine Publishing Company, 1974 .

Svendsen, E. A., ed. "Action and Thought in Industrial Arts Education." In American Council on Industrial Arts Teacher Education 12th Yearbook. Bloomington, II: MCKnight and MCKnight Publishing Company, 1963.

Taxis, Iinda A., ed. Man/Society/Technology. Washington, DC: American Industrial Arts Association, 1970.

Technical Foundation of America. Industry and Technology Education. Lansing, II: Technical Foundation of America, n.d.

Thomas, John H.; Smith, Stuart C.; and Hall, John S. Polling and Survey Research. Arlington, VA: National School public Relations Association, 1973.

Toffler, A. The Eco Spasm Report. New York: St. Martin's, 1964 ; Bantam Books, 1975.

- Future Shock. New York: Random House, 1970: Bantam Bocks, 197I.

- The Third Wave. New York: Morrow, 1980.

Tyack, D., and Hansot, E. "Hard Times, Hard Choices: The Case for Coherence in Public School Leadership." Phi Delta Kappan 63 (1982):511-515. 
Tyler, Ralph $\%$. Basic Principles of Curriculum and Instruction. 1974 ed. Chicago: University of Chicago Press, 1949 .

Tyler, Ralph, and Miller, Richard. "Social Forces and Trends." In Contemporary American Education. Edited by S. Dropkin, H. Full and E. Schwarcz. New York: Macmilian Company, 1966.

U.S. Bureau of the Census. "Profections of the Population of the United States; 1975-2050." In Current Population Report series $\mathrm{p}-25$, No. 601. Washington, DC: Government Printing office, July 5, 1977.

U.S. Congress, Congressional Clearinghouse on the Future. Harris Foil Finds Significant Changes in himericans. Washington, DC: Government Printing office, December 1977 .

U.S. Department of the Interior, Bureau of Education. "Industrial Arts in Secondary Schools in the War Emergency." In Secondary School Circular No.4, p.3. Washington, DC: Government Printing office, September 1918.

Vaughn, Samuel J., and Mays, Arthur B. Content and Methods of Industrial Arts. New York: Century Company, 1924.

Veiga, John $F$. "Getting the Mail Questionnaire Returned: Some Practical Research Considerations." Journal of Applied Psychology 59 (1974):217-218.

Vescera, Thomas P., and DiMeo, Peter A. "Industrial Arts Education, Futurism, and Professional Responsibility." Man/Society/Tachnology 41 (February 1982):13-14.

Vickery, Robert D. Curriculum Guide for Power Technology. Elwood, IN: Elwood Community High School, n.d.

Virginia state Department of Education. Standards of Excellence for Reading Programs in Virginia. Richmond, VA: Virginia state Department of Education, 1976. (ERIC Document Reproduction Service No. Ed 167 971).

Vocino, Thomas. "Thrse Variables in stimulating Responses to Mailed Questionnaires." Journal of Marketing (October 1977):76-77.

Walker, Bruce J., and Burdick, Richard K. "Advance Correspondence and Error in Mail Surveys." Journal of of Marketing Research 14 (1977):379-382. 
Walker, Robert, and Hemp, Paul E. Standards for

Agricultural occupations Programs in Illinois

Community colleges. Urbana, IL: Illinois University, Division of Agricultural Education, 1978. (ERIC

Document Reproduction Service No. Ed $164: 94)$.

Walters, John C. "Technology Education: Teaching Industrial Arts to Its Fullest Potential." Man/ Society/Techrology 36 (May-June 1977):233-235.

Warner, W. E. Policies in Industrial Arts Education. Columbus, OH: Ohio State University Press, 1928.

Watson, John J. "Improving the Response Rate in Mail Research." Journal of Advertising Research 5 $(1965): 48-50$.

Weatherspoon, Everette. "Effecting Curriculum Change in Industrial Arts through Systems Analysis." Man/ Society/Technology 35 (April 1976):207-209.

Wenrich, Ralph C., and Wenrich, J. William. Leadership in Administration of Vocational and Technical Education. Columbus, OH: Charles E. Merrill Publishing Company, 1974.

White, E. G. Counsels on Education. Mountain View, CA: Paciflc Press Publishing Association, 1968.

- Counsels to Parents, Teachers, and students. Mountain view, CA: Pacific Press Publishing Association, 1943.

wilber, Gordon 0 . Industrial Arts in General Education. Scranton, PA: International Textbook Co., 1948 .

Wiseman, James Allen. "An Evaluation of Driver Handbook Content Based on Life Saving Potential and

Administrative Necessity." Ed.D. dissertation, West Virginia University, 1972 .

Worthington, Robert M. "Industrial Arts Education: Issues and Directions." Journal of Epsilon Pi Tau 8 (Spring 1982): 18-24.

Wright, R. J. "Perspective: Industry as the Content Base for Industrial Arts." Man/Society/Technology 41 (April 1982):2・*4

Yarbrough, Earl G. "A Contemporary Role for Industriai Arts." Journal of Epsilon Pi Tau 3 (Fall 1977): $18-24$. 
zimmer, Herbert. "Validity of Extrapolating Nonresponse

Bias from Mail Questionnaire Follow-ups." The

Journal of Applied Psychology 40 (1956):117-121. 
NAME: P. John Williams

VITA

DATE OF BIRTH: MaY 15, 1953

PLACE OF BIRTH: Geelong, Australia

EDUCATION :

1974 Bachelor of Arts - Applied Arts

Avondale College

1977 Diploma of Secondary Education

Adelaide College of Education

1981 Master of Arts - Teaching

Andrews University

1985 Doctor of Philosophy

(Curriculum and Instruction)

Andrews University

PROFESSIONAL EXPERIENCE:

1975-76 Industrial Designer, Australia

1977-79 Teacher

Adelaide Adventist High School

Australia

1980-84 Graduate Assistant

Technology Education

Andrews university

Michigan

1983-84 Graduate Assistant

Educational Psychological services

Andrews University

Michigan 